\title{
Recent Developments in the [5+2] Cycloaddition
}

\author{
Hélène Pellissier ${ }^{\mathrm{a}, *}$ \\ a Aix Marseille Univ, CNRS, Centrale Marseille, iSm2, 13397 Marseille, France \\ Fax: (+33)-4-9128-2765; e-mail: h.pellissier@univ-amu.fr
}

\begin{abstract}
The [5+2] cycloaddition allows the synthesis of a diversity of complex highly functionalized seven-membered products in a single step. These cycloadducts can readily be further manipulated synthetically for use in the synthesis of a number of complex natural products and important biologically active products containing seven-membered rings. In addition to the common and highly efficient [5+2] cycloadditions of (oxido)pyrylium and (oxido)pyridinium ions with various $\pi$-systems, providing an easy access to a wide range of novel heterocyclic sevenmembered rings exhibiting an oxygen or nitrogen bridge, the metal-catalyzed [5+2] cycloadditions still attract a great attention and have become one of the most popular ways of constructing seven-membered compounds. Among the most important reactions are metal-catalyzed (hetero) [5+2] cycloadditions of vinyl-substituted three-membered rings, rhodium-catalyzed [5+2] cycloadditions of 3-acyloxy-1,4-enynes, and metal-catalyzed [5+2] cycloadditions of ortho-vinylphenols and ortho-vinyl/arylanilines.
\end{abstract}

Abbreviations: Ar: aryl; Bipy: bipyridine; $\mathrm{Bn}$ : benzyl; Boc: tert-butoxycarbonyl; cod: cyclooctadiene; coe: cyclooctene; $\mathrm{Cp}$ : cyclopentadienyl; $\mathrm{Cp}^{*}$ : pentamethylcyclopentadienyl; DABCO: 1,4-diazabicyclo[2.2.2] octane; dbcot: dibenzocyclooctatetraene; DBU: 1,8-diazabicyclo[5.4.0]undec-7-ene; DCE: 1,2dichloroethane; $d e$ : diastereomeric excess; DIPEA: diisopropylethylamine; DMAP: 4-( $N, N$-dimethylamino)pyridine; DMF: $N, N$-dimethylformamide; dppb: 1,4-bis(diphenylphosphino)butane; dppe: 1,2-bis(diphenylphosphino)ethane; ee: enantiomeric excess; Hept: heptyl; Hex: hexyl; HFIP: hexafluoroisopropyl alcohol; L: ligand; M: metal; MCPBA: 3-chloro- peroxybenzoic acid; MOM: methoxymethyl; Mes: mesyl; MS: molecular sieves; Naph: naphthyl; NBD: norbornadiene; Ns: nosyl (4-nitrobenzenesulfonyl); Pent: pentyl; Phth: phthaloyl; Piv: pivaloyl; PMB: $p$ methoxybenzyl; rr: regioselectivity ratio; r.t.: room temperature; TBS: tert-butyldimethylsilyl; TES: triethylsilyl; Tf: trifluoromethanesulfonyl; TFA: trifluoroacetic acid; TFE: 2,2,2-trifluoroethanol; THF: tetrahydrofuran; TIPS: triisopropylsilyl; TMP: 2,2,6,6-tetramethylpiperidine; TMS: trimethylsilyl; Tol: tolyl; Ts: 4-toluenesulfonyl (tosyl)

\section{Introduction}

2 Metal-Catalyzed [5+2] Cycloadditions of VinylSubstituted Three-Membered Rings

2.1 [5+2] Cycloadditions of Vinylcyclopropanes

2.2 Hetero [5+2] Cycloadditions of Vinylaziridines

2.3 Hetero [5+2] Cycloadditions of Vinyloxiranes

3 [5+2] Cycloadditions of (Oxido)pyrylium Ions

3.1 Intermolecular [5+2] Cycloadditions

3.2 Intramolecular [5+2] Cycloadditions

$4 \quad[5+2]$ Cycloadditions of (Oxido)pyridinium Ions

5 Rhodium-Catalyzed [5+2] Cycloadditions of 3Acyloxy-1,4-enynes

6 Metal-Catalyzed [5+2] Cycloadditions of orthoVinylphenols and ortho-Vinyl-/Arylanilines

7 [5+2] Cycloadditions of Metal-Containing 5-C Components

8 Miscellaneous [5+2] Cycloadditions

9 Conclusions

Keywords: biological activity; cycloaddition; natural products; transition metals

\section{Introduction}

Cycloaddition reactions are among the most important tools in organic chemistry, since these one-pot reactions allow synthesis of the complex cyclic skeletons of a number of natural products and biologically active substances. ${ }^{[1]}$ Allowing two new bonds to be formed in a single manipulation through a regio- and stereocontrolled fashion, these fundamental synthetic methodologies occupy a central position in synthetic organic chemistry. Among cycloadditions, the [5+2] cycloaddition exhibits a great potential in synthesis since it leads to seven-membered ring systems which are the structural core of many biologically important natural products. ${ }^{[2]}$ Notably, while synthetic approaches to five- and six-membered ring systems are 
Hélène Pellissier carried out her Ph.D. under the supervision of Dr. G. Gil in Marseille (France) in 1987. The work was focused on the reactivity of isocyanides. In 1988, she entered The National Center for Scientific Research (CNRS) as a researcher. After a postdoctoral period in Professor K. P. C. Vollhardt's group at the Uni-

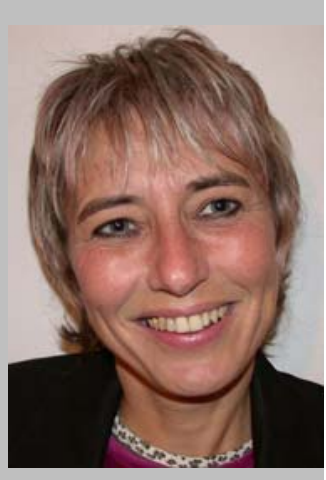
versity of California, Berkeley, she joined the group of Professor M. Santelli in Marseille in 1992, where she focused on the chemistry of 1,8-bis(trimethylsilyl)octa-2,6-diene and its application in the development of novel, very short total syntheses of steroids starting from 1,3-butadiene and benzocyclobutenes. She is currently chargée de recherche (CNRS) at Aix-Marseille Université.

common via cycloaddition reactions, seven-membered ring formations are not as well developed. The goal of this review is to cover the recent developments in [5+2] cycloaddition reactions reported since the beginning of 2014, since this field was most recently updated at that time in a book chapter. ${ }^{[3]}$ Earlier, several reviews had been published, covering the areas of $[5+2]$ cycloadditions, ${ }^{[4]}$ metal-catalyzed higher-order cycloadditions, ${ }^{[2 k, 1,5]}$ and the involvement of oxidopyrylium and pyridinium species in various dipolar cycloadditions. ${ }^{[6]}$ Moreover, it must be noted that Ylijoki and Stryker published a review in 2013, focussing on the applications of [5+2] cycloadditions to the synthesis of natural products, covering the literature up to 2012. ${ }^{[7]}$ The present review is subdivided into seven sections, dealing successively with metal-catalyzed [5+2] cycloadditions of vinyl-substituted three-membered rings, [5+2] cycloadditions of (oxido)pyrylium ions, [5+2] cycloadditions of (oxido)pyridinium ions, rhodium-catalyzed [5+2] cycloadditions of 3-acyloxy1,4-enynes, metal-catalyzed [5+2] cycloadditions of ortho-vinylphenols and ortho-vinyl-/arylanilines, [5+2] cycloadditions of metal-containing 5-C components, and miscellaneous [5+2] cycloadditions.

\section{Metal-Catalyzed [5+2] Cycloadditions of Vinyl-Substituted Three-Membered Rings}

\section{1 [5+2] Cycloadditions of Vinylcyclopropanes}

\subsubsection{Intermolecular Metal-Catalyzed [5+2] Cycloadditions}

Cycloaddition reactions allow the assembly of complex ring systems to be achieved in a convergent and often selective fashion from simple and readily available building blocks promoted by heat, light, Lewis acids, high pressure or sonication. Especially, metal catalysts provide new opportunities for stereoselective cycloaddition reactions since complexation of the metal to a $\pi$-system significantly modifies the reactivity of the latter, opening the way for improved reactivity and novel chemistry. ${ }^{[8]}$ Prompted by the growing number of structurally novel targets exhibiting powerful biological activities which incorporate seven-membered rings, ${ }^{[2,, 9]}$ and the limited number of cycloaddition processes for their assembly, Wender has developed powerful novel routes to seven-membered ring systems based on metal-catalyzed [5+2] cycloadditions of vinylcyclopropanes with $\pi$-systems (Scheme 1). ${ }^{\left[{ }^{[k, 5 c, e]}\right.}$ In the presence of a transition metal such as rhodium, a vinylcyclopropane can undergo a ring cleavage followed by a [5+2] process which occurs through two possible mechanisms as summarized in Scheme 1. ${ }^{[10]}$ They differ only in the order of the bond formation and cyclopropane cleavage steps.

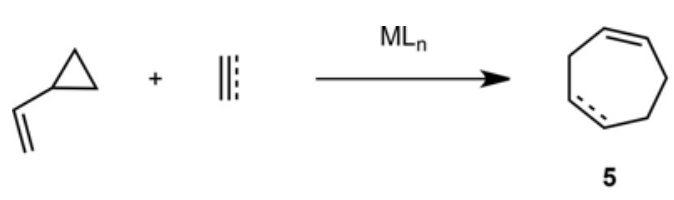

possible mechanisms:

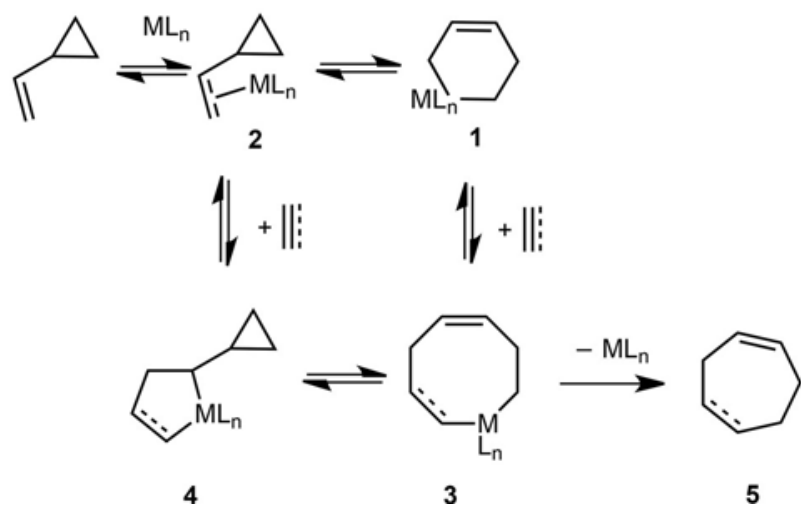

Scheme 1. The metal-catalyzed [5+2] cycloaddition of vinylcyclopropanes and possible mechanisms. 
In the former, the cyclopropane ring-opening occurs first after the initial vinylcyclopropane coordination, resulting in the formation of metallacyclohexene $\mathbf{1}$. The following capture of $\mathbf{1}$ by a $2 \pi$-component leads to the corresponding ring-expanded metallacyclooctene 3. Then, a reductive elimination leads to final product 5. In the second mechanism, the coupling of the coordinated vinylcyclopropane 2 with the $2 \pi$-component occurs first to provide the corresponding metallacyclopentane $\mathbf{4}$, followed by strain-driven cleavage of the adjacent cyclopropane by the carbon-metal bond (Scheme 1). It must be noted that other mechanistic possibilities exist for the [5+2] cycloaddition reaction. For example, it is also possible that the coordination of the $2 \pi$-component to $\mathbf{2}$ could lead directly to intermediate $\mathbf{3}$ through simultaneous insertion and cleavage. Moreover, a direct insertion into the cyclopropane to form a metallacyclobutane is also possible.

The first examples of intermolecular metal-catalyzed [5+2] cycloadditions of vinylcyclopropanes with alkynes were reported by Wender et al., in 1998. ${ }^{[11]}$ These reactions were catalyzed by $\left[\mathrm{RhCl}(\mathrm{CO})_{2}\right]_{2}$, allowing a wide range of cycloheptene derivatives to be achieved in generally high yields using a variety of internal, terminal, electron-rich and electron-poor alkynes (Scheme 2). ${ }^{[12]}$

However, the use of $\left[\mathrm{RhCl}(\mathrm{CO})_{2}\right]_{2}$ in intermolecular $[5+2]$ cycloadditions often requires heating at high temperature which, in turn, promotes competing cyclotrimerization of the alkyne partner, decomposition of the vinylcyclopropane or formation of undesired secondary isomerization products. In 2010, Wender et al. showed that the cationic rhodium(I) complex, $\left[\mathrm{Rh}\left(\mathrm{C}_{10} \mathrm{H}_{8}\right)(\mathrm{cod})\right]^{+} \mathrm{SbF}_{6}{ }^{-}$, at particularly low catalyst loadings $(0.2-0.5 \mathrm{~mol} \%)$, promoted intermolecular

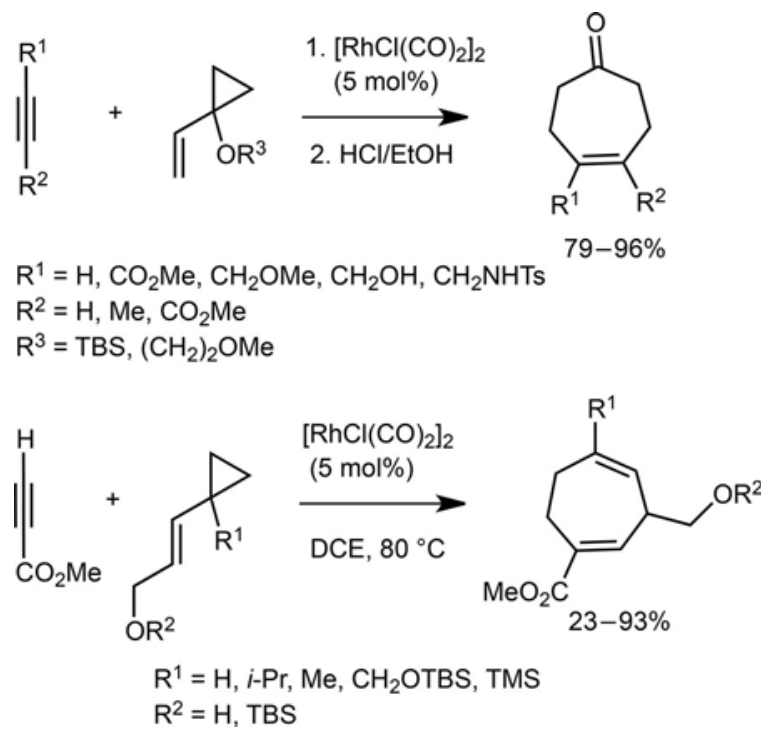

Scheme 2. First examples of rhodium-catalyzed intermolecular [5+2] cycloadditions of vinylcyclopropanes.
[5+2] cycloadditions of 1-alkoxy- and 1-alkyl-vinylcyclopropanes with a wide range of terminal and internal alkynes, providing at room temperature the corresponding cycloadducts in high yields. ${ }^{[13]}$ More recently, these authors applied the same catalyst to promote the $[5+2]$ cycloaddition of vinylcyclopropane 6 with propargyltrimethylsilanes 7 to give the corresponding cycloadducts 8 in high to quantitative yields (74$99 \%){ }^{[14]}$ As shown in Scheme 3, the reaction was gen-

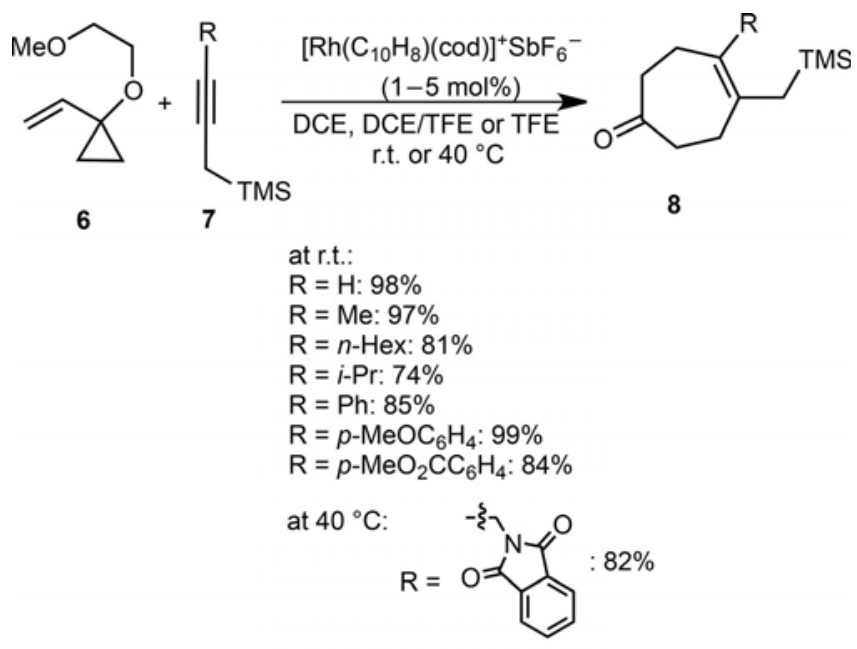

tandem $[5+2] /$ protodesilylation reaction:

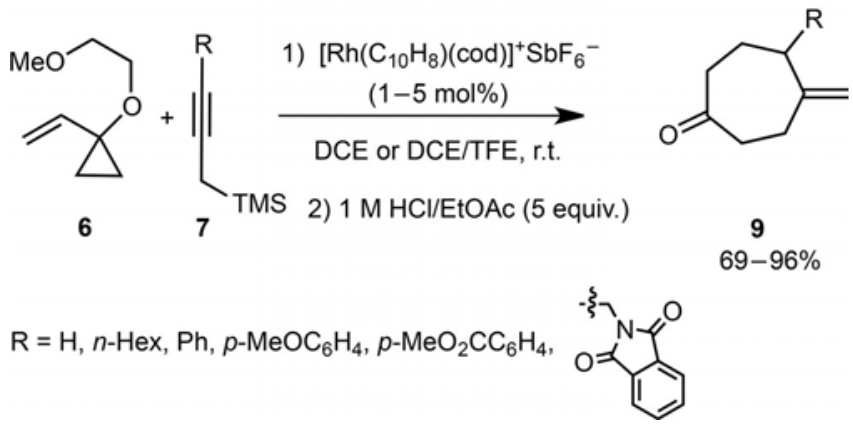

Scheme 3. The [5+2] cycloaddition of a vinylcyclopropane and propargyltrimethylsilanes catalyzed with $\left[\mathrm{Rh}\left(\mathrm{C}_{10} \mathrm{H}_{8}\right)(\mathrm{cod})\right]^{+} \mathrm{SbF}_{6}{ }^{-}$and a tandem [5+2] cycloaddition/ protodesilylation reaction.

erally performed at room temperature in the presence of $1-5 \mathrm{~mol} \%$ of $\left[\mathrm{Rh}\left(\mathrm{C}_{10} \mathrm{H}_{8}\right)(\mathrm{cod})\right]^{+} \mathrm{SbF}_{6}{ }^{-}$in $\mathrm{DCE}$ or TFE or mixtures of both of these solvents. The excellent results demonstrated that the process was tolerant to a variety of propargyltrimethylsilane substitutions including hydrogen, $n$ - and $i$-alkyl, aryl and heteroatom groups. Studying the subsequent protodesilylation of the thus-formed cycloadducts 8 by treatment with a $1 \mathrm{M} \mathrm{HCl} / \mathrm{AcOEt}$ solution to yield the corresponding (5-substituted)-4-methylenecycloheptanone derivatives 9, the authors showed that the combination of the two steps in a single flask was possible. Indeed, the corresponding tandem $[5+2]$ cycloaddi- 
tion/protodesilylation reaction was found to directly afford cycloheptanone derivatives 9 in high yields (69-96\%) starting from vinylcyclopropane 6 and the corresponding propargyltrimethylsilanes 7, as shown in Scheme 3. A great advantage of this novel methodology was related to the role played by propargyltrimethylsilanes as safe, easily handled synthetic equivalents of hard-to-access monosubstituted allenes. Indeed, only trisubstituted allenes had been previously successfully employed by Wender et al. as partners of vinylcyclopropanes in intermolecular $[5+2]$ cycloadditions. ${ }^{[15]}$

A domino reaction has been defined by Tietze as a reaction which involves two or more bond-forming transformations, taking place under the same reaction conditions, without adding additional reagents and catalysts, and in which the subsequent reactions result as a consequence of the functionality formed by bond formation or fragmentation in the previous step. ${ }^{[1]}$ The use of domino reactions including multicomponent ones in organic synthesis is increasing constantly, allowing the synthesis of a wide range of complex molecules from simple substrates through economical, one-pot processes that avoid the use of costly and time-consuming protection-deprotection processes, as well as purification procedures of intermediates. ${ }^{[1]}$ In this context, Wender et al. have developed novel three-component domino reactions initiated by a $[5+2]$ cycloaddition occurring between vinylcyclopropane $\mathbf{6}$ and 4-(trimethylsilyl)but-2-yn-1-ol $\mathbf{1 0}$ and promoted by $[\mathrm{Rh}(\mathrm{Naph})(\mathrm{cod})]^{+} \mathrm{SbF}_{6}^{-}$at room temperature in DCE as solvent. ${ }^{[18]}$ As shown in Scheme 4, the first step of the domino process afforded the corresponding intermediate cycloadduct $\mathbf{1 1}$ which then underwent a vinylogous Peterson reaction to give diene intermediate 12, evolving by way of either Lewis acid activation through intermediate $\mathbf{1 3}$ or cycloreversion of zwitterion $\mathbf{1 4}$ formed through bond formation between the oxygen and silicon atoms. Subsequently, diene 12 underwent a [4+2] cycloaddition with an alkene to provide the final product 15. Various alkenes were compatible with the reaction conditions, leading to the corresponding polycyclic products $\mathbf{1 5}$ in good to high yields (65-88\%). In addition to alkenes, alkynes could also be employed as partners in the process but in this case their addition was delayed until after the initial [5+2] cycloaddition and elimination processes were complete. Consequently, the three-component reaction qualified as a domino process with alkenes became namely a tandem reaction when alkynes were employed. As shown in Scheme 4, wide ranges of electron-rich, electron-poor, internal and terminal alkynes were tolerated, leading to the corresponding bicyclic cycloheptenes $\mathbf{1 6}$ in good to excellent yields (60-96\%).

Allenes are known to form stable rhodium complexes, sometimes through ligand exchange, suggest-
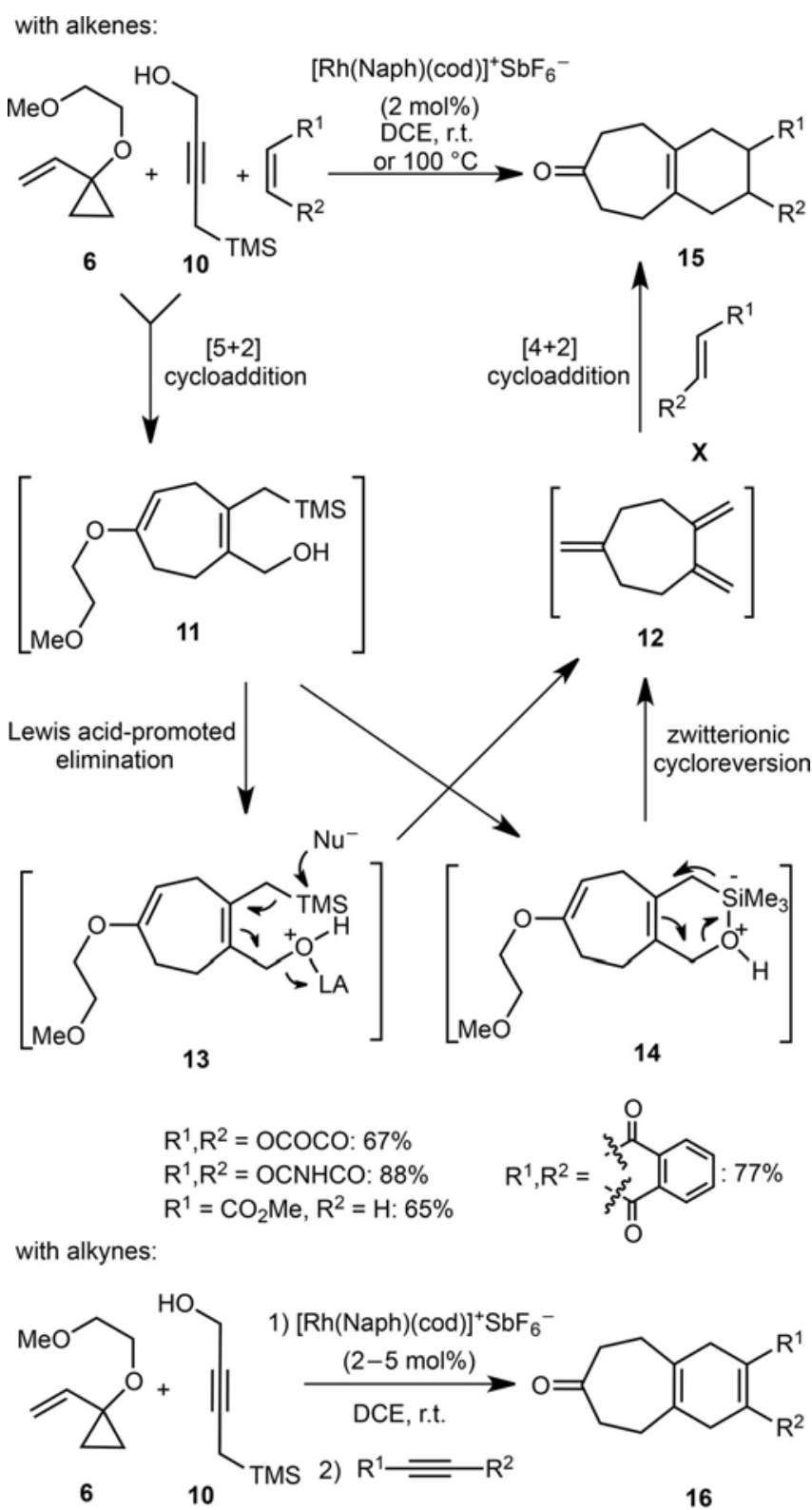

$$
\begin{array}{ll}
\mathrm{R}^{1}=\mathrm{CH}_{2} \mathrm{NHTs}, \mathrm{R}^{2}=\mathrm{H}: 78 \% & \mathrm{R}^{1}=\mathrm{TMS}, \mathrm{R}^{2}=\mathrm{H}: 96 \% \\
\mathrm{R}^{1}=\mathrm{Ph}, \mathrm{R}^{2}=\mathrm{H}: 93 \% & \mathrm{R}^{1}=\mathrm{R}^{2}=\mathrm{CH}_{2} \mathrm{OMe}: 96 \% \\
\mathrm{R}^{1}=0-\mathrm{Tol}^{2}, \mathrm{R}^{2}=\mathrm{H}: 60 \% & \mathrm{R}^{1}=\mathrm{CO}_{2} \mathrm{Me}, \mathrm{R}^{2}=\mathrm{Me}: 92 \% \\
\mathrm{R}^{1}=m-\mathrm{FC}_{6} \mathrm{H}_{4}, \mathrm{R}^{2}=\mathrm{H}: 86 \% & \mathrm{R}^{1}=\mathrm{R}^{2}=\mathrm{CO}_{2} \mathrm{Me}: 83 \% \\
\mathrm{R}^{1}=p-\mathrm{BrC}_{6} \mathrm{H}_{4}, \mathrm{R}^{2}=\mathrm{H}: 87 \% & \mathrm{R}^{1}=n-\mathrm{Bu}, \mathrm{R}^{2}=\mathrm{H}: 88 \% \\
& \mathrm{R}^{1}=\mathrm{Bn}, \mathrm{R}^{2}=\mathrm{H}: 90 \% \\
\mathrm{R}^{1}= &
\end{array}
$$

Scheme 4. Three-component domino/tandem [5+2] cycloaddition/vinylogous Peterson/[4+2] cycloaddition reactions of a vinylcyclopropane, 4-(trimethylsilyl)but-2-yn-1-ol and alkenes/alkynes catalyzed with $[\mathrm{Rh}(\mathrm{Naph})(\mathrm{cod})]^{+} \mathrm{SbF}_{6}{ }^{-}$.

ing that they might be suitable substrates in the intermolecular [5+2] cycloaddition. However, simple nonactivated allenes, while effective in the intramolecular $[5+2]$ reaction, possibly due to a high formal concen- 
tration effect and bidentate coordination, are unreactive in the intermolecular process. In 2005, Wender et al. demonstrated, however, that allenes substituted with an additional coordinating group, such as an alkynyl, alkenyl, cyano or cyanoalkyl group, were efficient $\mathrm{C}_{2}$ components in the intermolecular reaction. ${ }^{[15]}$ In spite of the excellent yields (up to 99\%) reported in this process, its substrate scope remained, however, limited. In this study, the presence of sterically encumbering methyl substituents on the terminal allene double bond was found to be necessary to achieve the intermolecular [5+2] cycloaddition. More recently, this was confirmed in the reaction of a sterically encumbered allene, such as dimethylalleneyne 17, with vinylcyclopropane $\mathbf{6}$ performed in the presence of $1 \mathrm{~mol} \%$ of $\left[\mathrm{Rh}(\mathrm{CO})_{2} \mathrm{Cl}\right]_{2}$ in $\mathrm{DCE}$ at $80^{\circ} \mathrm{C} .^{[19]} \mathrm{As}$ shown in Scheme 5, the reaction afforded the corre-

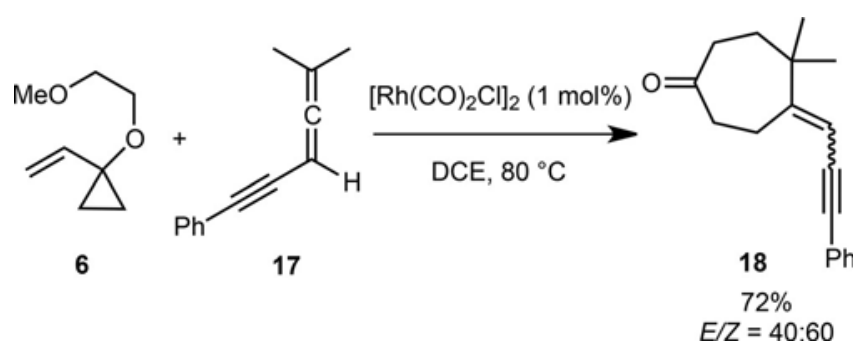

Scheme 5. The [5+2] cycloaddition of a vinylcyclopropane and a dimethylalleneyne catalyzed with $\left[\mathrm{Rh}(\mathrm{CO})_{2} \mathrm{Cl}\right]_{2}$.

sponding cycloadduct $\mathbf{1 8}$ in $72 \%$ yield as a 40:60 mixture of $E / Z$ diastereomers. Moreover, through density functional theory calculations, the authors demonstrated that the apparent low reactivity of terminally unsubstituted allenes was associated with a competing allene dimerization that irreversibly sequestered rhodium. On the other hand, with terminally substituted allenes such as $\mathbf{1 7}$, steric repulsion between the terminal substituents significantly increased the barrier of allene dimerization while the barrier of the $[5+2] \mathrm{cy}-$ cloaddition was not affected, and consequently the cycloaddition prevailed.

Metals other than rhodium have been successfully employed as catalysts in a number of intramolecular [5+2] cycloadditions, including ruthenium, ${ }^{[20]}$ nickel, ${ }^{[21]}$ and iron. ${ }^{[22]}$ In contrast, the intermolecular version remained exclusive to rhodium catalysis until 2015 when the first iridium-catalyzed intermolecular [5+2] cycloaddition of vinylcyclopropanes with alkynes was reported by Strand et al. ${ }^{[23]}$ Indeed, these authors demonstrated that cationic iridium complexes with cyclooctadiene (cod) or dibenzo[a,e]cyclooctatetraene (dbcot) ligands were highly efficient catalysts for intermolecular [5+2] cycloaddition between vinylcyclopropanes and disubstituted alkynes since the rates of catalysis were 50 times or higher in comparison with those arising from use of analogous rhodium complexes. For example, the reaction of vinylcyclopropane 6 with a range of disubstituted alkynes in the presence of $2.5-5 \mathrm{~mol} \%$ of $\left[\left\{\operatorname{Ir}(\operatorname{cod}) \mathrm{Cl}_{2}\right]\right.$ or $\left[\left\{\operatorname{Ir}(\mathrm{dbcot}) \mathrm{Cl}_{2}\right]\right.$ in a mixture of DCE and TFE as solvent at room temperature in the presence of $\mathrm{AgPF}_{6}$ as an additive led to the corresponding cycloadducts 19 in moderate to quantitative yields (18-98\%), as shown in Scheme 6. The scope of the process was extended to another less reactive vinylcyclopropane 20 which provided, by reaction with a symmetrical alkyne $\left(\mathrm{R}^{1}=\mathrm{R}^{2}=\mathrm{CH}_{2} \mathrm{OMe}\right)$ performed in the presence of $\left[\{\mathrm{Ir}(\mathrm{dbcot}) \mathrm{Cl}\}_{2}\right]$ as catalyst, the corresponding cycloheptene $\mathbf{2 1}$ in $90 \%$ yield. Moreover, when unsymmetrical alkynes $\left(\mathrm{R}^{1} \neq \mathrm{R}^{2}\right)$ were used as substrates, a mixture of two regioisomers $\mathbf{2 1}$ and $\mathbf{2 2}$ was obtained in good to excellent yields (75-96\%) and with moderate regioselectivity ratios $(58: 42$ to $67: 33$ $r r$ ), as shown in Scheme 6.
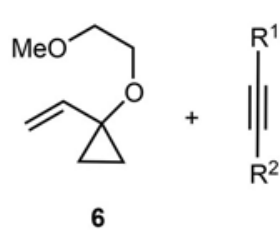

$\left[\{\operatorname{lr}(\operatorname{cod}) \mathrm{Cl}\}_{2}\right]$ or $\left[\{\mid \mathrm{I}(\mathrm{dbcot}) \mathrm{Cl}\}_{2}\right]$

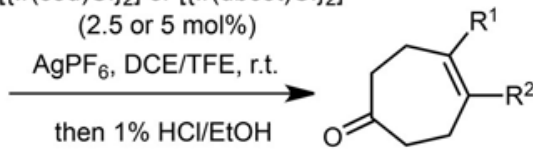

$$
\begin{aligned}
& \mathrm{R}^{1}=i-\mathrm{Pent}, \mathrm{R}^{2}=\mathrm{Me}: 98 \% \\
& \mathrm{R}^{1}=i-\mathrm{Pr}, \mathrm{R}^{2}=\mathrm{Me}: 93 \% \\
& \mathrm{R}^{1}=n-\mathrm{Bu}, \mathrm{R}^{2}=\mathrm{Cy}: 76 \% \\
& \mathrm{R}^{1}=\mathrm{Ph}, \mathrm{R}^{2}=\mathrm{Me}: 72 \% \\
& \mathrm{R}^{1}=\mathrm{R}^{2}=\mathrm{Ph}: 28 \% \\
& \mathrm{R}^{1}=\mathrm{H}, \mathrm{R}^{2}=\mathrm{Me}: 95 \% \\
& \mathrm{R}^{1}=n-\mathrm{Bu}, \mathrm{R}^{2}=\mathrm{TMS}: 70 \% \\
& \mathrm{R}^{1}=\mathrm{R}^{2}=\mathrm{CH}_{2} \mathrm{OMe}: 86 \% \\
& \mathrm{R}^{1}=\mathrm{R}^{2}=\mathrm{CH}_{2} \mathrm{OBn}: 18 \% \\
& \mathrm{R}^{1}=\mathrm{CH}_{2} \mathrm{NHTs}^{2}, \mathrm{R}^{2}=\mathrm{Me}: 72 \% \\
& \mathrm{R}^{1}=\left(\mathrm{CH}_{2}\right)_{2} \mathrm{OMe}, \mathrm{R}^{2}=\mathrm{Ph}: 24 \% \\
& \mathrm{R}^{1}=o-\mathrm{ClC}_{6} \mathrm{H}_{4}, \mathrm{R}^{2}=\mathrm{Me}: 51 \%
\end{aligned}
$$

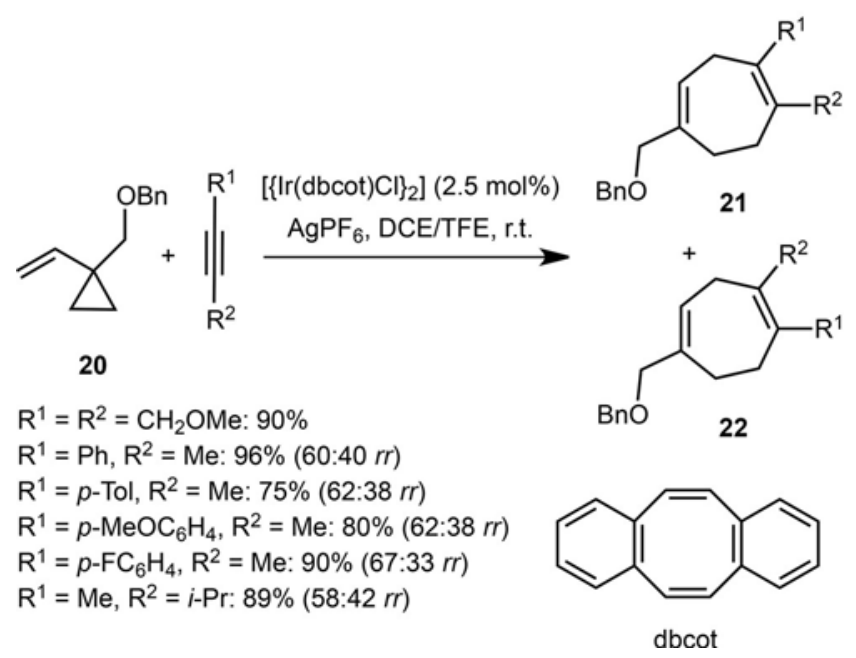

Scheme 6. Iridium-catalyzed [5+2] cycloadditions of vinylcyclopropanes and alkynes. 


\subsubsection{Intramolecular Metal-Catalyzed [5+2] Cycloadditions}

The first examples of metal-catalyzed intramolecular $[5+2]$ cycloadditions between vinylcyclopropanes and tethered alkynes were reported by Wender et al. in 1995, employing Wilkinson's catalyst $\left\{\left[\mathrm{RhCl}\left(\mathrm{PPh}_{3}\right)_{3}\right] \cdot{ }^{[24]}\right.$ As illustrated in Scheme 7, the corresponding cycloadducts were obtained in excellent yields by using a variety of tethered alkynes irrespective of the steric and electronic nature of the $\mathrm{R}^{1}$ group of the alkyne (Scheme 7). Closely related reaction conditions were also successfully applied to other tethered $\pi$-systems such as alkenes and allenes (Scheme 7).
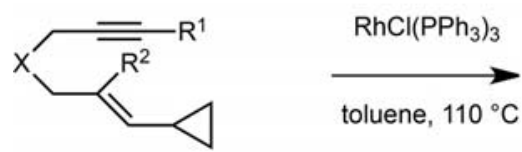

$\mathrm{X}=\mathrm{C}\left(\mathrm{CO}_{2} \mathrm{Me}\right)_{2}, \mathrm{O} ; \mathrm{R}^{1}=\mathrm{Me}, \mathrm{TMS}, \mathrm{Ph}, \mathrm{CO}_{2} \mathrm{Me} ; \mathrm{R}^{2}=\mathrm{H}, \mathrm{Me}$

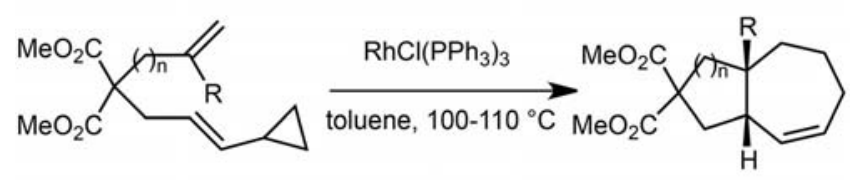

$$
\mathrm{R}=\mathrm{H}, \mathrm{Me} ; \mathrm{n}=1-2
$$

$77-94 \%$

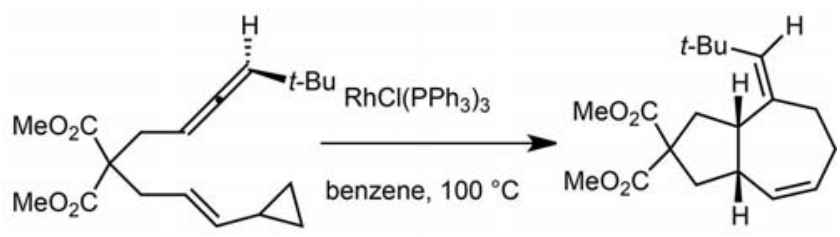

$96 \%, 92 \%$ ee

Scheme 7. First examples of rhodium-catalyzed intramolecular [5+2] cycloadditions of vinylcyclopropanes with various $\pi$-systems.

Ever since, various other rhodium catalysts ${ }^{[25]}$ have been successfully used to promote these reactions, such as the dimer $\left[\mathrm{RhCl}(\mathrm{CO})_{2}\right]_{2}$ developed by Wender and Sperandio in $1998,{ }^{[26]}$ bidentate phosphine chlororhodium dimers such as $[\mathrm{RhCl}(\mathrm{dppb})]_{2}$ developed by Zhang et al., ${ }^{[27]}$ $\left[\mathrm{Rh}\left(\mathrm{CH}_{2} \mathrm{Cl}_{2}\right)_{2}(\mathrm{dppe})\right]^{+} \mathrm{SbF}_{6}{ }^{-}$developed by Gilbertson and Hoge, ${ }^{[28]}$ and arene-rhodium complexes $[\mathrm{Rh}(\text { arene })(\operatorname{cod})]^{+} \mathrm{SbF}_{6}{ }^{-}$developed by Wender and Williams, ${ }^{[29]}$ among others. ${ }^{[30]}$ On the other hand, it was only in 2015 that a catalyst based on a metal other than rhodium was employed for the first time in intramolecular [5+2] cycloadditions of vinylcyclopropanes with alkynes by Strand et al. ${ }^{[23]}$ As shown in
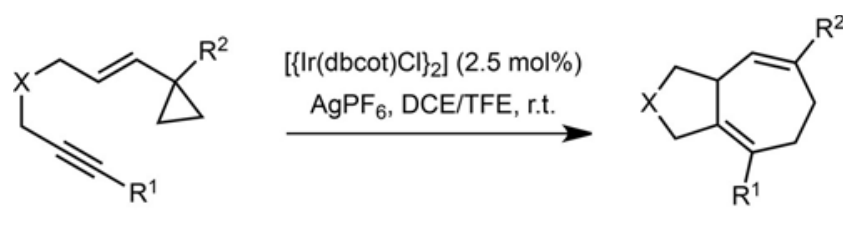

23

$$
\begin{aligned}
& \mathrm{R}^{1}=\mathrm{Me}, \mathrm{R}^{2}=\mathrm{H}, \mathrm{X}=\mathrm{C}\left(\mathrm{CO}_{2} \mathrm{Et}\right)_{2}: 88 \% \\
& \mathrm{R}^{1}=\mathrm{TMS}, \mathrm{R}^{2}=\mathrm{H}, \mathrm{X}=\mathrm{C}\left(\mathrm{CO}_{2} \mathrm{Et}\right)_{2}: 79 \% \\
& \mathrm{R}^{1}=\mathrm{Ph}, \mathrm{R}^{2}=\mathrm{H}, \mathrm{X}=\mathrm{C}\left(\mathrm{CO}_{2} \mathrm{Et}\right)_{2}: 89 \% \\
& \mathrm{R}^{1}=\mathrm{Me}, \mathrm{R}^{2}=\mathrm{H}, \mathrm{X}=\mathrm{NTs}: 85 \% \\
& \mathrm{R}^{1}=\mathrm{Me}, \mathrm{R}^{2}=\mathrm{CH}_{2} \mathrm{OBn}, \mathrm{X}=\mathrm{NTs}: 37 \% \\
& \mathrm{R}^{1}=\mathrm{Me}, \mathrm{R}^{2}=\mathrm{CH}_{2} \mathrm{OBn}, \mathrm{X}=\mathrm{C}\left(\mathrm{CO}_{2} \mathrm{Et}\right)_{2}: 75 \%
\end{aligned}
$$

24

Scheme 8. Intramolecular [5+2] cycloaddition of vinylcyclopropanes and alkynes catalyzed with $\left[\{\operatorname{Ir}(\mathrm{dbcot}) \mathrm{Cl}\}_{2}\right]$.

Scheme 8, the intramolecular [5+2] cycloaddition of a range of tethered vinylcyclopropanes $\mathbf{2 3}$ and alkynes catalyzed by $2.5 \mathrm{~mol} \%$ of $\left[\left\{\operatorname{Ir}(\mathrm{dbcot}) \mathrm{Cl}_{2}\right]\right.$ in the presence of $\mathrm{AgPF}_{6}$ as an additive in a mixture of DCE and TFE as solvent afforded the corresponding diversely functionalized bicyclic products $\mathbf{2 4}$ in good to high yields (37-89\%).

\subsection{Hetero [5+2] Cycloadditions of Vinylaziridines}

Besides seven-membered carbocycles, related heterocycles, such as azepine derivatives, are ubiquitous structural motifs found in an array of natural products and pharmaceuticals exhibiting diverse biological properties. ${ }^{[31]}$ Therefore, the development of efficient synthetic methods to access these important compounds has been extensively pursued by chemists. ${ }^{[32]}$ Inspired by the pioneering works on the rhodium-catalyzed hetero [5+2] cycloaddition of cyclopropylimines with electron-deficient alkynes reported by Wender in $2002,{ }^{[33]}$ Zhang et al. have developed a rhodium-catalyzed intramolecular hetero [5+2] cycloaddition of optically enriched vinylaziridine-alkyne substrates for the synthesis of chiral fused 2,5-dihydroazepines based on a chirality-transfer strategy. ${ }^{[34]}$ Indeed, a wide variety of enantioenriched vinylaziridine-alkyne substrates $25(X=N T s, 83$ to $>99 \%$ ee $)$ was found to undergo intramolecular hetero [5+2] cycloadditions in the presence of $5 \mathrm{~mol} \%$ of $\left[\mathrm{Rh}(\mathrm{NBD})_{2}\right]^{+} \mathrm{BF}_{4}^{-}$in DCE at $30^{\circ} \mathrm{C}$, leading to the corresponding chiral azepine derivatives 26 in good to quantitative yields (59-98\%) with high to excellent enantioselectivities ( 83 to $>99 \%$ ee) (Scheme 9). A study of the substrate scope showed that the alkynes could be substituted by aryl, heteroaryl, alkyl, as well as cyclohexenyl groups. Notably, both internal and terminal alkynes were compatible. In addition, substrates bearing a geminal diester $\left[\mathrm{X}=\mathrm{C}\left(\mathrm{CO}_{2} \mathrm{Me}\right)_{2}\right]$ or an oxygen tether $(\mathrm{X}=\mathrm{O})$ yielded the corresponding chiral azepines in comparable yields and enantioselectivities $(57-94 \%$ yield, $83-98 \%$ ee). This highly effi- 


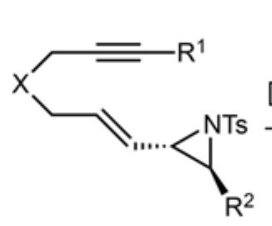

25

83 to $>99 \%$ ee with $X=N T s$ :

$\mathrm{R}^{1}=\mathrm{Ph}, p-\mathrm{MeOC}_{6} \mathrm{H}_{4}, p-\mathrm{ClC}_{6} \mathrm{H}_{4}, \mathrm{Me}, n-\mathrm{Bu},\left(\mathrm{CH}_{2}\right)_{3} \mathrm{OTBS},\left(\mathrm{CH}_{2}\right)_{3} \mathrm{OH}$, 1-cyclohexenyl, $\mathrm{H}$

$\mathrm{R}^{2}=\mathrm{H}, \mathrm{Me}, n-\mathrm{Pr}, i-\mathrm{Pr}$ :

$59-98 \%, 83$ to $>99 \%$ ee

with $\mathrm{X}=\mathrm{O}, \mathrm{R}^{1}=\mathrm{Ph}, \mathrm{R}^{2}=\mathrm{H}: 90 \%, 98 \%$ ee

with $\mathrm{X}=\mathrm{C}\left(\mathrm{CO}_{2} \mathrm{Me}\right)_{2}, \mathrm{R}^{1}=\mathrm{Ph}, \mathrm{Me}, \mathrm{R}^{2}=\mathrm{H}, \mathrm{Me}: 57-94 \%, 83-91 \%$ ee

Scheme 9. Rhodium-catalyzed intramolecular hetero [5+2] cycloaddition of enantioenriched vinylaziridines and alkynes.

cient methodology constituted a novel mild access to the important azepine architectures with both excellent functional-group compatibility and high enantioselectivity of up to $>99 \%$ ee achieved for the first time through complete chirality transfer.

In 2016, Lan et al. reported a density functional theory method, M11L, to study the mechanism of these reactions. ${ }^{[35]}$ The computational results suggested a metallahydropyridine pathway for the generation of the azepines, involving an aziridine cleavage, followed by a $2 \pi$ insertion of the alkyne group into the $\mathrm{Rh}-\mathrm{C}$ bond, and a final reductive elimination from a rhodium(III) cation (Scheme 10). Indeed, it was proposed that the catalytic cycle began with the coordination of vinylaziridine $\mathbf{2 5}$ to $\mathrm{RhL}_{2}{ }^{+}$, leading to nitrogen-coordinated species 27, from which an aziridine cleavage generated metallahydropyridine complex 28. Then, an intramolecular coordination of the alkyne moiety towards rhodium provided intermediate 29 , and a $2 \pi$ insertion occurred to give metallahydroazocine complex 30. A subsequent reductive elimination afforded intermediate 31. The azepine product 26 was finally released after a ligand exchange with regeneration of the active species 27.

In 2015, Zhang et al. also reported the first example of rhodium-catalyzed hetero [5+2] cycloadditions between vinylaziridines and alkenes. ${ }^{[36]}$ As shown in Scheme 11, the [5+2] cycloaddition of a range of enantioenriched monosubstituted alkenes $\mathbf{3 2}$ performed at $30^{\circ} \mathrm{C}$ in DCE as solvent in the presence of $5 \mathrm{~mol} \%$ of $\left[\mathrm{Rh}\left(\mathrm{C}_{10} \mathrm{H}_{8}\right)(\mathrm{cod})\right]^{+} \mathrm{SbF}_{6}{ }^{-}$as catalyst afforded the corresponding chiral cis-fused bicyclic azepines 33 bearing two contiguous stereogenic centers as single diastereomers in good to excellent yields (84$96 \%$ ) and uniformly high enantioselectivities (91$99 \%$ ee). The transformation was tolerant to tethers incorporating sulfonamides $(\mathrm{X}=\mathrm{NTs}, \mathrm{NNs})$, geminal diester $\left[\mathrm{X}=\mathrm{C}\left(\mathrm{CO}_{2} \mathrm{Me}\right)_{2}\right]$ and ether functionalities

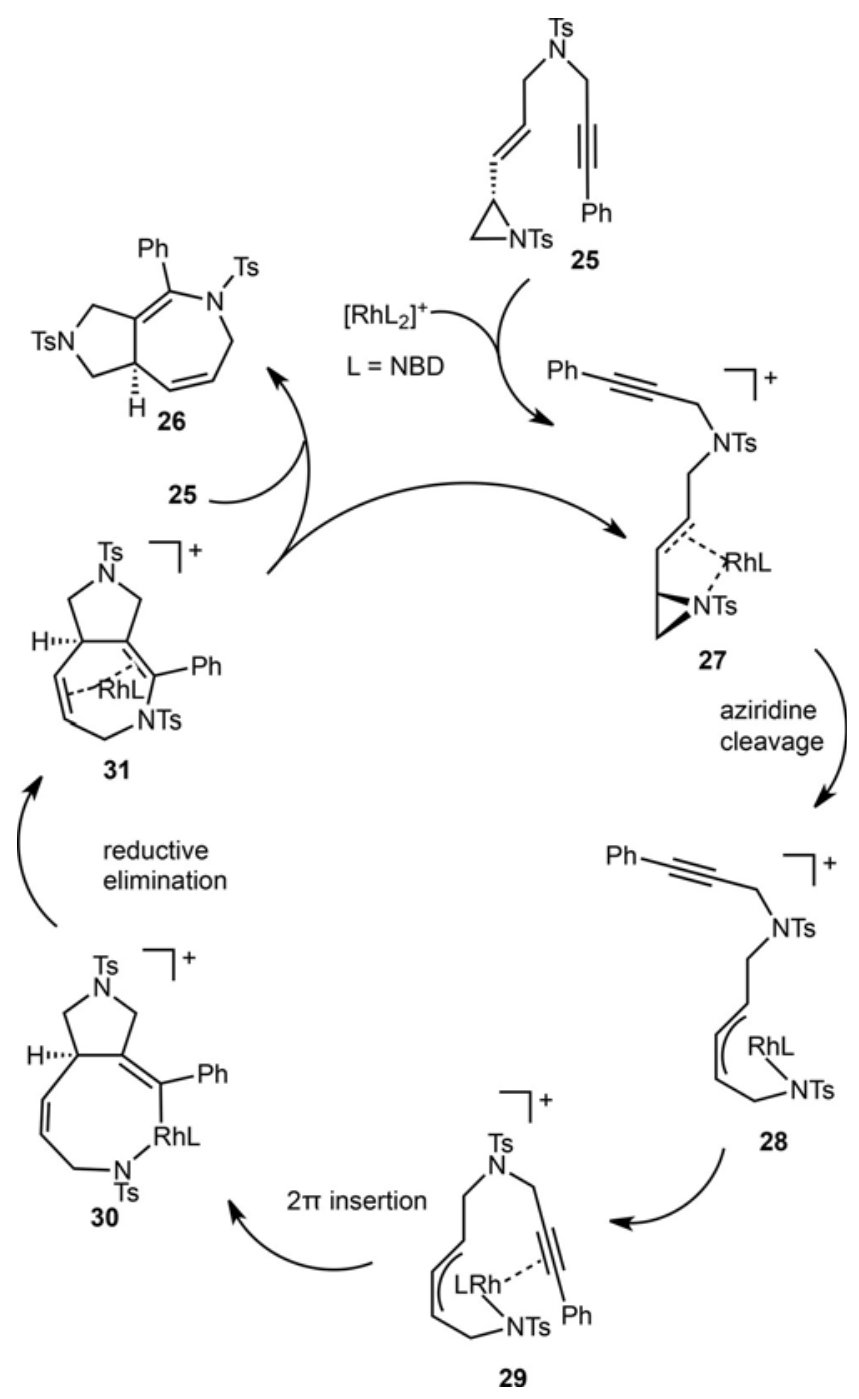

Scheme 10. Proposed mechanism for rhodium-catalyzed intramolecular hetero [5+2] cycloaddition of vinylaziridines and alkynes.

$(\mathrm{X}=\mathrm{O})$. The scope of this methodology was extended to disubstituted alkenes $\mathbf{3 4}$ which led to the corresponding bicyclic azepines $\mathbf{3 5}$ exhibiting in this case a trans-ring fusion rather than a cis-ring fusion obtained from the monosubstituted alkenes. These trans-fused products were generally obtained in good to high yields (65-93\%) except for the substrate bearing a methyl group at the alkene terminus $(\mathrm{R}=\mathrm{Me})$ which yielded the corresponding product in only $15 \%$ yield. In contrast, uniformly excellent enantioselectivities (92-99\% ee) were achieved in all cases of disubstituted alkenes by using $5-10 \mathrm{~mol} \%$ of $\left[\left\{\mathrm{Rh}(\mathrm{NBD}) \mathrm{Cl}_{2}\right] /\right.$ $\mathrm{AgSbF}_{6}$ or $[\mathrm{Rh}(\mathrm{IPr})(\mathrm{cod}) \mathrm{Cl}] / \mathrm{AgSbF}_{6}$ as catalyst in DCE at $80^{\circ} \mathrm{C}$ (Scheme 11).

In addition, the same authors developed an intermolecular version of the rhodium-catalyzed hetero $[5+2]$ cycloaddition of vinylaziridines and terminal alkynes. ${ }^{[37]}$ The optimal reaction conditions included the 

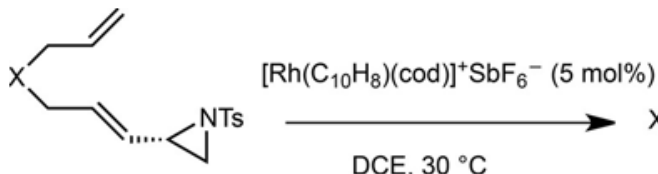

DCE, $30^{\circ} \mathrm{C}$

32

$92-99 \%$ ee

$\mathrm{X}=\mathrm{NTs}, \mathrm{NNs}, \mathrm{O}, \mathrm{C}\left(\mathrm{CO}_{2} \mathrm{Me}\right)_{2}$

$84-96 \%,>99 \%$ de

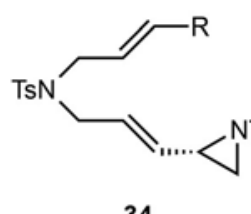

34

$95-99 \%$ ee $91-99 \%$ ee

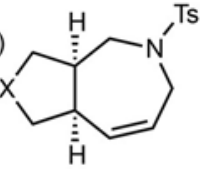

33

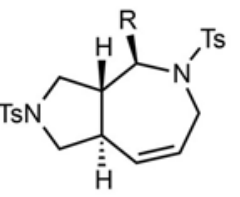

35

$15-93 \%$, >99\% de $92-99 \%$ ee
$\mathrm{R}=\mathrm{Ph}, p-\mathrm{Tol}, p-\mathrm{FC}_{6} \mathrm{H}_{4}, \mathrm{Me},(E)-\mathrm{MeCH}=\mathrm{CH}$

catalyst $=\left[\{R h(N B D) C l\}_{2}\right] / \mathrm{AgSbF}_{6}$ or $[\mathrm{Rh}(\mathrm{IPr})(\mathrm{cod}) \mathrm{Cl}] / \mathrm{AgSbF}_{6}$

Scheme 11. Rhodium-catalyzed intramolecular hetero [5+2] cycloadditions of vinylaziridines and alkenes.

use of $5 \mathrm{~mol} \%$ of $\left[\mathrm{Rh}\left(\mathrm{C}_{10} \mathrm{H}_{8}\right)(\mathrm{cod})\right]^{+} \mathrm{SbF}_{6}{ }^{-}$as catalyst employed in DCE at $0{ }^{\circ} \mathrm{C}$ to room temperature. As shown in Scheme 12, the reaction of various $N$-tosylvinylaziridines $36\left(\mathrm{R}^{2}=\mathrm{Ts}\right)$ with a range of aryl, heteroaryl and alkyl terminal alkynes provided the corresponding 2,5-dihydroazepines $\mathbf{3 7}$ in low to excellent yields (17-.97\%). In most cases, these cycloadducts were achieved as single regioisomers, except for alkylalkynes which yielded mixtures of the corresponding azepine $\mathbf{3 7}$ and its regioisomer in moderate to good ratios $(77: 23$ to $93: 7 \mathrm{rr}$ ). The scope of the reaction

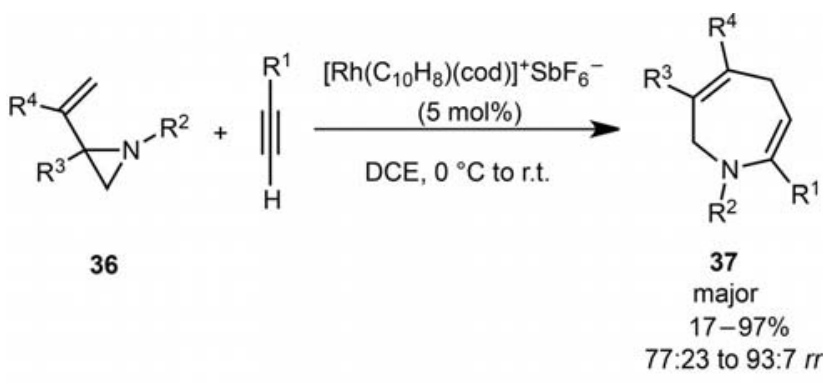

$\mathrm{R}^{1}=\mathrm{Ph}, p-\mathrm{EtOC}_{6} \mathrm{H}_{4}, p-(t-\mathrm{Bu}) \mathrm{C}_{6} \mathrm{H}_{4}, p$-Tol, $m$-Tol, o-Tol, $p-\mathrm{FC}_{6} \mathrm{H}_{4}$, $p-\mathrm{ClC}_{6} \mathrm{H}_{4}, p-\mathrm{BrC}_{6} \mathrm{H}_{4}, p-\mathrm{AcC}_{6} \mathrm{H}_{4}, p-\mathrm{MeO}_{2} \mathrm{CC}_{6} \mathrm{H}_{4}, 1-\mathrm{Naph}, 2-\mathrm{Naph}$, 2-thienyl, 2-benzofuranyl, cyclohexenyl, $n$ - $\mathrm{Pr}, n$-Pent, $\mathrm{BnCH}_{2}, i-\mathrm{Bu}$, $c$ - $\mathrm{Pr},\left(\mathrm{CH}_{2}\right)_{3} \mathrm{OBn},\left(\mathrm{CH}_{2}\right)_{2} \mathrm{CO}_{2} \mathrm{Me},\left(\mathrm{CH}_{2}\right)_{3} \mathrm{Phth}$, Et, TMS, $p-\mathrm{MeOC}_{6} \mathrm{H}_{4}$, $\left(\mathrm{CH}_{2}\right)_{3}$ OTBS

$\mathrm{R}^{2}=\mathrm{Ts}, \mathrm{Ns}, \mathrm{Mes}$

$\mathrm{R}^{3}=\mathrm{H}, \mathrm{Me}$

$\mathrm{R}^{4}=\mathrm{Me}, \mathrm{H}, i-\mathrm{Pr}, n-\mathrm{Bu}, \mathrm{Ph}$, OTBS, OTES

Scheme 12. Rhodium-catalyzed intermolecular [5+2] cycloaddition of vinylaziridines and alkynes. could be extended to several differently substituted vinylaziridines, including $N$-nosyl- and $N$-mesylvinylaziridines, providing the corresponding products in good yields $(62-70 \%)$. Interestingly in this study, the authors showed that by simply switching the catalyst to $\left[\mathrm{Rh}(\mathrm{NBD})_{2}\right]^{+} \mathrm{BF}_{4}^{-}, \mathrm{a}[3+2]$ cycloaddition occurred instead of the $[5+2]$ one.

To explain the precedent results, Huang et al. investigated the mechanism of this rhodium-catalyzed intermolecular [5+2] cycloaddition of vinylaziridines with alkynes through density functional theory calculations. ${ }^{[38]}$ These calculations showed that the reaction was initiated by a $\mathrm{C}-\mathrm{N}$ oxidative addition to form an $\mathrm{Rh}$-allyl complex $\mathbf{3 8}$. The latter isomerized into intermediate 39 from which a migratory insertion of the alkyne into the $\mathrm{Rh}-\mathrm{N}$ bond led to intermediate $\mathbf{4 0}$. This species was finally submitted to a $\mathrm{C}-\mathrm{C}$ reductive elimination to give the final [5+2] cycloadduct $\mathbf{3 7}$, as depicted in Scheme 13.

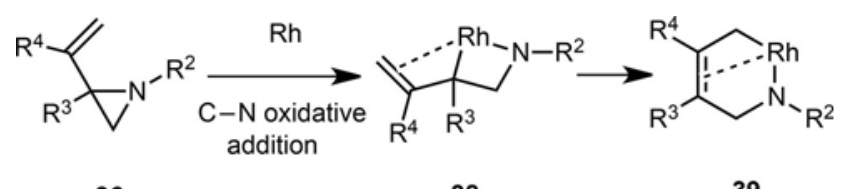

36

38

39

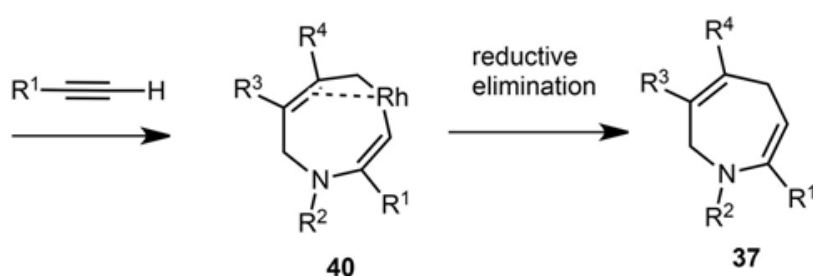

Scheme 13. Mechanism for rhodium-catalyzed intermolecular hetero [5+2] cycloaddition of vinylaziridines and alkynes.

\subsection{Hetero [5+2] Cycloadditions of Vinyloxiranes}

In 2017, Feng and Zhang reported the first use of vinyloxiranes in rhodium-catalyzed intramolecular hetero $[5+2]$ cycloadditions with alkynes. ${ }^{[39]}$ As shown in Scheme 14, when internal alkynes $\mathbf{4 1}$ were submitted in dichloromethane at $0^{\circ} \mathrm{C}$ to $5 \mathrm{~mol} \%$ of

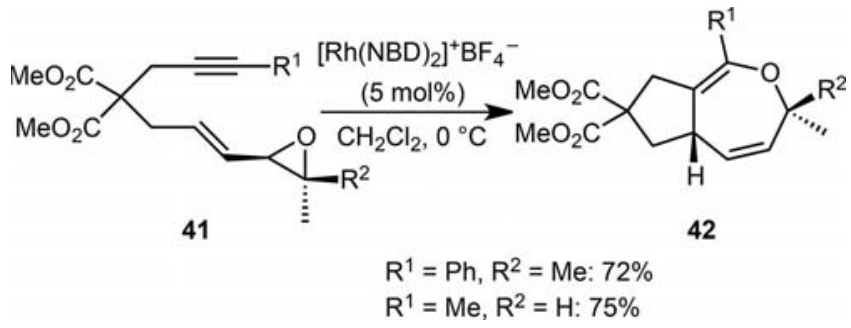

Scheme 14. Rhodium-catalyzed intramolecular hetero [5+2] cycloaddition of vinyloxiranes and alkynes. 
$\left[\mathrm{Rh}(\mathrm{NBD})_{2}\right]^{+} \mathrm{BF}_{4}^{-}$as catalyst, they underwent a stereoselective $[5+2]$ cycloaddition to form the corresponding bicyclic 2,5-dihydrooxepins $\mathbf{4 2}$ in good yields (72-75\%).

Since these 2,5-dihydrooxepin products 42 were found to be unstable at room temperature for prolonged reaction times because of the presence of an enol ether moiety, these authors decided to intercept them through a Claisen rearrangement. Indeed, they developed rhodium-catalyzed domino intramolecular hetero [5+2] cycloaddition/Claisen rearrangement reactions of vinyloxiranes $\mathbf{4 1}$ or $\mathbf{4 3}$ and alkynes. ${ }^{[39]}$ The reactions were performed in DCE at room temperature in the presence of $5-10 \mathrm{~mol} \%$ of $\left[\mathrm{Rh}(\mathrm{NBD})_{2}\right]^{+} \mathrm{BF}_{4}^{-}$, allowing the one-pot formation of the corresponding tetrasubstituted vinylcyclopropanes 44 in moderate to high yields (45-92\%), as shown in Scheme 15. Notably, the process was compatible to
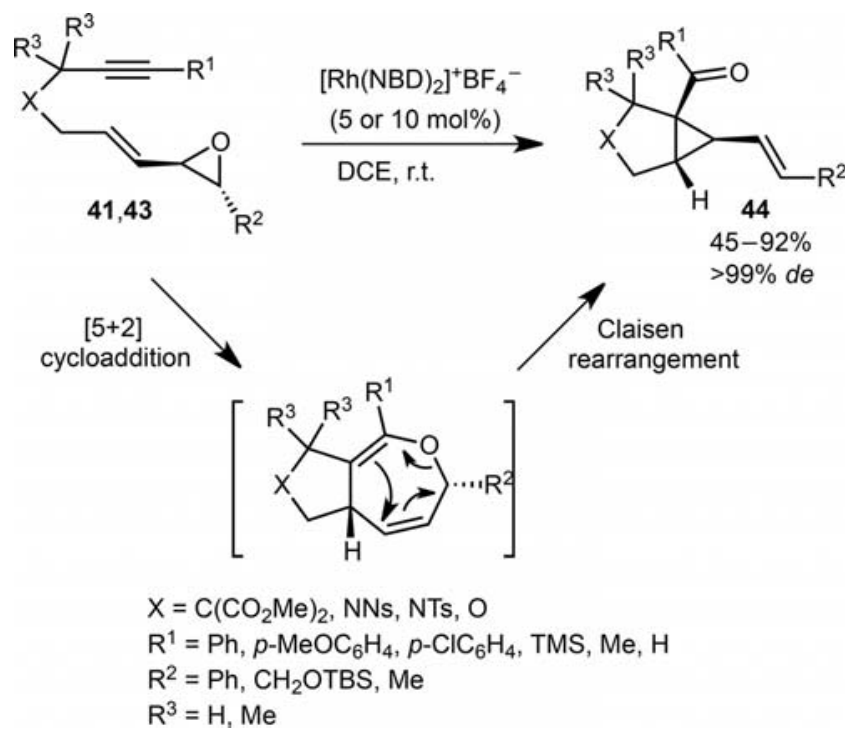

Scheme 15. Rhodium-catalyzed domino intramolecular hetero [5+2] cycloaddition/Claisen rearrangement reaction of vinyloxiranes and alkynes.

both internal and terminal alkynes. Moreover, the authors performed the reaction with an enantioenriched substrate $\left(\mathrm{X}=\mathrm{NTs}, \mathrm{R}^{1}=\mathrm{Ph}, \mathrm{R}^{2}=\mathrm{Et}, \mathrm{R}^{3}=\mathrm{H}, 92 \% e e\right)$ which afforded the corresponding cycloadduct in $85 \%$ yield as a single diastereomer in $90 \%$ ee, demonstrating the complete transfer of chirality in the domino reaction.

In addition, the same authors found that the reaction of vinyloxirane-alkynes $\mathbf{4 1}$ at $75^{\circ} \mathrm{C}$ in the presence of the same rhodium catalyst led to another type of product, such as multifunctional five-membered rings 45. ${ }^{[39]}$ These products arose from the same domino reaction as above (Scheme 15) but followed by a cyclopropane ring-opening reaction occurring at $75^{\circ} \mathrm{C}$. As shown in Scheme 16, the novel rhodium-cat-

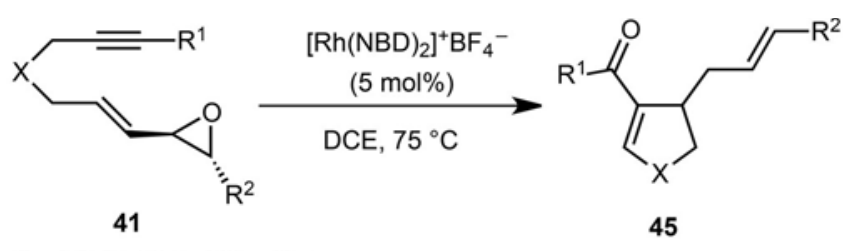

$\mathrm{X}=\mathrm{C}\left(\mathrm{CO}_{2} \mathrm{Me}\right)_{2}, \mathrm{NNs}, \mathrm{NTs}$

$\mathrm{R}^{1}=\mathrm{Ph}, p-\mathrm{MeOC}_{6} \mathrm{H}_{4}, p-\mathrm{ClC}_{6} \mathrm{H}_{4}, \mathrm{Me}, \mathrm{TMS}$

$41-94 \%$

$\mathrm{R}^{2}=\mathrm{Ph}, \mathrm{Me}$
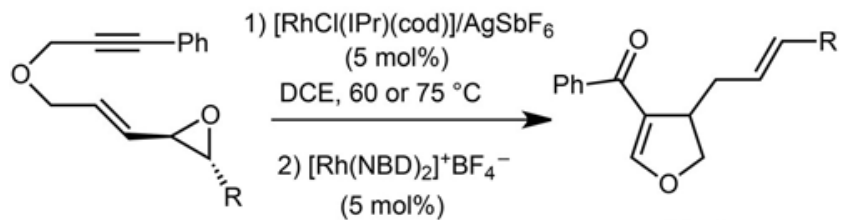

$41 a, b$

$75^{\circ} \mathrm{C}$

45a, b

$\mathrm{R}=\mathrm{Ph}: 61 \%$

$\mathrm{R}=\mathrm{Me}: 40 \%$

proposed mechanism:
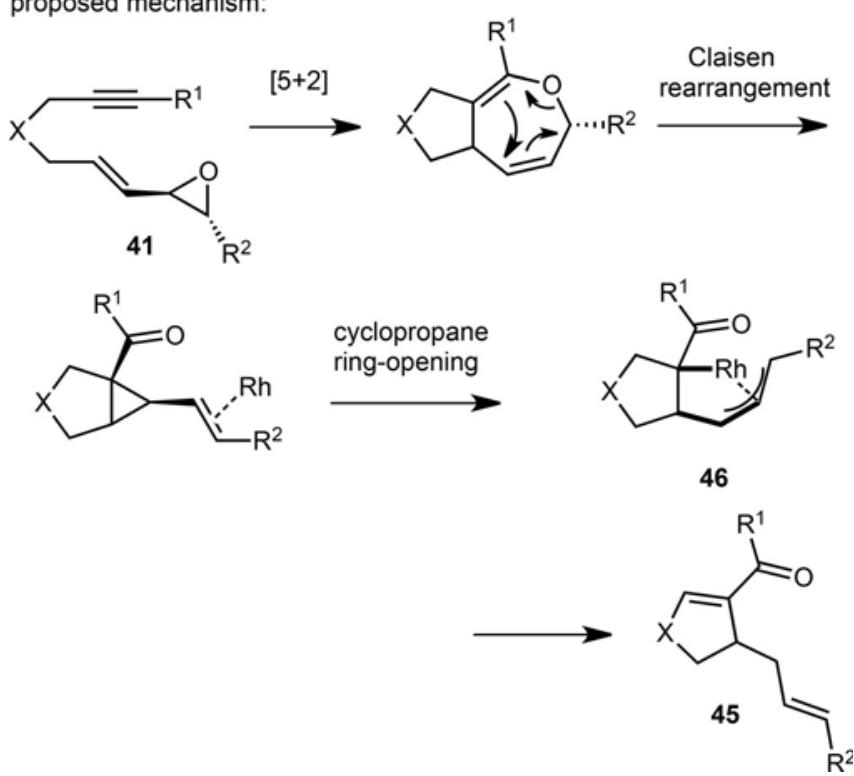

Scheme 16. Rhodium-catalyzed domino/tandem intramolecular hetero [5+2] cycloaddition/Claisen rearrangement/cyclopropane ring-opening reactions of vinyloxiranes and alkynes.

alyzed domino intramolecular hetero [5+2] cycloaddition/Claisen rearrangement/cyclopropane ring-opening reaction of vinyloxirane-alkynes $\mathbf{4 1}$ bearing sulfonamide or geminal diester functions $[\mathrm{X}=\mathrm{NTs}$, NNs, $\left.\mathrm{C}\left(\mathrm{CO}_{2} \mathrm{Me}\right)_{2}\right]$ promoted by $5 \mathrm{~mol} \%$ of $\left[\mathrm{Rh}(\mathrm{NBD})_{2}\right]^{+} \mathrm{BF}_{4}{ }^{-}$as catalyst yielded the corresponding five-membered products $\mathbf{4 5}$ in moderate to excellent yields (41-94\%). The process was compatible with a variety of alkynes, including aryl, methyl and trimethylsilyl ones. On the other hand, substrates 41a, b bearing an oxygen linker $(\mathrm{X}=\mathrm{O})$ gave the corresponding products $\mathbf{4 5 a}, \mathbf{b}$ in poor yields when using $\left[\mathrm{Rh}(\mathrm{NBD})_{2}\right]^{+} \mathrm{BF}_{4}^{-}$as catalyst. However, these yields could be improved (40-61\%) by performing the reaction through a stepwise addition of [ $\mathrm{RhCl}(\mathrm{IPr})(\operatorname{cod})] /$ $\mathrm{AgSbF}_{6}$ and $\left[\mathrm{Rh}(\mathrm{NBD})_{2}\right]^{+} \mathrm{BF}_{4}^{-}(5 \mathrm{~mol} \%$ of each $)$. 
Consequently, in this case the process became namely a tandem instead of a domino reaction. The mechanism of these rhodium-catalyzed domino/tandem intramolecular hetero [5+2] cycloaddition/Claisen rearrangement/cyclopropane ring-opening reactions is highlighted in Scheme 16.

Remarkably, these authors could intercept rhodium(III) intermediate 46 (Scheme 16) by another tethered alkyne through a final [5+2] cycloaddition. ${ }^{[39]}$ Indeed, when a series of vinyloxirane-diyne substrates 47 were submitted to $5-10 \mathrm{~mol} \%$ of $\left[\mathrm{Rh}(\mathrm{NBD})_{2}\right]^{+} \mathrm{BF}_{4}^{-}$in $\mathrm{DCE}$ at $80^{\circ} \mathrm{C}$, they underwent a rhodium-catalyzed domino intramolecular hetero [5+2] cycloaddition/Claisen rearrangement/cyclopropane ring-opening/[5+2] cycloaddition reaction to afford the corresponding hetero- and carbotricyclic products 48 as single regio- and diastereomers in moderate to high yields (41-91\%), as shown in Scheme 17. A wide variety of tethers (nitrogen, oxygen, and geminal diester) were found to be compatible. Moreover, this remarkable one-pot process was compatible to both internal and terminal alkynes. In addition, the authors demonstrated the complete transfer of chirality in the domino reaction of optically pure substrates.

\section{3 [5+2] Cycloadditions of (Oxido)pyrylium Ions}

\subsection{Intermolecular [5+2] Cycloadditions}

The synthesis of seven-membered rings can also be achieved through thermal $[5+2]$ cycloadditions of oxidopyrylium ions, involving pentadienyl cations as $4 \pi$ components. $^{[5 \mathrm{a}-\mathrm{d}, 6,40]}$ Indeed, the cycloaddition of 3-oxidopyrylium ylides, generated from the corresponding acetoxypyranones or derivatives, with alkenes constitutes a versatile and stereocontrolled entry into highly functionalized oxa-bridged cycloadducts. For example, submitted to either heat or a tertiary base such as TEA, an acetoxypyranone generates the corresponding carbonyl ylide formulated as a 3-oxidopyrylium. The pioneering studies in the area of intermolecular [5+2] acetoxypyranone cycloadditions were reported by Hendrickson and Farina in 1980 who reported the cycloaddition between acetoxypyranone and acrolein (Scheme 18). ${ }^{[41]}$ Ever since, a diversity of alkenes has been successfully applied to these reactions by several groups. ${ }^{[6,42]}$ Furthermore, many of the thus-formed products have been used as key intermediates in the synthesis of a number of important natural products. $^{[43]}$

In spite of the potential of [5+2] cycloadditions of oxidopyrylium ylides, however, asymmetric variants of these methodologies still remain limited. Most of
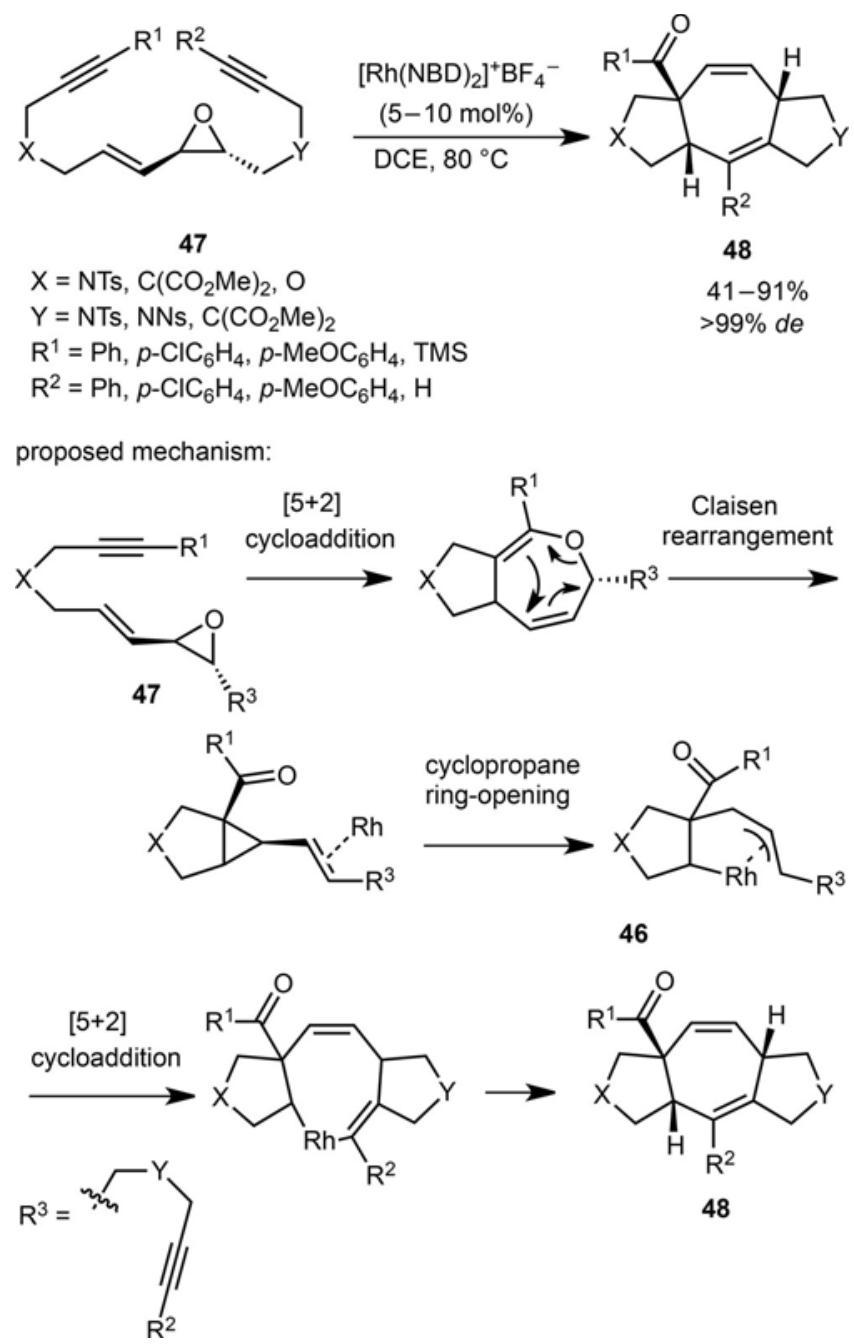

Scheme 17. Rhodium-catalyzed domino intramolecular hetero [5+2] cycloaddition/Claisen rearrangement/cyclopropane ring-opening/[5+2] cycloaddition reaction of vinyloxiranes and diynes.

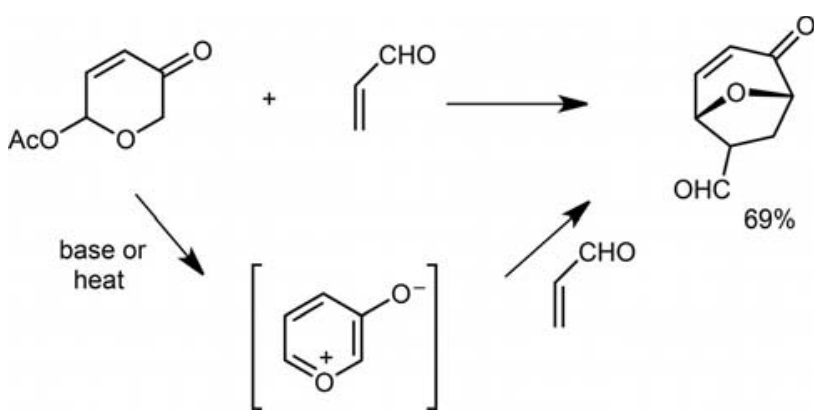

Scheme 18. Early intermolecular [5+2] cycloaddition of acetoxypyrone and acrolein.

them are based on the use of chiral auxiliaries. ${ }^{[4]}$ The first enantioselective version was described in 2011 by Jacobsen et al. who employed a bifunctional primary amine/thiourea organocatalyst, generating the pyryli- 
um ylide from a 6-benzoyloxypyranone derivative by condensation with the amino catalyst. ${ }^{[45]}$ As an alternative, Vicario and Reyes recently developed the use of chiral secondary amines as organocatalysts for the $[5+2]$ cycloaddition between $\alpha, \beta$-unsaturated aldehydes and oxidopyrylium ylides on the basis of dienamine activation. ${ }^{[46]}$ As shown in Scheme 19, these au-

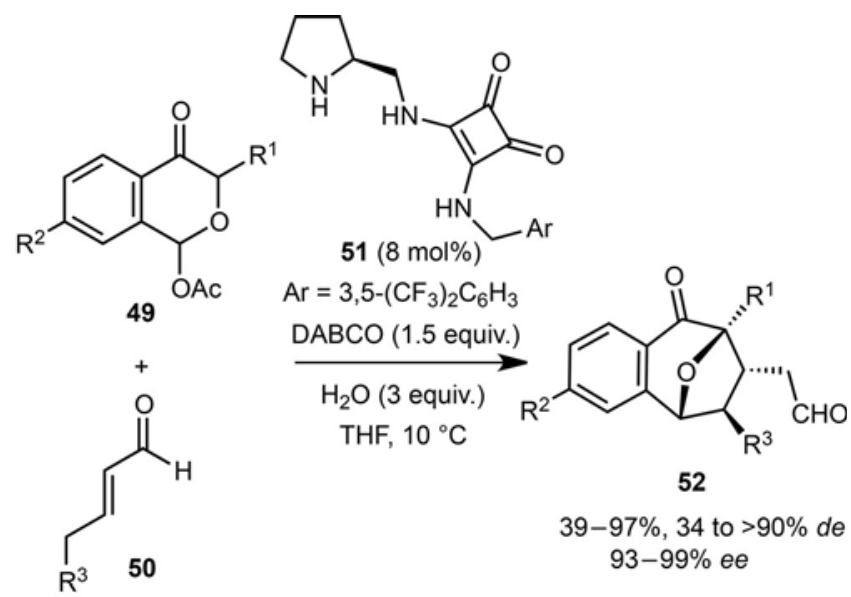

$\mathrm{R}^{1}=\mathrm{H}, \mathrm{Me}$

$\mathrm{R}^{2}=\mathrm{H}, \mathrm{Me}, \mathrm{Ph}$

$\mathrm{R}^{3}=\mathrm{Me}, n-\mathrm{Pr}, n$-Hept, $i$ - $\mathrm{Pr}, \mathrm{Ph}, p-\mathrm{MeOC}_{6} \mathrm{H}_{4}, o-\mathrm{MeOC}_{6} \mathrm{H}_{4}, m-\mathrm{MeOC}_{6} \mathrm{H}_{4}$, p-Tol, $p$ - $\mathrm{ClC}_{6} \mathrm{H}_{4}, \mathrm{Bn}, \mathrm{CH}_{2}-(\mathrm{Z})-(\mathrm{CH}=\mathrm{CH}) \mathrm{Et}, \mathrm{CH}_{2} \mathrm{NHCbz}, \mathrm{CH}=\mathrm{CH}_{2}, \mathrm{H}$

proposed transition state based on dienamine activation:

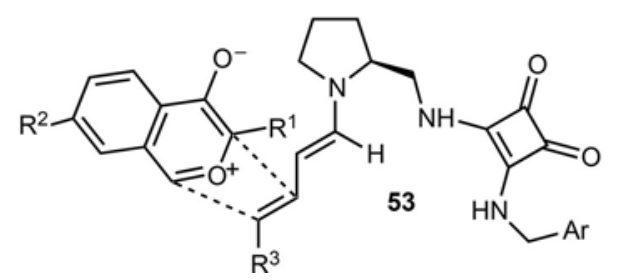

Scheme 19. Enantioselective organocatalytic [5+2] cycloaddition of benzopyrylium ions and $\alpha, \beta$-unsaturated aldehydes.

thors successfully developed reactions of benzopyrylium ions, in situ generated from the corresponding 1acetoxyisochroman-4-ones 49 , with a range of $\alpha, \beta$-unsaturated aldehydes $\mathbf{5 0}$ promoted by $8 \mathrm{~mol} \%$ of proline-derived squaramide bifunctional catalyst $\mathbf{5 1}$ in the presence of $\mathrm{DABCO}$ as a base in THF at $10^{\circ} \mathrm{C}$. These processes afforded the corresponding chiral 8oxabicyclo[3.2.1] octane derivatives $\mathbf{5 2}$ in moderate to quantitative yields (39-97\%), moderate to high diastereoselectivities (34 to $>90 \%$ de) and uniformly excellent enantioselectivities $(93-99 \%$ ee). The authors proposed that the reaction evolved through dienamine intermediate $\mathbf{5 3}$ formed by condensation of the $\alpha, \beta$-unsaturated aldehyde with the organocatalyst. This intermediate could play the role of a suitable electron-rich alkene, which participated as a chiral dipolarophile in the $[5+2]$ cycloaddition with the benzo- pyrylium ion. A study of the substrate scope showed that in addition to variously substituted aromatic $\alpha, \beta$ unsaturated aldehydes, aliphatic ones were also good substrates regardless of the length of the alkyl substituent, although a slightly lower yield was observed when the steric bulk of this substituent was increased (56\% yield with $\mathrm{R}=i$-Pr vs. $91-92 \%$ with $\mathrm{R}=\mathrm{Me}, n$ $\operatorname{Pr})$. Even functionalized $\alpha, \beta$-unsaturated aldehydes $\left[\mathrm{R}=\mathrm{CH}=\mathrm{CH}_{2}, \quad \mathrm{CH}_{2} \mathrm{NHCbz}, \quad \mathrm{CH}_{2}-(\mathrm{Z})-(\mathrm{CH}=\mathrm{CH}) \mathrm{Et}\right]$ provided good results (39-85\% yields, 50 to $>90 \%$ $d e$, 93-99\% ee), thus demonstrating the functionalgroup compatibility of the methodology.

On the basis of DFT calculations, these authors have proposed the catalytic cycle depicted in Scheme $20 .{ }^{[47]}$ It began with the formation of intermediate 54 through the initial activation of the two reagents by the organocatalyst. Calculations of the several possibilities for generating intermediate 56 from intermediate $\mathbf{5 4}$ showed that the most favorable pathway corresponded to the formation of intermediate 55 through incorporation of the oxidopyrylium ylide $\mathbf{5 7}$ to intermediate $\mathbf{5 5}$, followed by release of the

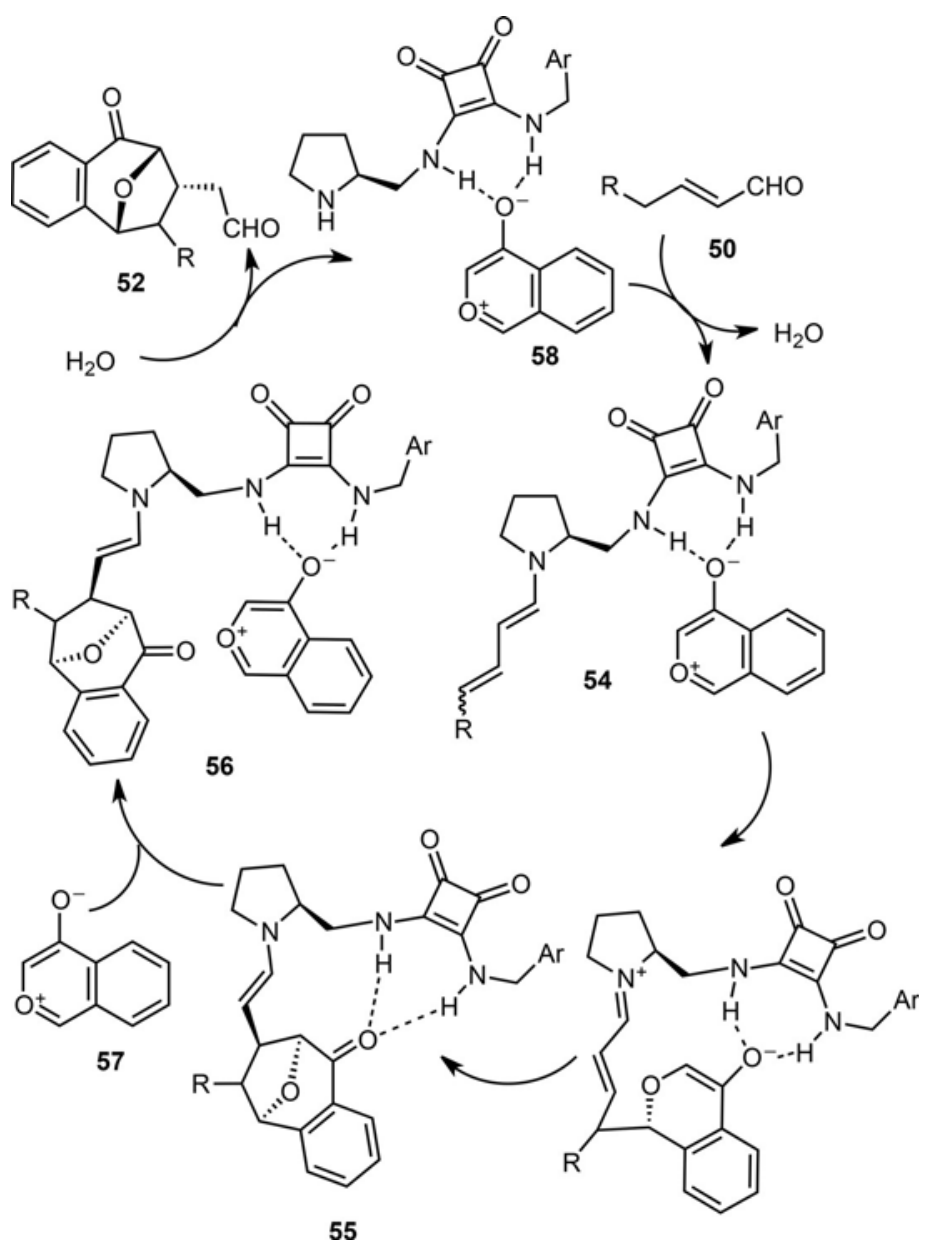

Scheme 20. Catalytic cycle for enantioselective organocatalytic [5+2] cycloaddition of benzopyrylium ions and $\alpha, \beta$-unsaturated aldehydes. 
product and formation of dienamine $\mathbf{5 4}$ from intermediate $\mathbf{5 8}$ and the $\alpha, \beta$-unsaturated aldehyde.

In 2016, Murelli et al. discovered that $\alpha$-hydroxy- $\gamma$ pyrone-based oxidopyrylium dimers 59 could undergo exchange by heating in the presence of alcohols to generate new oxidopyrylium species 60 (mechanism in Scheme 21). ${ }^{[4]}$ The latter could then undergo a

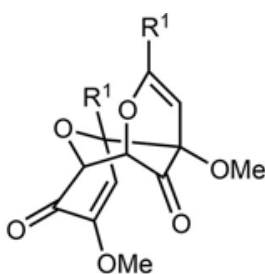

59

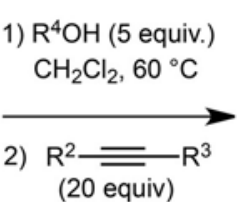

microwaves, $100^{\circ} \mathrm{C}$

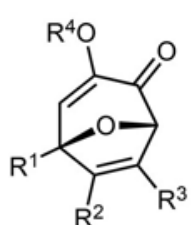

61

$24-65 \%$
$\mathrm{R}^{1}=\mathrm{Me}, \mathrm{MOM}$

$\mathrm{R}^{2}=\mathrm{CO}_{2}-t-\mathrm{Bu}, \mathrm{CO}_{2} \mathrm{Et}, \mathrm{Ac}, \mathrm{CO}_{2} \mathrm{Me}, \mathrm{Ph}, p-\mathrm{F}_{3} \mathrm{CC}_{6} \mathrm{H}_{4}$,

$p-\mathrm{MeOC}_{6} \mathrm{H}_{4}, p-(\mathrm{HC} \equiv \mathrm{C}) \mathrm{C}_{6} \mathrm{H}_{4}$

$\mathrm{R}^{3}=\mathrm{H}, \mathrm{CO}_{2} \mathrm{Me}$

$\mathrm{R}^{4}=\mathrm{Bn}, \mathrm{CH}_{2}(p-\mathrm{Tol}), \mathrm{CH}_{2}\left(p-\mathrm{F}_{3} \mathrm{CC}_{6} \mathrm{H}_{4}\right), \mathrm{CH}_{2}(t-\mathrm{Bu}),\left(\mathrm{CH}_{2}\right)_{2} \mathrm{CN}, i-\mathrm{Pr}$, allyl

proposed mechanism:

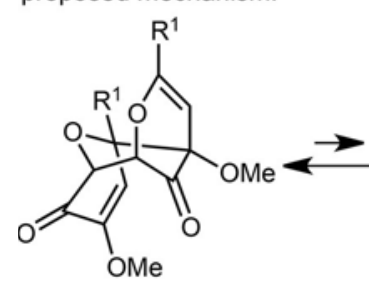

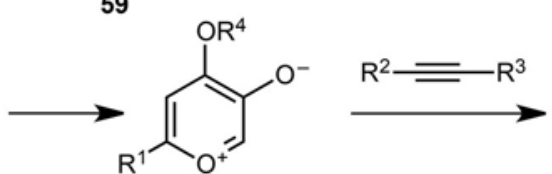<smiles>[R20]CCC(OC)c1cc([R7])[o+]cc1[O-]</smiles>

60<smiles>[R2]OC1=C[C@@]2([R])O[C@@H](C1=O)C([R])=C2[R]</smiles>

Scheme 21. The [5+2] cycloaddition of $\alpha$-hydroxy- $\gamma$-pyronebased oxidopyrylium dimers, alcohols and alkynes.

[5+2] cycloaddition with alkynes under microwave irradiation at $100^{\circ} \mathrm{C}$ in dichloromethane to afford the corresponding bicyclic products $\mathbf{6 1}$ in moderate yields (24-65\%). In addition to benzyl alcohols bearing either electron-donating or electron-withdrawing substituents on the phenyl ring, primary aliphatic alcohols with an adjacent hindered group $\left[\mathrm{R}^{4}=\mathrm{CH}_{2}(t-\right.$ $\mathrm{Bu})]$ or a base-sensitive functionality $\left[\mathrm{R}^{4}=\left(\mathrm{CH}_{2}\right)_{2} \mathrm{CN}\right]$ were also tolerated, giving comparable results (42$57 \%$ ). On the other hand, steric limitations were illustrated in the reaction of a secondary alcohol $\left(\mathrm{R}^{4}=i\right.$ $\mathrm{PrOH})$ which required a longer reaction time and provided a lower yield (32\%). Moreover, attempts to use a tertiary alcohol, such as tert-butyl alcohol, did not lead to the formation of the corresponding product. Notably, the reaction conditions were compatible to both terminal alkynes and symmetrical internal ones. It must be noted that the formed products can be considered as precursors of $\alpha$-hydroxytropolones, which have been identified as therapeutic leads for a variety of diseases related to their ability to bind to and inhibit important dinuclear metalloenzymes.

Earlier in 2014, Jacobsen and Witten reported enantioselective organocatalytic [5+2] cycloadditions of pyrylium ions in situ generated from the corresponding alkenylpyranones $\mathbf{6 2}$ with electron-rich alkenes such as vinyl ethers 63 (Scheme 22). ${ }^{[49]}$ The reactions were promoted in toluene at room temperature by a dual catalyst system composed of chiral primary aminothiourea 64 and achiral thiourea 65 which<smiles>FC(F)(F)c1cc(NC(=S)Nc2cc(C(F)(F)F)cc(C(F)(F)F)c2)cc(C(F)(F)F)c1</smiles>
$65(20 \mathrm{~mol} \%)$<smiles>[R]C1OC([R])(OC(=O)c2cc(F)c(F)c(F)c2)C=CC1=O</smiles><smiles>NC1CCCC[C@@H]1NC(=S)Nc1c(-c2ccccc2)cccc1-c1ccccc1</smiles><smiles>CCCCCCCC(=O)O</smiles>
toluene, $23^{\circ} \mathrm{C}$<smiles>[R]c1ccc(N[C@H]2CCCC[C@H]2NC(=S)Nc2c(-c3ccccc3)cccc2-c2ccc(C(F)(F)F)cc2)c(N([TlH]O)C(=S)N([TlH])c2cc(C(F)(F)F)cc(C(F)(F)F)c2)c1</smiles><smiles>[R19]OC=CC</smiles>

$22-95 \%, 64-96 \%$ ee

$\mathrm{R}^{1}=\mathrm{Me}, n-\mathrm{Hex}, \mathrm{Bn}, i-\mathrm{Bu}, \mathrm{CH}_{2} \mathrm{OTBS}, \mathrm{H}$ $\mathrm{R}^{2}=\mathrm{H}, \mathrm{CH}_{2} \mathrm{OTBS}$ $\mathrm{R}^{3}=\mathrm{Et}, \mathrm{Bn}, \mathrm{MOM}$

Scheme 22. Enantioselective organocatalytic [5+2] cycloaddition of pyrylium ions and vinyl ethers. 
allowed, in the presence of $\mathrm{AcOH}$ as additive, the formation of intermediate thiourea-complexed aminopyrylium salt $\mathbf{6 6}$ (Scheme 22). These reactions afforded a range of chiral 8-oxabicyclo[3.2.1] octane derivatives 67 in moderate to excellent yields (22-95\%) and enantioselectivities $(64-96 \%$ ee $)$. The study of the substrate scope of the process showed that pyranones could bear different aliphatic substituents at the 6-position $\left(\mathrm{R}^{1}\right)$, however, lower yields $(22-26 \%)$ were obtained with $\beta$-branched substituents $\left(\mathrm{R}^{1}=i\right.$ - $\left.\mathrm{Pr}, \mathrm{Bn}\right)$. The reaction conditions were compatible to several terminal alkenes, such as ethyl vinyl ether, benzyl vinyl ether, and (methoxymethoxy)ethane while electron-deficient olefins, such as acrylonitrile or methyl acrylate, were completely inert. The utility of this novel methodology was demonstrated by the conversion of cycloadducts into various complex multifunctional chiral products which could be considered as potent building blocks for the synthesis of natural and biologically active compounds.

\subsection{Intramolecular [5+2] Cycloadditions}

In most cases, intramolecular [5+2] cycloadditions of oxidopyrylium species involve alkenes as partners. The synthetic utility of these methodologies has been demonstrated by their applications in the synthesis of various oxa-bridged cycloheptanoid fragments of complex natural products, ${ }^{[50]}$ such as the antitumor agent phorbol, ${ }^{[51]}$ the antibiotic guanacastepene, ${ }^{[52]}$ phomoidride $\mathrm{B},{ }^{[53]}$ a cyathin diterpene,${ }^{[54]}$ the sesquiterpene anthecularin, ${ }^{[55]}$ the diterpene $(+)$-intricarene ${ }^{[56]} 12$-hydroxydaphnetoxins, ${ }^{[57]}$ hainanolidol and harringtonolide, ${ }^{[58]}$ as well as arteminolides. ${ }^{[59]}$ In 2014, Sohn reported the preparation of an intermediate to the biogenic precursors of arteminolides which was based on an intramolecular [5+2] cycloaddition of an oxidopyrylium ion exhibiting a vinylsilyl ether. ${ }^{[60]}$ As shown in Scheme 23, submitting pyran $\mathbf{6 8}$ to treatment by DBU in dichloromethane generated the corresponding oxidopyrylium ion $\mathbf{6 9}$ which further underwent intramolecular [5+2] cycloaddition with the tethered vinyl silyl ether to afford product $\mathbf{7 0}$ as a single diastereomer in $71 \%$ yield. The latter was subsequently converted into a common intermediate towards the biogenic precursor of arteminolides.

Another intramolecular [5+2] cycloaddition of an oxidopyrylium ion, generated from the corresponding alkene-tethered acetoxypyranone $\mathbf{7 1}$, constituted the first step of a domino reaction reported by Mitchell et al. in 2014. ${ }^{[61]}$ Performed in the presence of $\mathrm{DABCO}$ as base in acetonitrile at $60^{\circ} \mathrm{C}$, this intramolecular [5+2] cycloaddition, leading to intermediate 72, was followed by the oxa-Michael addition of an alcohol to afford the corresponding bridged tetracyclic ethers 73 in moderate to good yields $(21-73 \%)$. As
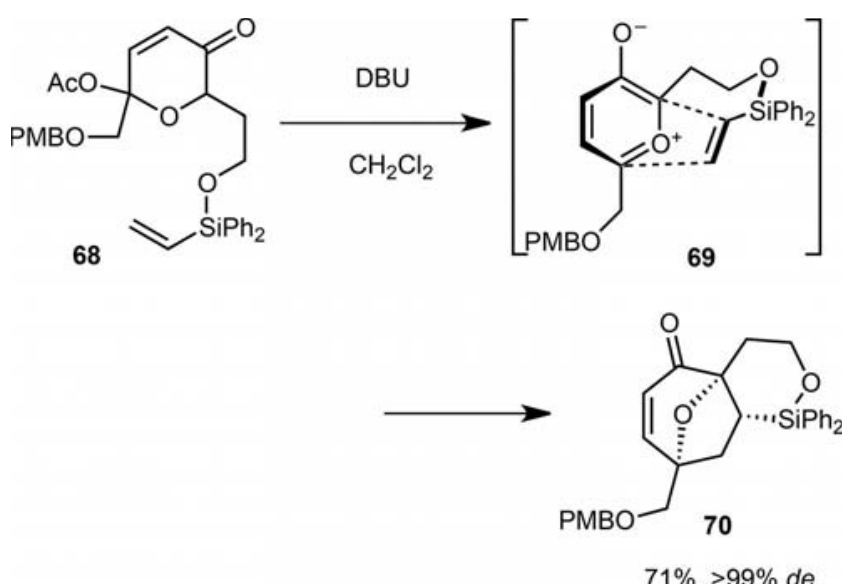

Scheme 23. The [5+2] cycloaddition of an oxidopyrylium ion exhibiting a vinylsilyl ether.

shown in Scheme 24, starting from a 67:33 mixture of anti/syn-diastereomers of alkene-tethered acetoxypyranone 71, the products were obtained as almost single diastereomers exhibiting six stereogenic centers (> $90 \% d e$ ). The domino reaction was compatible with a variety of primary aliphatic alcohols including functionalized ones, which provided uniformly good yields $(53-63 \%)$. On the other hand, more hindered alcohols, such as isopropyl alcohol, gave mixed results ( $\leq$ $53 \%$ yield). The lowest yield $(21 \%)$ was obtained in the reaction involving an aromatic alcohol such as $p$ cresol. The process was also applied to highly functionalized Boc-L-serine methyl ester which yielded the corresponding product in good yield $(73 \%)$ as a 1:1 mixture of diastereomers.

Until 2014, there was no report in the literature concerning [5+2] cycloadditions in which the $2 \pi$ component was derived from the $\mathrm{C}-2=\mathrm{C}-3$ bond of an<smiles>CC(=O)OC1C=CC(=O)C(CCC/C=C/CO)O1</smiles>

71

$67: 33$ anti/syn

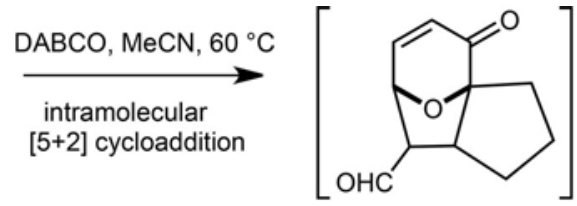

72

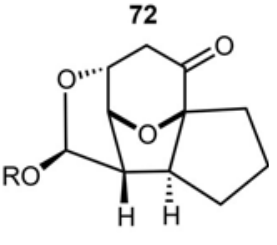

73

$21-73 \%$

$>90 \%$ de
$\mathrm{R}=\mathrm{Me},\left(\mathrm{CH}_{2}\right)_{4} \mathrm{CH}=\mathrm{CH}_{2}, \mathrm{CH}_{2}\left(p-\mathrm{MeOC}_{6} \mathrm{H}_{4}\right), \mathrm{CH}_{2} \mathrm{C} \equiv \mathrm{CH}, i-\mathrm{Pr}, p-\mathrm{Tol}$, $\mathrm{CH}_{2} \mathrm{CH}\left(\mathrm{CO}_{2} \mathrm{Me}\right)(\mathrm{NHBoC})$

Scheme 24. Domino [5+2] cycloaddition/oxa-Michael reaction of an oxidopyrylium ion exhibiting an alkene with alcohols. 
indole. Indeed, the first dearomative indole [5+2] cycloaddition of oxidopyrylium ions was reported by $\mathrm{Li}$ et al. in 2017. ${ }^{[62]}$ As shown in Scheme 25, the successive treatment of indole kojic acid derivatives $\mathbf{7 4}$ with

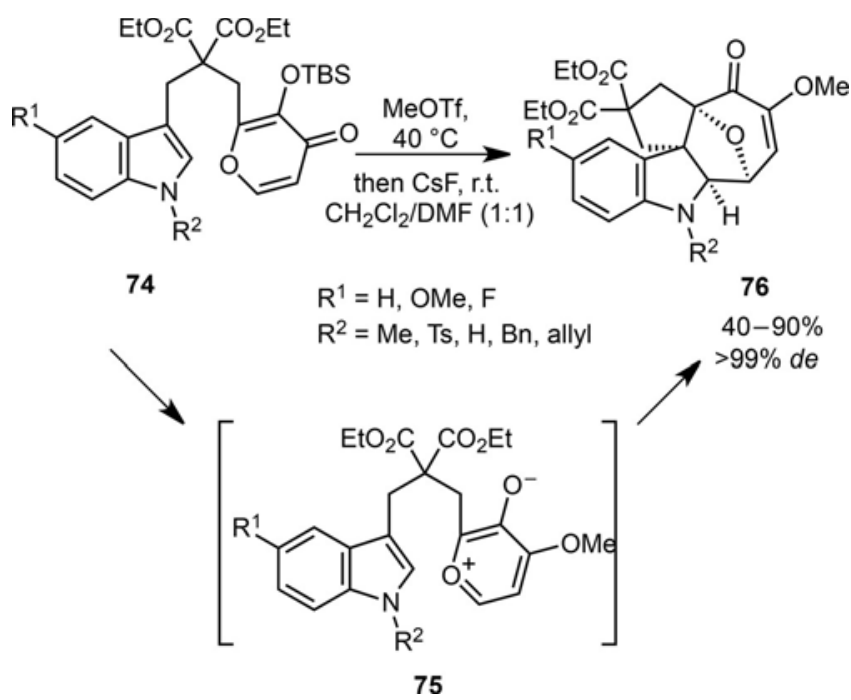

Scheme 25. Dearomative indole [5+2] cycloadditions of oxidopyrylium ions and alkenes.

MeOTf at $40{ }^{\circ} \mathrm{C}$ and then $\mathrm{CsF}$ at $25^{\circ} \mathrm{C}$ in a $1: 1$ mixture of $\mathrm{CH}_{2} \mathrm{Cl}_{2} / \mathrm{DMF}$ as solvent resulted in the in situ generation of the corresponding methoxypyrylium salts 75, which subsequently underwent an intramolecular [5+2] cycloaddition with the $\mathrm{C}-2=\mathrm{C}-3$ bond of the indole moiety to afford the corresponding oxacyclohepta $[b]$ indoles 76. These highly functionalized and synthetically challenging products were remarkably obtained through exclusive endo selectivity ( $>$ $99 \% d e)$ in moderate to high yields $(40-90 \%)$. The substrate scope of the process was found to be wide since a variety of indoles bearing electron-donating or electron-withdrawing substituents at the C-5 position were compatible. The reaction conditions were tolerant with $\mathrm{N}$-unprotected indoles as well as methyl-, tosyl-, benzyl-, and allyl-protected indoles.

In 2015, the same authors investigated for the first time a novel type of substrates in intramolecular $[5+2]$ cycloadditions, such as acetoxypyranones bearing an alkene tethered at the $\mathrm{C}-3$ position of the acetoxypyranone. ${ }^{[63]}$ In this case, the reaction is called a type $2[5+2]$ cycloaddition. When variously substituted substrates $\mathbf{7 7}$ were submitted to 1.5 equivalents of 2,2,6,6-tetramethylpiperidine (TMP) as a base in acetonitrile at 160 or $100^{\circ} \mathrm{C}$, they led to the corresponding bicyclo[4.4.1] undecanes $\mathbf{7 8}$ as sole products (Scheme 26). These highly functionalized and challenging bridged seven-membered ring compounds were obtained through unique endo selectivity in uniformly high yields $(85-98 \%)$ with low to excellent dia-<smiles>[R]C(=O)OC1OC([R])C(=O)C=C1C([R6])CCC([R])([R])C([R3])=C([R])[R]</smiles>

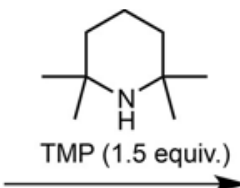

$\mathrm{MeCN}, 100$ or $160^{\circ} \mathrm{C}$

$\mathrm{R}^{1}=\mathrm{H}, \mathrm{Me}, \mathrm{CO}_{2} \mathrm{Me}$

$\mathrm{R}^{2}=\mathrm{H}, \mathrm{Me}$

$\mathrm{R}^{3}=\mathrm{H}, \mathrm{Me}$

$\mathrm{R}^{4}=\mathrm{H}$, OTIPS, OTBS, OAC

$\mathrm{R}^{5}=\mathrm{H}$

$R^{4}, R^{5}==0$

$\mathrm{R}^{6}=\mathrm{H}$, OTBS

$\mathrm{R}^{7}=\mathrm{H}, \mathrm{Ph}, \mathrm{Me}, \mathrm{Et}$

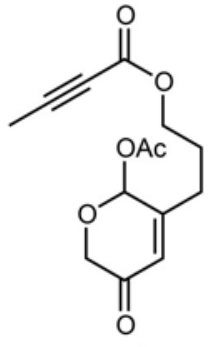

79

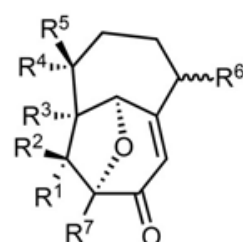

78

$85-98 \%$

12 to $>90 \%$ de

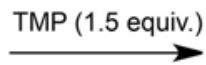

$\mathrm{MeCN}, 160^{\circ} \mathrm{C}$

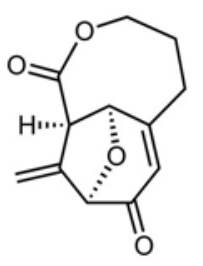

80
Scheme 26. Type $2[5+2]$ cycloadditions of oxidopyrylium ions and alkenes or alkyne.

stereoselectivities (12 to $>90 \%$ de). The scope of this methodology could be extended to an oxygen/alkynetethered substrate $\mathbf{7 9}$, leading to the corresponding type 2 cycloadduct $\mathbf{8 0}$ as sole product in $94 \%$ yield (Scheme 26). To demonstrate the utility of this novel methodology, it was applied to the synthesis of the highly strained tricyclic cores of the natural products ingenol and cyclocitrinol.

With the aim of developing a novel total synthesis of the natural product eurifoloid A, the same authors recently applied this novel concept to substrate 81. ${ }^{[64]}$ Under related reaction conditions as above, it underwent the type $2[5+2]$ cycloaddition to afford the corresponding tricyclic core-containing product 82 including the required bicyclo[4.4.1]undecane ring system in 38\% yield, as shown in Scheme 27.

It must be noted that intramolecular [5+2] cycloadditions of oxidopyrylium ions with alkynes have been much less developed than those involving alkenes. ${ }^{[65]}$ A very recent example reported by $\mathrm{Li}$ et al. was applied to develop a novel total synthesis of (-)-colchicine. ${ }^{[66]}$ Indeed, a key step of this synthesis was the intramolecular [5+2] cycloaddition of chiral intermediate acetoxypyranone $\mathbf{8 3}$ performed in the presence of $\mathrm{NaHCO}_{3}$ as a base in dichloromethane at $120^{\circ} \mathrm{C}$ to give the corresponding enantiopure tricyclic product 84 (Scheme 28). The latter was subsequently converted into the natural product $(-)$-colchicine which was obtained in enantiopure form with $9.2 \%$ overall yield. 


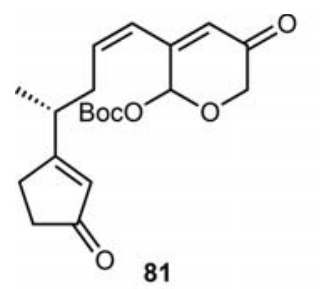

TMP (1.5 equiv.)

$\mathrm{MeCN}, 150^{\circ} \mathrm{C}$

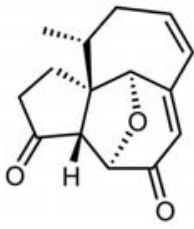

82

$38 \%$

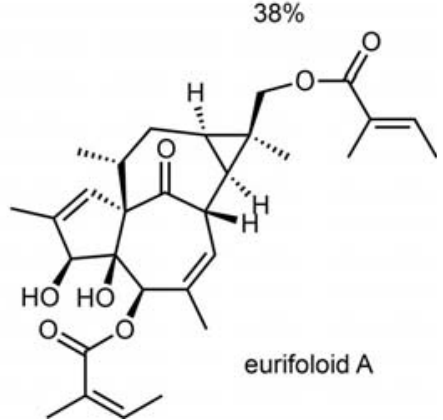

Scheme 27. Type $2[5+2]$ cycloaddition of oxidopyrylium ion and alkene and synthesis of the [5-7-7] tricyclic core of eurifoloid A.<smiles>C#Cc1c(CC[C@H](NC)c2ccc(CO)o2)cc(OC)c(OC)c1OC</smiles>

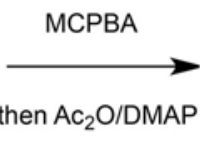<smiles>CC#Cc1c(CC[C@H](N)[C@H]2C=CC(=O)CO2)cc(OC)c(OC)c1OC</smiles>
$\mathrm{NaHCO}_{3}$ $\longrightarrow$ 83<smiles>CCNCCCN[C@H]1CCc2cc(OC)c(OC)c(OC)c2C2=CC=C(OC)C(=O)CC21</smiles>

84

$52 \%$ ( 2 steps), $>99 \%$ de (-)-colchicine

$9.2 \%$ overall yield $>99 \%$ ee
Scheme 28. The [5+2] cycloaddition of oxidopyrylium ion and alkyne and total synthesis of $(-)$-colchicine.

\section{4 [5+2] Cycloadditions of (Oxido)pyridinium Ions}

The chemistry of 3-oxidopyridinium betaines has been widely investigated by several groups among which that of Katritzky in the 1980s applied their
$[5+2]$ cycloaddition to the synthesis of core fragments of tropone alkaloids and related natural products. ${ }^{[5 b]}$ An advantage of these reactions results from the commercial availability of 3-hydroxypyridine. Upon thermal activation, this and related ylides react with electron-deficient dipolarophiles to afford the corresponding azabicyclic adducts in moderate yields and variable degrees of regio- and stereoselectivity. ${ }^{[6 a]}$ Several groups have developed both inter- and intramolecular $[5+2]$ cycloadditions of oxidopyridinium ions with alkenes, and some of these reactions have constituted key steps in the syntheses of important natural products, such as tricyclic cocaine analogs, ${ }^{[67]}$ sarains, ${ }^{[68]}$ and the hetisine alkaloid nominine. ${ }^{[69]}$ In addition, asymmetric versions of the [5+2] cycloaddition of oxidopyridinium ions have been developed but they were based on the use of chiral substrates and auxiliaries. ${ }^{[70]}$ As a recent example, Gaich and Krüger reported the [5+2] cycloaddition of Aggarwal's chiral ketene equivalent $\mathbf{8 5}^{[71]}$ with oxidopyridinium ion $\mathbf{8 6}$ as a key step in the total synthesis of various sarpagine alkaloids. ${ }^{[72]}$ Indeed, the reaction was performed in the presence of DIPEA in dichloromethane, leading to the desired regioisomer $\mathbf{8 7}$ as major product in $52 \%$ yield and high enantioselectivity of $93 \% e e$, as shown in Scheme 29. This product was further converted into three monoterpenoid indole alkaloids, such as vellosimine, $N$-methylvellosimine, and 10-methoxyvellosimine in eight steps from $\mathbf{8 5}$ and $\mathbf{8 6}$ in 10 $13 \%$ overall yields.

In 2014, Yoo et al. reported the in situ generation of air-stable azomethine ylides $\mathbf{8 8}$ via a rhodium-catalyzed reaction between pyridines $\mathbf{8 9}$ and 1-tosyl-1,2,3-

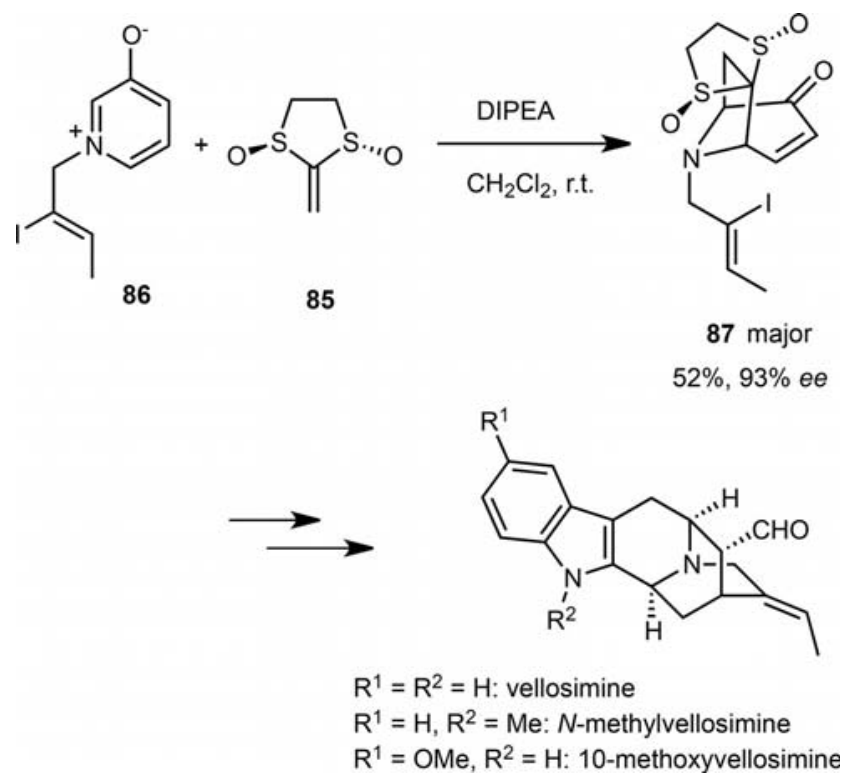

Scheme 29. The [5+2] cycloaddition of oxidopyridinium ion and Aggarwal's chiral ketene equivalent and total synthesis of sarpagine alkaloids. 
triazoles 90. ${ }^{[73]}$ These pyridinium ions reacted through $[5+2]$ cycloaddition in benzene at $100^{\circ} \mathrm{C}$ with activated alkynes, such as acetylenedicarboxylates 91, to afford the corresponding 1,4-diazepines 92 in homogeneously good to high yields (65-88\%), as shown in Scheme 30. Notably, the one-pot reaction was cata-

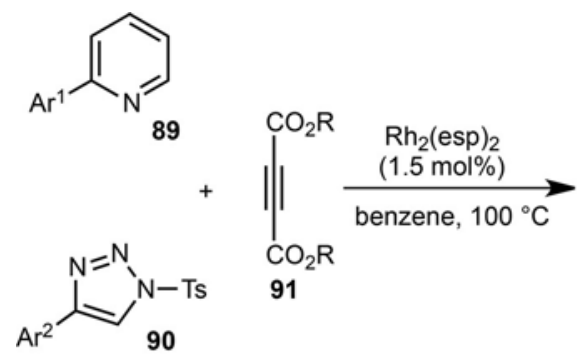

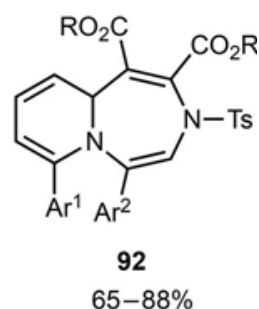

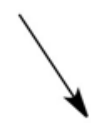

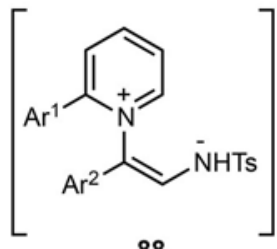

88

$\mathrm{Ar}^{1}=\mathrm{Ph}, p$-Tol, $p$ - $\mathrm{MeOC}_{6} \mathrm{H}_{4}, p-\mathrm{ClC}_{6} \mathrm{H}_{4}, p-\mathrm{FC}_{6} \mathrm{H}_{4}, p-\mathrm{AcC}_{6} \mathrm{H}_{4}, m$-Tol, $m-\mathrm{MeOC}_{6} \mathrm{H}_{4}, 2-\mathrm{Naph}, p-\mathrm{F}_{3} \mathrm{CC}_{6} \mathrm{H}_{4}, m-\mathrm{FC}_{6} \mathrm{H}_{4}$ $\mathrm{Ar}^{2}=\mathrm{Ph}, p-\mathrm{Tol}, p-\mathrm{MeOC}_{6} \mathrm{H}_{4}, p-\mathrm{F}_{3} \mathrm{CC}_{6} \mathrm{H}_{4}, m-\mathrm{FC}_{6} \mathrm{H}_{4}$ $\mathrm{R}=\mathrm{Me}, \mathrm{Et}$

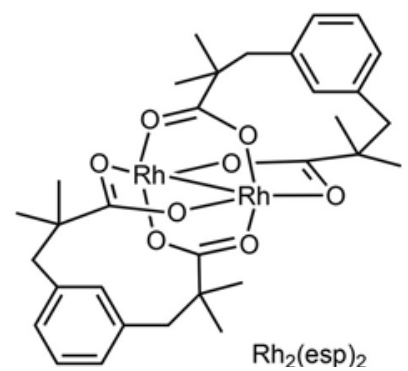

Scheme 30. Three-component [5+2] cycloaddition of pyridines, 1-tosyl-1,2,3-triazoles and activated alkynes.

lyzed with only $1.5 \mathrm{~mol} \%$ of $\mathrm{Rh}_{2}(\mathrm{esp})_{2}$. Its efficiency was not influenced by either electronic or steric properties of the 2-aryl substituent on the pyridine $\left(A r^{1}\right)$ as well as those of the 4-aryltriazole $\left(\mathrm{Ar}^{2}\right)$. Moreover, the process was compatible with dimethyl and diethyl acetylenedicarboxylates. In addition to the fact that the 1,4-diazepine moiety is a privileged structure of a wide range of natural and pharmaceutical products, it must be highlighted that this study represented the first catalytic three-component [5+2] cycloaddition of pyridines, 1-sulfonyl-1,2,3-triazoles and activated alkynes.
Very recently, the same authors reported the first $[5+2]$ cycloaddition of related isolable pyridinium zwitterions 93 with benzyne 94. ${ }^{[74]}$ The latter was in situ generated by treatment of the corresponding 2(trimethylsilyl)phenyl triflate $\mathbf{9 5}$ in the presence of a fluoride source, such as $\mathrm{CsF}$, in acetonitrile at $25^{\circ} \mathrm{C}$. Actually, the [5+2] cycloadduct 96 was not isolated since it subsequently reacted with a second equivalent of benzyne 94 through a [2+2] cycloaddition to lead to the final polycyclic 1,4-benzodiazepine 97 in moderate yield (36-54\%), as shown in Scheme 31. This remarkable domino [5+2] cycloaddition/[2+2] cycloaddition reaction was compatible with variously paraand meta-substituted pyridinium ions $\left(\mathrm{Ar}^{1}\right)$. Moreover, a pyridinium substrate bearing a naphthyl group $\left(\mathrm{Ar}^{1}=2-\mathrm{Naph}\right)$ was also a suitable reactant, giving the corresponding product in $54 \%$ yield. On the other hand, the reaction of ortho-substituted pyridine zwitterions and benzyne did not undergo the domino reaction. Furthermore, the efficiency of the process was
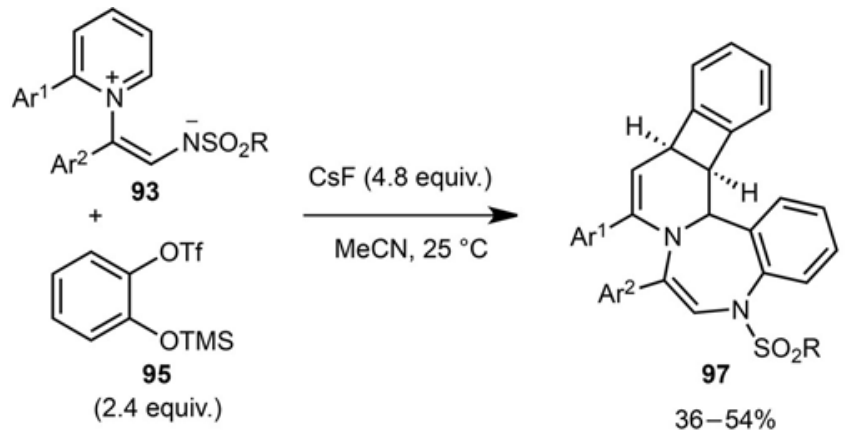

$\mathrm{Ar}^{1}=\mathrm{Ph}, p$-Tol, $p-\mathrm{MeOC}_{6} \mathrm{H}_{4}, p-\mathrm{ClC}_{6} \mathrm{H}_{4}, p-\mathrm{FC}_{6} \mathrm{H}_{4}, p-\mathrm{AcC}_{6} \mathrm{H}_{4}, m-\mathrm{Tol}$, 2-Naph

$\mathrm{Ar}^{2}=\mathrm{Ph}, p-\mathrm{Tol}, p-\mathrm{MeOC}_{6} \mathrm{H}_{4}, p-(t-\mathrm{Bu}) \mathrm{C}_{6} \mathrm{H}_{4}, p-\mathrm{F}_{3} \mathrm{CC}_{6} \mathrm{H}_{4}, p-\mathrm{FC}_{6} \mathrm{H}_{4}$, $p-\mathrm{BrC}_{6} \mathrm{H}_{4}, m-\mathrm{Tol}, m-\mathrm{FC}_{6} \mathrm{H}_{4}$

$\mathrm{R}=p$ - Tol, $\mathrm{Ph}, p-\mathrm{F}_{3} \mathrm{CC}_{6} \mathrm{H}_{4}, n-\mathrm{Bu}$

\section{proposed mechanism:}

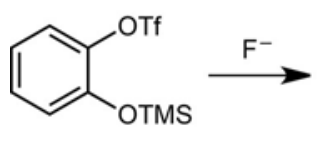<smiles>c1ccccc#1</smiles>

94

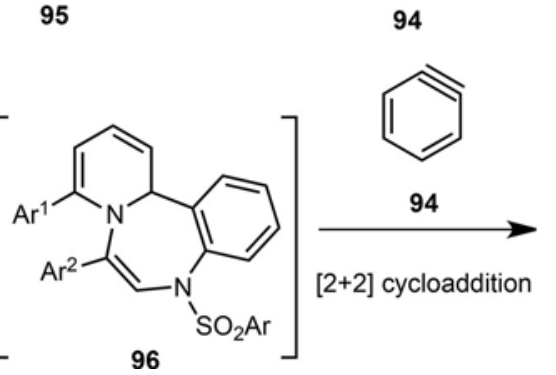

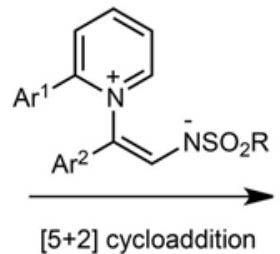<smiles>[R]OS(=O)(=O)N1C=C([Y10])N2C([Al])=C[C@H]3c4ccccc4[C@H]3C2c2ccccc21</smiles>

Scheme 31. Domino [5+2] cycloaddition/[2+2] cycloaddition reaction of pyridinium zwitterions and benzyne. 
not influenced by the electronic properties of the $\mathrm{Ar}^{2}$ substituent nor by those of the sulfonyl group on the pyridinium zwitterion. This novel metal-free, mild and efficient one-pot protocol opened a new route to highly desirable polycyclic 1,4-benzodiazepines which represent very important products in medicinal chemistry.

\section{Rhodium-Catalyzed [5+2] Cycloadditions of 3-Acyloxy-1,4-enynes}

In 2011, Tang et al. demonstrated that 3-acyloxy-1,4enynes could be employed as novel five-carbon building blocks in rhodium-catalyzed intramolecular [5+2] cycloadditions with alkynes. ${ }^{[75]}$ This discovery has led to the development of new methods for the preparation of highly substituted seven-membered rings. ${ }^{[76]}$ In 2015, these authors reported the intermolecular version of this methodology catalyzed by Wilkinson's catalyst in chloroform at $50^{\circ} \mathrm{C}^{[77]}$ As shown in Scheme 32, the reaction with functionalized terminal alkynes as generally performed with only $0.5 \mathrm{~mol} \%$ of catalyst led to the corresponding cycloheptatrienes 99 in moderate to quantitative yields (58-97\%) as almost single regioisomers in most cases of the substrates. The scope of the process was extended to symmetrical<smiles>[R]C#CC</smiles>

98 $\mathrm{Ar}=p-\left(\mathrm{NMe}_{2}\right) \mathrm{C}_{6} \mathrm{H}_{4}$

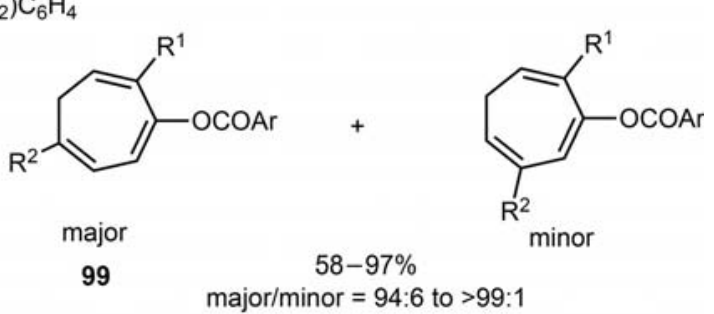

$\mathrm{R}^{1}=\mathrm{Me}, n-$ Pent

$\mathrm{R}^{2}=\mathrm{CH}_{2} \mathrm{OH}, \mathrm{C}(\mathrm{Me})_{2} \mathrm{OH}, \mathrm{CH}_{2} \mathrm{NHSO}_{2}\left(p-\mathrm{BrC}_{6} \mathrm{H}_{4}\right), \mathrm{CH}_{2} \mathrm{OPh}$, $\left(\mathrm{CH}_{2}\right)_{2} \mathrm{CN},(\mathrm{E})-\mathrm{CH}=\mathrm{CHCH}_{2} \mathrm{OH}$<smiles>C#CC(C)(C=C)OC(=O)Br</smiles>

$98 \mathrm{a}$<smiles>[R]C#CC[R]</smiles>$$
\text { [R }
$$

$\mathrm{R}=\mathrm{CH}_{2} \mathrm{OH}: 82 \%$
$\mathrm{R}=\mathrm{CO}_{2} \mathrm{Me}: 89 \%$

$100 a, b$

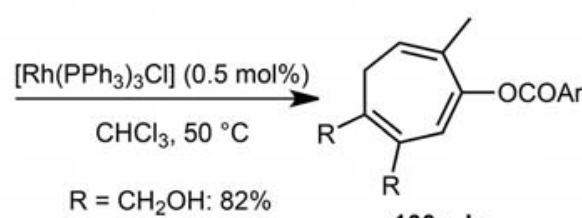

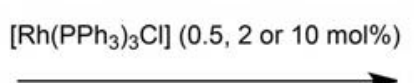

$\mathrm{CHCl}_{3}, 50^{\circ} \mathrm{C}$
Scheme 32. Intermolecular [5+2] cycloadditions of 3-acyloxy-1,4-enynes and alkynes. internal alkynes which led to the corresponding cycloadducts 100a, b in high yields (82-89\%), as shown in Scheme 32.

Using this methodology, these authors developed a novel route to prepare substituted tropones which are known to exhibit a broad spectrum of pharmaceutical activities. ${ }^{[78]}$ Indeed, a wide range of these products were generated by transformation of cycloheptatrienes derived from rhodium-catalyzed intermolecular [5+2] cycloadditions of 3-acetyl-1,4-enynes $\mathbf{1 0 1}$ with propargylic alcohols 102. As shown in Scheme 33, the reaction performed with $5 \mathrm{~mol} \%$ of Wilkinson's catalyst in chloroform at $65^{\circ} \mathrm{C}$ led to the expected cycloheptatrienes $\mathbf{1 0 3}$ as single regioisomers in good yields $(62-73 \%)$. In the case of internal alkynes 104, improved results were obtained by catalyzing the reactions with $5 \mathrm{~mol} \%$ of $[\mathrm{Rh}(\operatorname{cod}) \mathrm{Cl}]_{2}$ in the presence of an electron-deficient ligand such as ( $p$ $\left.\mathrm{CF}_{3} \mathrm{C}_{6} \mathrm{H}_{4}\right)_{3} \mathrm{P}$. Under these conditions, the reaction of 3-acetyl-1,4-enyne 101a with internal alkynes $\mathbf{1 0 4}$ provided the corresponding cycloheptatrienes $\mathbf{1 0 5}$ in good to high yields (51-90\%), as shown in Scheme 33. Several of these products were further submitted to a three-step mesylation, elimination and hydrolysis se-

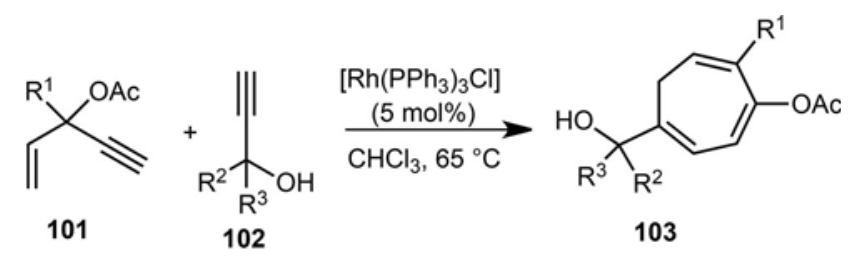

$\mathrm{R}^{1}=\mathrm{Me}, n-$ Pent

$62-73 \%$

$\mathrm{R}^{2}=\mathrm{Me}, n-\mathrm{Pent}, \mathrm{CH}_{2} \mathrm{Bn}, \mathrm{Ph}, t-\mathrm{Bu}, n-\mathrm{Pr}$

$\mathrm{R}^{3}=\mathrm{H}, \mathrm{Me}$<smiles>[R]C#CC([R20])O</smiles>

$\mathrm{R}^{1}=\mathrm{H}, \mathrm{Me}, \mathrm{CH}_{2} \mathrm{OTBS}$

$51-90 \%$

$\mathrm{R}^{2}=\mathrm{CH}_{2} \mathrm{Bn}, \mathrm{CH}_{2} \mathrm{OTBS}, \mathrm{H}$

synthesis of substituted tropones:<smiles>[R]C1=CCC(C([R])([R])O)=C([R])C=C1OC([R])(C)O</smiles>

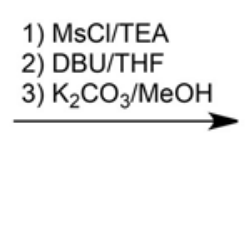

103,105

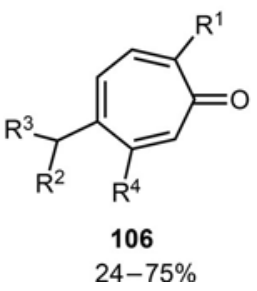

$24-75 \%$
Scheme 33. Intermolecular [5+2] cycloadditions of 3-acyloxy-1,4-enynes with propargyl alcohols and synthesis of substituted tropones. 
quence to afford various di- and trisubstituted tropones 106 (Scheme 33).

As an extension of their early work dealing with rhodium-catalyzed intramolecular [5+2] cycloadditions of 3-acyloxy-1,4-enynes with tethered alkynes, ${ }^{[75]}$ these authors also reported the first rhodium-catalyzed highly stereoselective intramolecular [5+2] cycloaddition of 3-acyloxy-1,4-enynes with tethered alkenes. ${ }^{[79]}$ As shown in Scheme 34, the process was catalyzed by a combination of $5 \mathrm{~mol} \%$ of $\left[\mathrm{Rh}(\mathrm{coe})_{2} \mathrm{Cl}\right]_{2}$ with $30 \mathrm{~mol} \%$ of $\left[3,5-\left(\mathrm{CF}_{3}\right)_{2} \mathrm{C}_{6} \mathrm{H}_{3}\right]_{3} \mathrm{P}$ as ligand in DCE as solvent at $80^{\circ} \mathrm{C}$. Under these reaction conditions, the [5+2] cycloaddtion of a variety of 3-acyloxy-1,4enynes 107 with alkenes led to the corresponding cisfused bicyclo[5.3.0]decadienes 108 in good yields (53$84 \%)$ as almost single diastereomers $(>90 \% d e)$. The

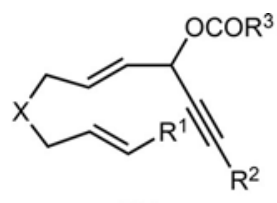

107

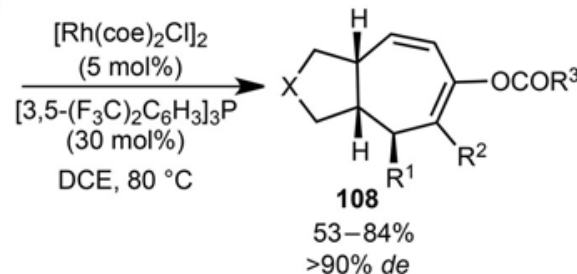

$\mathrm{X}=\mathrm{C}\left(\mathrm{CO}_{2} \mathrm{Me}\right)_{2}, \mathrm{CH}_{2}, \mathrm{O}, \mathrm{C}(\mathrm{CN})_{2}, \mathrm{NTs}, \mathrm{NSO}_{2}\left(p-\mathrm{BrC}_{6} \mathrm{H}_{4}\right)$

$\mathrm{R}^{1}=\mathrm{H}, \mathrm{Ph}, p-\mathrm{MeOC}_{6} \mathrm{H}_{4}, p-\mathrm{BrC}_{6} \mathrm{H}_{4}$

$\mathrm{R}^{2}=\mathrm{H}, \mathrm{Br}$

$\mathrm{R}^{3}=t-\mathrm{Bu}, p-\mathrm{Me}_{2} \mathrm{NC}_{6} \mathrm{H}_{4}, \mathrm{Me}$

proposed mechanism $\left(\mathrm{R}^{2}=\mathrm{H}\right)$ :

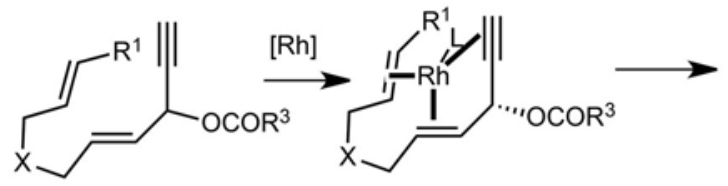

107

109

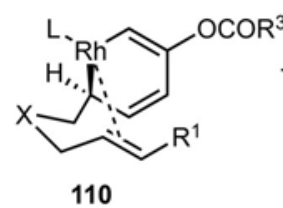

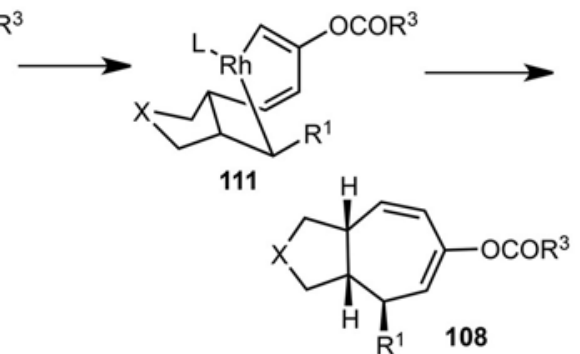

with transfer of chirality:

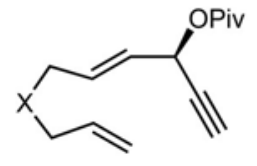

107a, b

$94-98 \%$ ee $\mathrm{X}=\mathrm{C}\left(\mathrm{CO}_{2} \mathrm{Me}\right)_{2}, \mathrm{NSO}_{2}\left(p-\mathrm{BrC}_{6} \mathrm{H}_{4}\right)$ same conditions
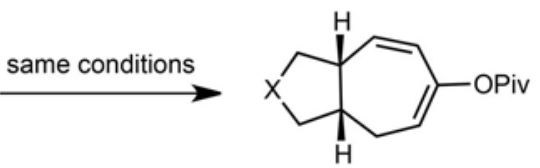

$108 \mathrm{a}, \mathrm{b}$

$72-85 \%$ $>99 \%$ de $86-90 \%$ ee
Scheme 34. Rhodium-catalyzed intramolecular [5+2] cycloadditions of 3-acyloxy-1,4-enynes and alkenes. best yields were generally obtained in the reaction of terminal alkynes while internal alkynes provided moderate yields (51-54\%). The mechanism depicted in Scheme 34 begins with the formation of rhodium complex 109 which promotes the 1,2-acyloxy migration and oxidative cyclization to form metallacyclohexadiene intermediate 110. A subsequent insertion of the tethered alkene to this metallacycle affords intermediate 111. Then, the reductive elimination of metallacyclooctadiene $\mathbf{1 1 1}$ provides the final cycloheptadiene product 108. In addition, the authors also performed the reaction starting from optically enriched substrates 107a, b (94-98\% ee) and demonstrated that the chirality could be efficiently transferred to the cycloaddition products $\mathbf{1 0 8 a}, \mathbf{b}$ since the enantioselectivities of the latter ranged from $86 \%$ to $90 \%$ ee in combination with a complete diastereoselectivity (Scheme 34).

Almost the same reaction conditions were applied to the rhodium-catalyzed intramolecular [5+2] cycloaddition of 3-acyloxy-1,4-enynes $\mathbf{1 1 2}$ with tethered allenes. ${ }^{[79 b]}$ As shown in Scheme 35, the reaction performed at $90^{\circ} \mathrm{C}$ in the presence of $5 \mathrm{~mol} \%$ of $\left[\mathrm{Rh}(\mathrm{coe})_{2} \mathrm{Cl}\right]_{2}$ and $30 \mathrm{~mol} \%$ of $\left[3,5-\left(\mathrm{CF}_{3}\right)_{2} \mathrm{C}_{6} \mathrm{H}_{3}\right]_{3} \mathrm{P}$ as ligand in DCE afforded the corresponding cis-fused bicyclic products $\mathbf{1 1 3}$ in moderate to good yields (45$58 \%$ ) as single diastereomers in most cases.

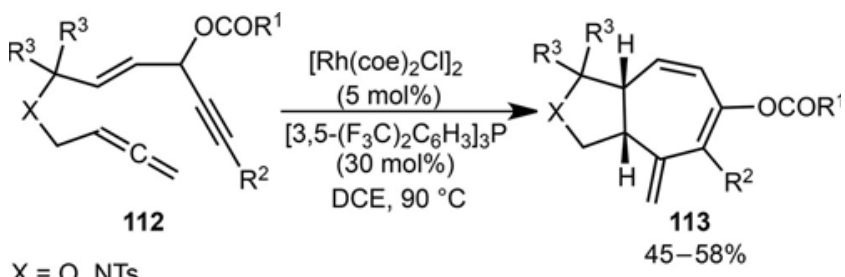

$\mathrm{X}=\mathrm{O}, \mathrm{NTS}$

$\mathrm{R}^{1}=p-\left(\mathrm{Me}_{2} \mathrm{~N}\right) \mathrm{C}_{6} \mathrm{H}_{4}, t-\mathrm{Bu}$

$\mathrm{R}^{2}=\mathrm{H}, \mathrm{Br}$

$\mathrm{R}^{3}=\mathrm{H}, \mathrm{Me}$

Scheme 35. Intramolecular [5+2] cycloaddition of 3-acyloxy1,4-enynes and allenes.

The presence of an electron-withdrawing group, such as a ketone, conjugated with the alkyne of the enyne substrate, is capable to switch the regioselectivity of the reaction, facilitating the 1,2-migration of the acyloxy group instead of a 1,3-migration. Indeed, a new type of 3-acyloxy-1,4-enyne five-carbon building block was developed by the same authors for rhodium-catalyzed intramolecular $[5+2]$ cycloadditions. ${ }^{[80]}$ When these inverted 3-acyloxy-6-keto-1,4-enyne substrates 114 were submitted to $5 \mathrm{~mol} \%$ of $\left[\mathrm{Rh}(\operatorname{cod})_{2}\right]^{+} \mathrm{BF}_{4}^{-}$in dichloromethane at room temperature to $50{ }^{\circ} \mathrm{C}$, they provided the corresponding bicyclic [5.3.0]decatrienes $\mathbf{1 1 5}$ which are different from those achieved in previous methods because of the positions of the alkene and the acyloxy group and the 
presence of a ketone function conjugated to the alkyne (Scheme 36). These highly functionalized seven-membered products were obtained in good yields $(41-85 \%)$ by using this novel [5+2] cycloaddition in which the acyloxy group migrated towards the

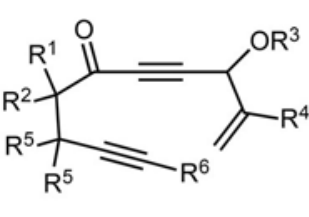

114

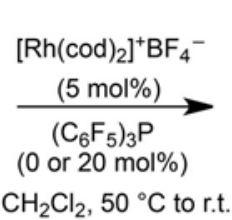

$\mathrm{CH}_{2} \mathrm{Cl}_{2}, 50^{\circ} \mathrm{C}$ to r.t.

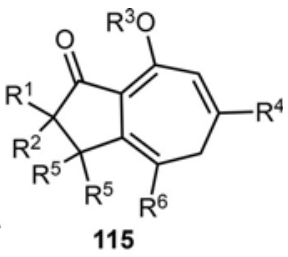

$41-85 \%$

$$
\begin{aligned}
& \mathrm{R}^{1}=\mathrm{Ph}, \mathrm{H}, \mathrm{Me} \\
& \mathrm{R}^{2}=\mathrm{Ph}, \mathrm{H}, \mathrm{Me} \\
& \mathrm{R}^{1}, \mathrm{R}^{2}=\left(\mathrm{CH}_{2}\right)_{5} \\
& \mathrm{R}^{3}=\mathrm{Piv}, \mathrm{Ac} \\
& \mathrm{R}^{4}=\mathrm{H}, \mathrm{Me}, \mathrm{Ph}, p-\mathrm{O}_{2} \mathrm{NC}_{6} \mathrm{H}_{4}, p-\mathrm{EtO}_{2} \mathrm{CC}_{6} \mathrm{H}_{4} \\
& \mathrm{R}^{5}=\mathrm{H}, \mathrm{Me} \\
& \mathrm{R}^{6}=\mathrm{H}, \mathrm{CH} \mathrm{H}_{2} \mathrm{OH}
\end{aligned}
$$

proposed mechanism (with $\mathrm{R}^{1}=\mathrm{R}^{2}=\mathrm{R}^{4}=\mathrm{R}^{5}=\mathrm{R}^{6}=\mathrm{H}, \mathrm{R}^{3}=$ Piv):
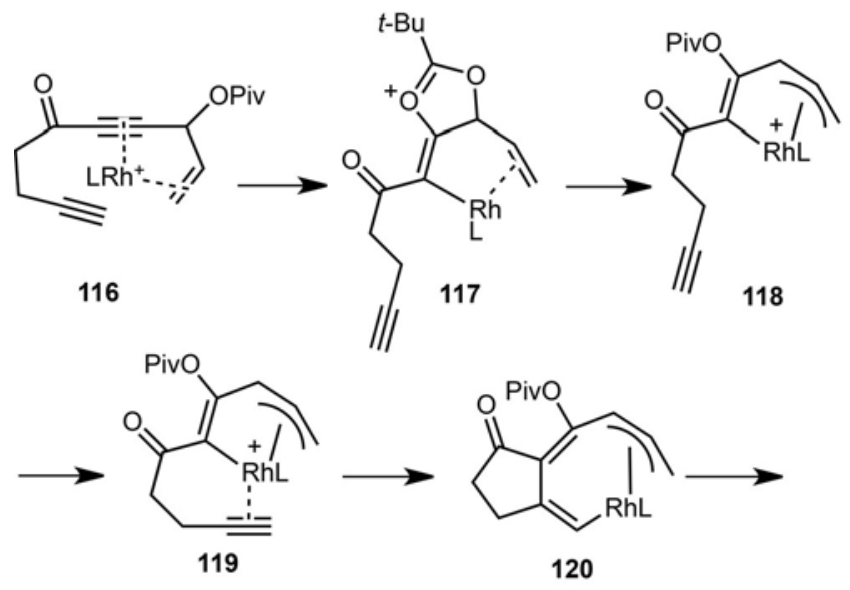

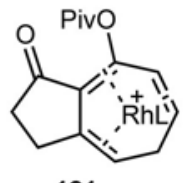

121
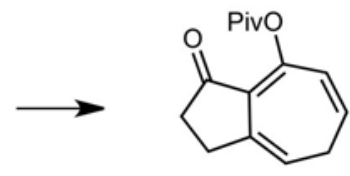

$115 \mathrm{a}$
Scheme 36. Intramolecular [5+2] cycloaddition of inverted 3-acyloxy-1,4-enynes and alkynes.

five-membered ring of the bicyclic products. On the basis of experimental and theoretical studies, the authors have proposed the mechanism depicted in Scheme 36 to explain these results. After the coordination of the rhodium catalyst to the 1,4-enyne in intermediate 116, a cascade 1,2-acyloxy migration and oxidation cyclization led to the formation of intermediates 117, 118 and 119. Then, a direct insertion of the tethered alkyne into the $\mathrm{Rh}-\mathrm{C}-5\left(s p^{2}\right)$ bond in intermediate 119 afforded intermediate 120 which led to the final product through reductive elimination.

\section{Metal-Catalyzed [5+2] Cycloadditions of ortho-Vinylphenols and ortho-Vinyl-/Arylanilines}

In 2014, Gulias and Mascarenas demonstrated that ortho-vinylphenols 122 underwent a formal [5+2] cycloaddition with internal alkynes when treated with catalytic amounts of $\left[\mathrm{Cp}^{*} \mathrm{RhCl}_{2}\right]_{2}$ in the presence of $\mathrm{Cu}(\mathrm{OAc})_{2}$ in acetonitrile at $85^{\circ} \mathrm{C} .{ }^{[81]}$ The reaction involved the cleavage of the terminal $\mathrm{C}-\mathrm{H}$ bond of the alkenyl moiety, leading to highly valuable benzoxepines 123 in good to quantitative yields (52-99\%), as shown in Scheme 37. Generally, good yields were achieved in the reaction of symmetrical alkynes bearing electron-rich or electron-deficient aryl substituents (60-90\%) while dialkyl-substituted alkynes provided lower yields (52-65\%). The reaction conditions were also compatible with unsymmetrical aryl/alkyl alkynes which reacted with high regioselectivity (up to 14:1 $r r$ ), leading to the corresponding products in which the phenyl group $\left(\mathrm{R}^{4}=\mathrm{Ph}\right)$ was situated on the carbon tethered to the oxygen group of the products. Moreover, a wide variety of substituents $\left(\mathrm{R}^{1}, \mathrm{R}^{2}, \mathrm{R}^{3}\right)$ on the aryl group of the vinylphenol were tolerated. To explain the results, the authors proposed the mechanism depicted in Scheme 37 which began with the phenolic substrate $\mathbf{1 2 2}$ replacing one of the acetates of the catalyst to give intermediate 124. The latter could evolve to the rhodacycle $\mathbf{1 2 5}$ either through a typical concerted metallation/deprotonation step (path A) or through an intramolecular electrophilic attack of the conjugated alkene (path B) to the electrophilic rhodium(I) followed by a base-assisted deprotonation to yield the rearomatized intermediate 125. This intermediate then coordinated the alkyne, and a migratory insertion occurred to give intermediate 126, which evolved through reductive elimination to afford the final product and an $\mathrm{Rh}(\mathrm{I})$ species which was then reoxidized to regenerate the catalyst.

In 2016, the same authors also demonstrated that ortho-vinylphenol 127 could react with a broad range of allenes $\mathbf{1 2 8}$ to give the corresponding [5+2] cycloadducts 129 when treated with palladium(II) catalysts under oxidative conditions (Scheme 38$).{ }^{[82]}$ The reactions were catalyzed by $7.5 \mathrm{~mol} \%$ of $\mathrm{Pd}(\mathrm{OAc})_{2}$ in the presence of $50 \mathrm{~mol} \%$ of $\mathrm{Cu}(\mathrm{OAc})_{2}$ in acetonitrile at $85^{\circ} \mathrm{C}$ or in some cases in toluene at $110^{\circ} \mathrm{C}$ in the presence of $7.5 \mathrm{~mol} \%$ of 2,2'-bipyridine (2,2'-Bipy) as an additive. They led to benzoxepine products 129 in good to high yields (60-92\%) with excellent regioselectivities (90:10 to $>95: 5 \mathrm{rr})$. Symmetrical 1,3-disubstituted allenes $\left(\mathrm{R}^{1}=\mathrm{R}^{3}=\mathrm{Ph}\right.$ or $\left.n-\mathrm{Pr}, \mathrm{R}^{2}=\mathrm{H}\right)$ provided the corresponding products with good yields (70$87 \%$ ) and high $E: Z$ ratios (91:9 to $94: 6)$. Cyclic allenes also led to the expected products in up to $79 \%$ yield as a single regioisomer. Moreover, 1,1-disubsti- 


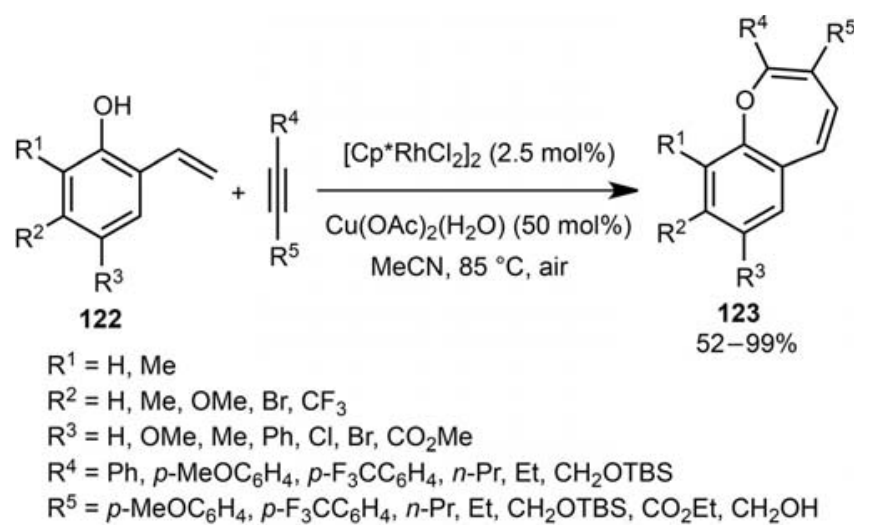

proposed mechanistic cycle:

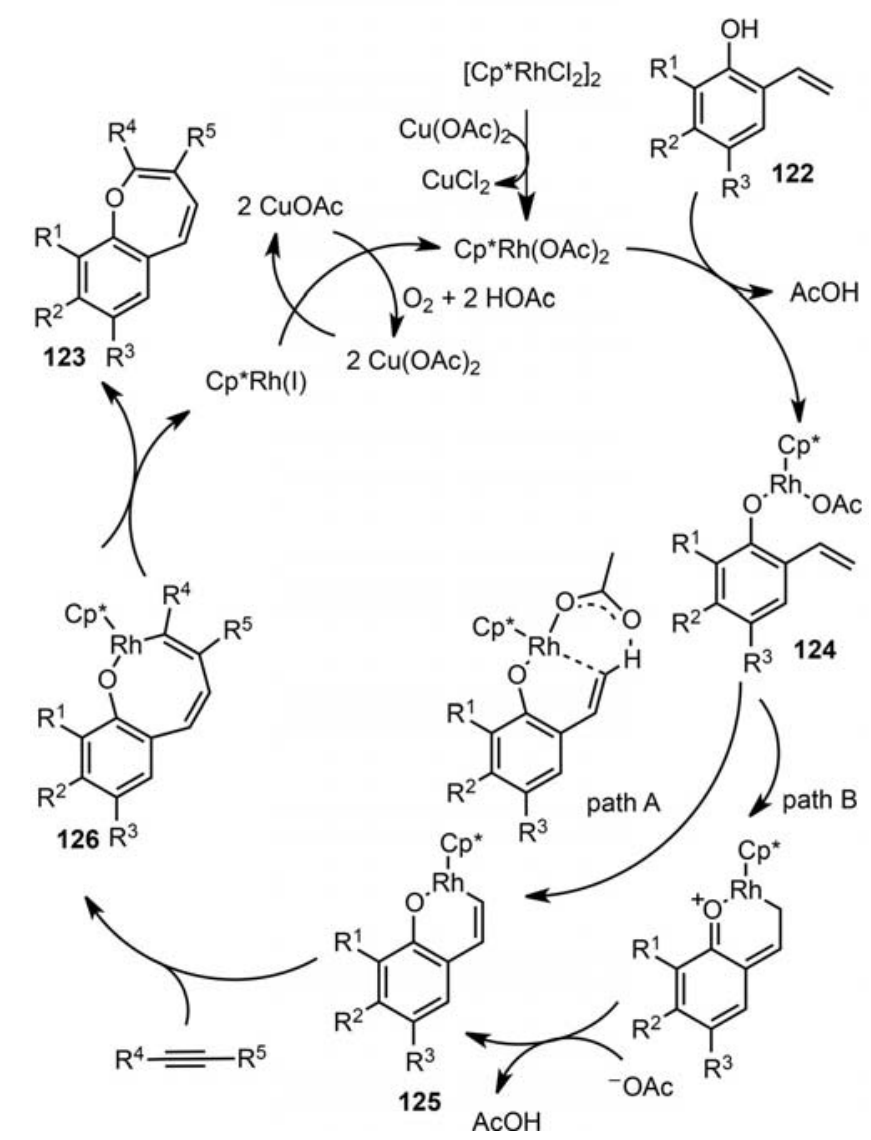

Scheme 37. Rhodium-catalyzed [5+2] cycloaddition of ortho-vinylphenols and alkynes.

tuted allenes underwent the cycloaddition with excellent regioselectivities (>95:5 rr) combined with high yields (71-92\%). Monosubstituted allenes, such as phenylallene or cyclohexylallene, were also compatible, providing the corresponding products in 69 and $71 \%$ yields, respectively, but in these cases by using $2,2^{\prime}$-Bipy as an additive in toluene at $110^{\circ} \mathrm{C}$. Furthermore, trisubstituted allenes also underwent the reaction with excellent yields $(82-88 \%)$ and regioselectivities (91:9 to $>95: 5 r r)$. Notably, the reaction was<smiles>[R1]C=C=C([R])[Y]</smiles>

$\underset{\mathrm{Cu}(\mathrm{OAc})_{2}(50 \mathrm{~mol} \%)}{\longrightarrow}$

2,2'-Bipy (0 or $7.5 \mathrm{~mol} \%$ )

MeCN, $85^{\circ} \mathrm{C}$ or toluene, $110^{\circ} \mathrm{C}$

$\mathrm{R}^{1}=\mathrm{Ph}, n-\mathrm{Pr}, \mathrm{H}$

$\mathrm{R}^{2}=\mathrm{Ph}, n-\mathrm{Pr}, \mathrm{Me}, \mathrm{H}$

128

$\mathrm{R}^{3}=i-\mathrm{Pr}, \mathrm{TMS}, \mathrm{H}, \mathrm{Cy}$

$R^{2}, R^{3}=\left(\mathrm{CH}_{2}\right)_{5}$

$R^{1}, R^{3}=\left(\mathrm{CH}_{2}\right)_{6}$<smiles>[R]C([R])=C1C=C(C)c2ccccc2OC1[R]</smiles>

129

$60-92 \%$

$90: 10$ to $>95: 5 \mathrm{rr}$<smiles>[R]C(=O)c1cc([R3])c([R])cc1O</smiles>

$R^{2}$

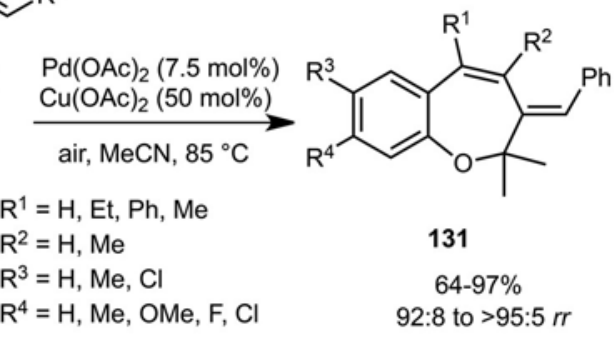

$128 \mathrm{a}$

$92: 8$ to $>95: 5 r$

proposed mechanism for the formation of $129 a\left(R^{1}=P h, R^{2}=R^{3}=M e\right)$ :

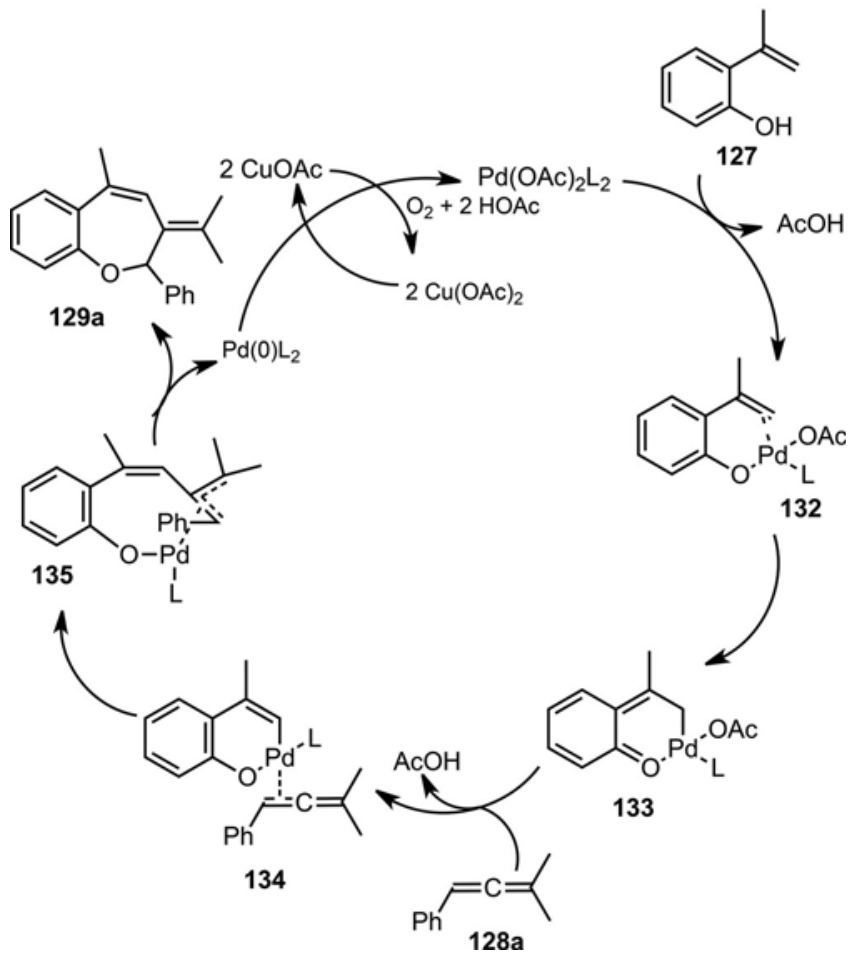

Scheme 38. Palladium-catalyzed [5+2] cycloadditions of ortho-vinylphenols and allenes.

found to be not restricted to ortho-vinylphenol $\mathbf{1 2 7}$ since related substrates $\mathbf{1 3 0}$ bearing various substituents also afforded by reaction with 128a the corresponding products $\mathbf{1 3 1}$ in high yields $(64-97 \%)$ and 
regioselectivities ( $92: 8$ to $>95: 5 \mathrm{rr}$ ), as shown in Scheme 38 (second equation). A plausible catalytic cycle is depicted in Scheme 38. It involved an initial ligand exchange between the phenol derivative $\mathbf{1 2 7}$ and the palladium acetate complex to give intermediate 132, which then evolved through intramolecular attack of the conjugated alkene to the palladium center to afford intermediate 133. The latter then underwent a base-induced rearomatization to form sixmembered palladacycle 134. The next step consisted of the coordination of the allene 128a $\left(\mathrm{R}^{1}=\mathrm{Ph}, \mathrm{R}^{2}=\right.$ $\mathrm{R}^{3}=\mathrm{Me}$ ) followed by a regioselective migratory insertion to give $\pi$-allylic palladacycle $\mathbf{1 3 5}$, which underwent a reductive elimination step to achieve the final product 129a. The resulting $\mathrm{Pd}(0)$ species was reoxidized to $\mathrm{PdII})$ by $\mathrm{Cu}(\mathrm{OAc})_{2}$ and air.

As an extension of these works (Scheme 38), ${ }^{[82]}$ Gulias and Mascarenas developed related reactions involving ortho-vinylanilides, in 2017. ${ }^{[83]}$ Indeed, ortho-vinylanilides $\mathbf{1 3 6}$ reacted with allenes $\mathbf{1 2 8}$ in the presence of $5 \mathrm{~mol} \%$ of $\mathrm{Pd}(\mathrm{OAc})_{2}$ combined with $50 \mathrm{~mol} \%$ of $\mathrm{Cu}(\mathrm{OAc})_{2}$ and two equivalents of triethylamine in acetonitrile at $82^{\circ} \mathrm{C}$ to give the corresponding [5+2] cycloadducts $\mathbf{1 3 7}$ in moderate to high yields (40-92\%), as illustrated in Scheme 39. A wide variety of these highly valuable 2,3-dihydro- $1 H$-benzo[b]azepines was achieved starting from either 1,1disubstituted symmetrical allenes, such as dimethyland diphenylallenes, cyclic allenes, non-symmetrical allenes or trisubstituted allenes which all provided good yields. Moreover, the presence of various substituents (X, Y, Z) at the ortho-, meta-, and para-positions of the aryl group of anilides was tolerated as well as that of substituents at the internal position of the alkene $\left(R^{4}\right)$.

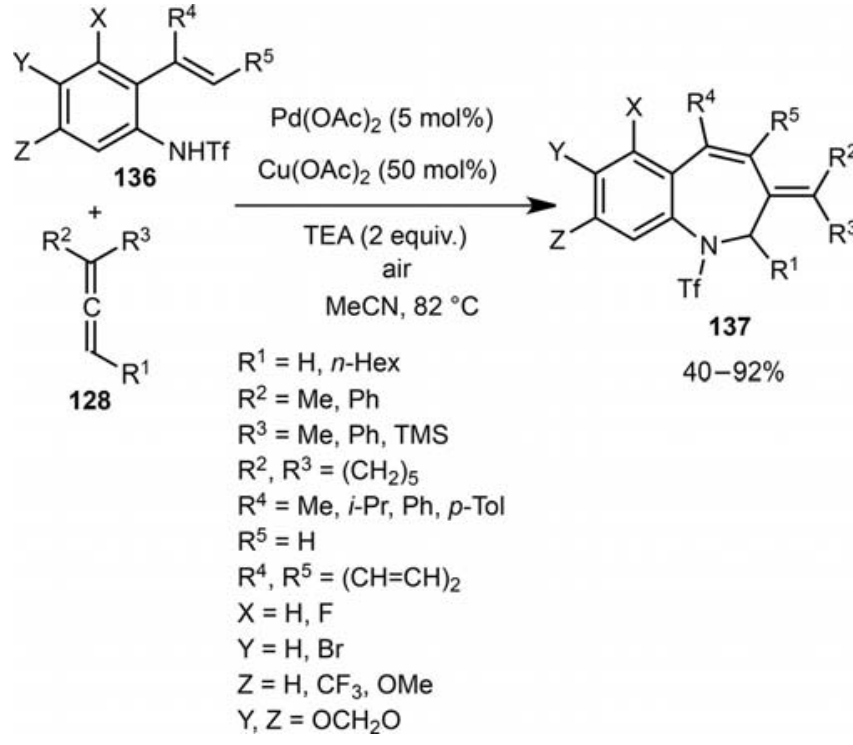

Scheme 39. Palladium-catalyzed [5+2] cycloaddition of ortho-vinylanilines and allenes.
In 2017, Luan et al. reported a novel diastereoselective synthesis of dibenzo[ $b, d]$ azepines based on the palladium(II)-catalyzed [5+2] cycloaddition of orthoarylanilines with 1,3-dienes. ${ }^{[84]}$ Indeed, in the presence of $5 \mathrm{~mol} \%$ of $\mathrm{Pd}(\mathrm{TFA})_{2}$ and 2.1 equivalents of $\mathrm{Cu}(\mathrm{OAc})_{2}$ in acetonitrile at $120^{\circ} \mathrm{C}$, a range of orthoarylanilines $\mathbf{1 3 8}$ reacted with 1,3-dienes $\mathbf{1 3 9}$ to give the corresponding [5+2] cycloadducts $\mathbf{1 4 0}$ in moderate to high yields (34-92\%). These products, exhibit-<smiles>[R]c1ccc(-c2c(N[SH3+])cc([R8])c([R])c2[R])c([R])c1[R]</smiles><smiles>[R]C=CC=C</smiles>

$\mathrm{R}^{1}=\mathrm{H}, \mathrm{Me}, \mathrm{OMe}, \mathrm{F}$

$\mathrm{R}^{2}=\mathrm{H}, \mathrm{Me}$

$\mathrm{R}^{3}=\mathrm{H}, \mathrm{OMe}$

$\mathrm{R}^{4}=\mathrm{H}, \mathrm{Me}$

$\mathrm{R}^{5}=\mathrm{H}, \mathrm{F}, \mathrm{CF}_{3}, \mathrm{CN}, \mathrm{Cl}, \mathrm{CO}_{2} \mathrm{Et}, \mathrm{Ph}, \mathrm{NO}_{2}, \mathrm{Me}, \mathrm{OMe} \quad>90 \%$ de

$\mathrm{R}^{6}=\mathrm{H}, \mathrm{Me}$

$\mathrm{R}^{7}=\mathrm{CO}_{2} \mathrm{Et}, \mathrm{CONMe}_{2}, \mathrm{CO}_{2} \mathrm{H}, \mathrm{Ph}, o-\mathrm{MeOC}_{6} \mathrm{H}_{4}, p-\mathrm{FC}_{6} \mathrm{H}_{4}, m-\mathrm{O}_{2} \mathrm{NC}_{6} \mathrm{H}_{4}$, 2-thienyl, 2-furyl, $\mathrm{CH}_{2} \mathrm{Bn}$

proposed mechanism with 138a $\left(R^{1}=R^{2}=R^{3}=R^{4}=R^{5}=R^{6}=H\right)$ :

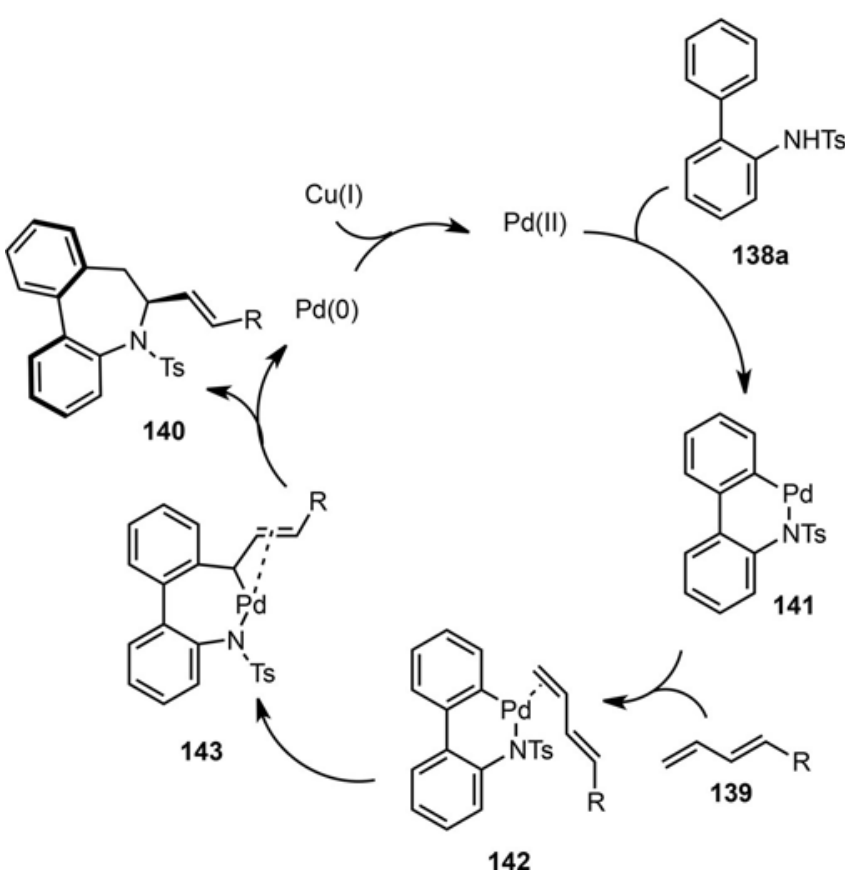

Scheme 40. Palladium-catalyzed [5+2] cycloaddition of ortho-arylanilines and 1,3-dienes. 
ing both axial and central stereogenic elements, were obtained as single diastereomers $(>90 \%$ de). Studying the substrate scope of the process, the authors showed that various substituents including functionalized ones on both aromatic rings of the ortho-arylanilines were tolerated. Concerning the scope of the 1,3dienes, in all cases the reaction occurred regiospecifically towards the terminal double bond, and other possible regioisomers were not detected. 1,3-Dienes bearing ester, amide, carboxylic acid, aromatic, alkyl, 2-thienyl or 2-furyl groups all reacted smoothly. The authors have proposed the mechanism depicted in Scheme 40 which began with the complexation of $\operatorname{Pd}(\mathrm{II})$ species with substrate 138a followed by the electrophilic palladation of the $\mathrm{C}-\mathrm{H}$ bond to generate the six-membered palladium species 141. Subsequently, coordination and migratory insertion of 1,3-diene 139 with 141 formed the eight-membered palladacycle 143, which was further stabilized with the second $\mathrm{C}=$ $\mathrm{C}$ double bond from 139. Finally, a $\mathrm{C}-\mathrm{N}$ reductive elimination took place to deliver product 140 and concomitantly regenerate the $\mathrm{Pd}(\mathrm{II})$ species with $\mathrm{Cu}(\mathrm{II})$ oxidant.

A [5+2] cycloaddition of an ortho-vinylphenol with an alkyne related to that described by Gulias and Mascarenas (Scheme 37) was very recently included by Wang et al. in a rhodium-catalyzed domino reaction of 3-(1H-indol-3-yl)-3-oxopropanenitriles 144 with two equivalents of symmetrical internal alkynes. ${ }^{[85]}$ As shown in Scheme 41, the process was performed in the presence of $5 \mathrm{~mol} \%$ of $\left[\mathrm{Cp}^{*} \mathrm{RhCl}_{2}\right]_{2}$ and 2.5 equivalents of $\mathrm{Cu}(\mathrm{OAc})_{2}$ in $\mathrm{DMF}$ at $100^{\circ} \mathrm{C}$,
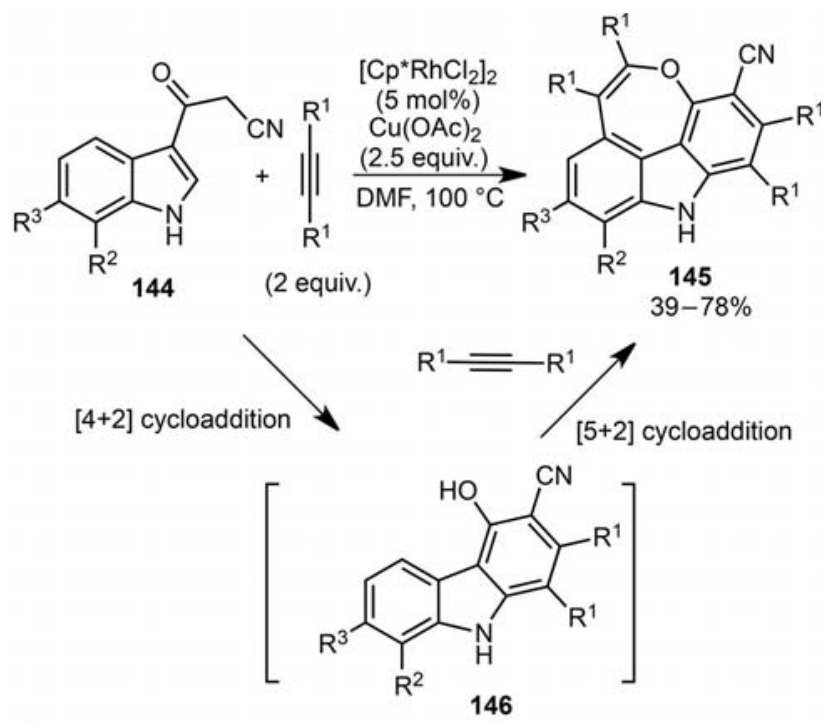

$\mathrm{R}^{1}=\mathrm{Ph}, 2$-thienyl, $p-\mathrm{FC}_{6} \mathrm{H}_{4}, p-\mathrm{F}_{3} \mathrm{CC}_{6} \mathrm{H}_{4}$

$\mathrm{R}^{2}=\mathrm{H}, \mathrm{Me}, \mathrm{OMe}, \mathrm{Cl}$

$\mathrm{R}^{3}=\mathrm{H}, \mathrm{Me}, \mathrm{OMe}, \mathrm{F}, \mathrm{Cl}, \mathrm{CO}_{2} \mathrm{Me}$

Scheme 41. Rhodium-catalyzed domino [4+2] cycloaddition/ [5+2] cycloaddition reaction of 3-( $1 H$-indol-3-yl)-3-oxopropanenitriles and alkynes. leading to a range of $4 H$-oxepino[2,3,4,5-def]carbazoles 145 through successive [4+2] cycloaddition and $[5+2]$ cycloaddition. Indeed, a first equivalent of internal alkyne underwent a [4+2] cycloaddition with 3(1H-indol-3-yl)-3-oxopropanenitrile $\mathbf{1 4 4}$ to give the corresponding intermediate 146 which subsequently reacted with a second equivalent of alkyne through a $[5+2]$ cycloaddition to afford the final domino product 145. The reactions of a broad range of variously substituted substrates proceeded in good yields (39$78 \%$ ), as shown in Scheme 41.

\section{7 [5+2] Cycloadditions of Metal-Containing 5-C Components}

A mechanistically intriguing process is the [5+2] cycloaddition occurring between an alkyne and a $\eta^{5}$ pentadienyl complex, reported for the first time by Ernst et al., in 1992. ${ }^{[86]}$ Ever since, various metals including titanium, ${ }^{[87]}$ zirconium, ${ }^{[88]}$ manganese, ${ }^{[89]}$ chromium, ${ }^{[90]}$ and cobalt ${ }^{[91]}$ have been used to mediate these reactions, providing seven-membered ring complexes in good yields. Especially, excellent yields were recently reported by Stryker et al. in the reaction of a series of air-stable acyclic $\eta^{5}$-pentadienyl cobalt complexes with alkynes to produce under notably mild conditions the corresponding cycloheptadienyl complexes in high yields (89-98\%). ${ }^{[91]}$ In 2015, these authors investigated the extension of this process to variously substituted $\eta^{5}$-pentadienyl cobalt complexes. ${ }^{\text {[92] }}$ As shown in Scheme 42, the cobalt-mediated reaction of a range of mono- and disubstituted $\eta^{5}$-pentadienyl cobalt complexes 147 with alkynes afforded at room temperature in dichloromethane the corresponding non-conjugated $\eta^{2}, \eta^{3}$-cycloheptadienyl cycloadducts 148 in high yields (68-98\%) and with excellent selectivity and complete diastereocontrol. These products isomerized quantitatively to the corresponding fully conjugated $\eta^{5}$-cycloheptadienyl complexes 149 upon heating at $70^{\circ} \mathrm{C}$. The best results (85-99\%) were achieved by using acetylene and 2-butyne as alkynes while pentadienyl complexes lacking 1-substituents or bearing additional internal methyl groups (2- or 3substituents) displayed attenuated reactivity. The presence of substituents, such as a methyl group, at the 5-position of the pentadienyl fragment was also tolerated. The utility of this methodology was shown by the synthesis of bicyclic adduct $\mathbf{1 5 0}$ via intramolecular nucleophilic addition of the corresponding cycloheptadienyl complexe $\mathbf{1 4 8 a}$ by treatment with $\mathrm{K}_{2} \mathrm{CO}_{3}$ in methanol at room temperature. As shown in Scheme 42, this bicyclic product was obtained in almost quantitative yield (97\%).

While the precedent study (Scheme 42) showed that the cycloaddition reactivity of cobalt- $\eta^{5}$-penta- 


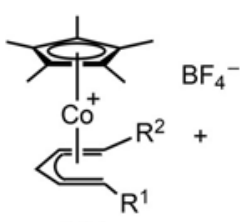

147

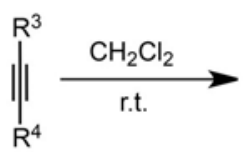

$\mathrm{R}^{2}$
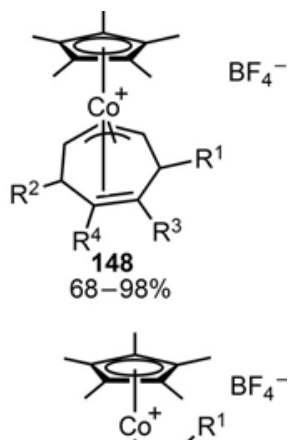

$70^{\circ} \mathrm{C}$

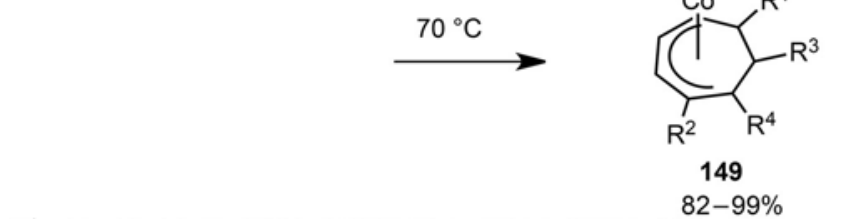

$\mathrm{R}^{1}=\mathrm{Me}, \mathrm{Ph}, \mathrm{Et}, \mathrm{H},\left(\mathrm{CH}_{2}\right)_{2} \mathrm{CH}\left(\mathrm{CO}_{2} \mathrm{Me}\right)_{2},\left(\mathrm{CH}_{2}\right)_{3} \mathrm{CH}\left(\mathrm{CO}_{2} \mathrm{Me}\right)_{2}$

$\mathrm{R}^{2}=\mathrm{H}, \mathrm{Me}$

$\mathrm{R}^{3}=\mathrm{H}, \mathrm{Me}$

$\mathrm{R}^{4}=\mathrm{H}, \mathrm{Me}, \mathrm{OEt}, n-\mathrm{Pr}, \mathrm{TMS}$

synthesis of bicyclic product $\mathbf{1 5 0}$ through cyclization of cycloheptadienyl complex 148a:

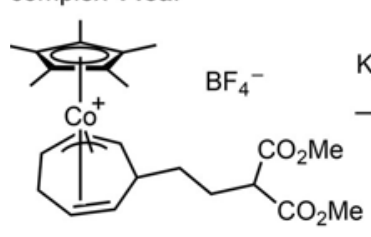

$148 \mathrm{a}$

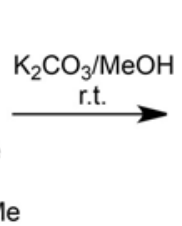

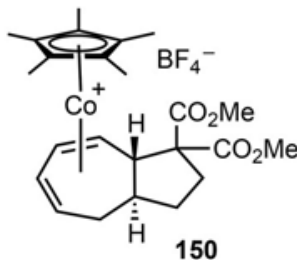

$97 \%$
Scheme 42. Cobalt-mediated $\eta^{5}$-pentadienyl/alkyne [5+2] cycloaddition and further cyclization of a cycloadduct.

dienyl complexes with alkynes was highly dependent on the substitution pattern of the $\eta^{5}$-pentadienyl complex with substituents tolerated only at the C-1 and C-5 positions, Ylijoki et al. later demonstrated that $\eta^{5}$ 1,2,5-trimethylpentadienyl cobalt complex $\mathbf{1 5 1}$ was highly reactive towards acetylene. ${ }^{[93]}$ As shown in Scheme 43, the reaction between these two substrates led to the corresponding trisubstituted cycloheptadienyl cobalt complex $\mathbf{1 5 2}$ in $87 \%$ yield. The structure of the pentadienyl complex $\mathbf{1 5 1}$ and that of the resulting cycloheptadienyl one $\mathbf{1 5 2}$ were characterized through spectroscopic and crystallographic studies.
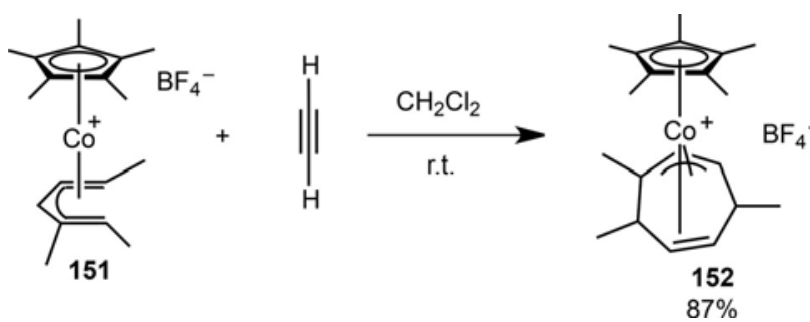

Scheme 43. Cobalt-mediated $\eta^{5}$-1,2,5-trimethylpentadienyl/ acetylene [5+2] cycloaddition.
In another context, Tanino et al. have developed novel five-carbon unit $\mathbf{1 5 3}$ exhibiting a dicobalt acetylene complex moiety and an enol silyl ether moiety. ${ }^{[94]}$ The latter was further submitted to [5+2] cycloaddition with silyl enol ethers $\mathbf{1 5 4}$ in the presence of a Lewis acid such as $\mathrm{EtAlCl}_{2}$ in dichloromethane as solvent. The reaction led to the corresponding 1-acetyl2-silyloxycycloheptane derivatives $\mathbf{1 5 5}$ as single diastereomers having the three contiguous substituents on the seven-membered ring all arranged $c i s$ to each other, as shown in Scheme 44. The process was compatible to variously substituted silyl enol ethers which all provided good yields (70-86\%) and complete diastereoselectivity. The reaction proceeded according the mechanism depicted in Scheme 44 through the intermolecular addition of cationic species $\mathbf{1 5 6}$ to enol

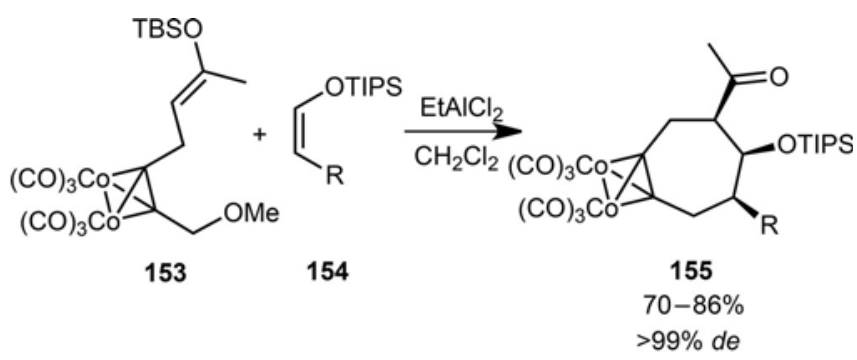

$\mathrm{R}=\mathrm{Me}, \mathrm{Ph},\left(\mathrm{CH}_{2}\right)_{2} \mathrm{Cl}$, allyl, $\mathrm{CH}_{2} \mathrm{CH}=\mathrm{C}(\mathrm{Me})_{2}$

proposed mechanism:

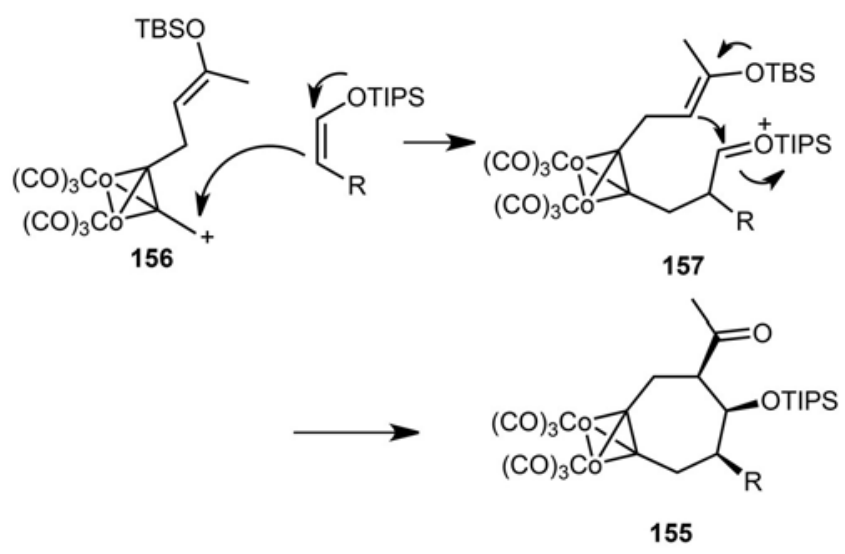

[5+2] cycloaddition of dicobalt acetylene complexes with cyclic silyl enol ethers:

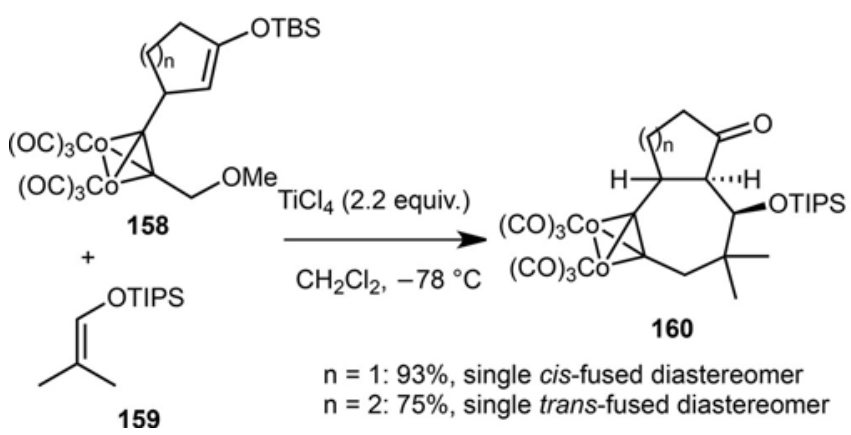

Scheme 44. The [5+2] cycloadditions of dicobalt acetylene complexes and silyl enol ethers. 
silyl ether $\mathbf{1 5 4}$ followed by the intramolecular cyclization of the resulting silyloxonium ion $\mathbf{1 5 7}$ to give the final cycloheptanone derivative $\mathbf{1 5 5}$ in a stereoselective fashion. The scope of the methodology could be extended to dicobalt acetylene complexes 158 exhibiting a cyclic enol silyl ether moiety. In this case, better results were achieved by using $\mathrm{TiCl}_{4}$ instead of EtAlCl${ }_{2}$ as Lewis acid. The reaction of complexes 158a $(\mathrm{n}=1)$ with silyl enol ether $\mathbf{1 5 9}$ derived from isobutyraldehyde led to the corresponding bicyclic ketone 160a as a single diastereomer possessing the cis-fused junction in $93 \%$ yield. On the other hand, the reaction of complex $\mathbf{1 5 8 b}(n=2)$ afforded the corresponding trans-fused product $\mathbf{1 6 0 b}$ as a single diastereomer in $75 \%$ yield (Scheme 44 ).

\section{Miscellaneous [5+2] Cycloadditions}

In 2014, France et al. reported a highly efficient catalytic formal [5+2] cycloaddition approach to a novel diastereoselective synthesis of azepino[1,2-a]indoles. ${ }^{[95]}$ Indeed, various functionalized products $\mathbf{1 6 1}$ were achieved in low to high yields (15-92\%) and cisdiastereoselectivities $(24-94 \%$ de) by reaction of the corresponding $N$-indolyl alkylidene $\beta$-amide esters 162 with alkenes performed in the presence of $10 \mathrm{~mol} \%$ of $\mathrm{Sc}(\mathrm{OTf})_{3}$ in dichoromethane at room temperature (Scheme 45). The best results were obtained in the reaction of para-substituted styrenes as alkene partners while ortho-substituted styrenes provided reduced yields and diastereoselectivities (1566\% vs. 33-78\% yields, 23-50\% de vs. 90-94\% de). 1,1-Disubstituted alkenes readily gave the corresponding products in good yields (64-92\%) albeit with a low diastereoselectivity $(30 \%$ de) as long as one of the substituents was aromatic. Even a trisubstituted alkene was tolerated, leading to the desired product in $84 \%$ yield and $50 \%$ de. In addition to substituted styrenes, 2-vinylnaphthalene also underwent the reaction with $45 \%$ yield and $88 \%$ de. Besides aromatic alkenes, phenyl vinyl sulfide $\left(R^{2}=R^{4}=H, R^{3}=\right.$ $\mathrm{SPh}$ ) was also found to be a compatible substrate, leading to the corresponding product in $85 \%$ yield and $84 \%$ de. Mechanistically, the reaction could initially involve the Lewis acid activation of alkylidene 162 followed by the intermolecular attack of the alkene through a Michael addition to yield the 1,4-dipolar intermediate 163. The latter then underwent a direct intramolecular Friedel-Crafts-type alkylation to afford the final product $\mathbf{1 6 1}$.

In another context, $\mathrm{Li}$ and Luo have developed hetero [5+2] cycloadditions of 2-(2-aminoethyl)oxiranes 164 with alkynes promoted by a combination of $\mathrm{FeCl}_{3}$ and $\mathrm{BF}_{3}\left(\mathrm{Et}_{2} \mathrm{O}\right) .{ }^{[96]}$ The process afforded in the presence of $10 \mathrm{~mol} \%$ of $\mathrm{FeCl}_{3}$ and 1 equivalent of $\mathrm{BF}_{3}\left(\mathrm{Et}_{2} \mathrm{O}\right)$ in dichloromethane at room temperature

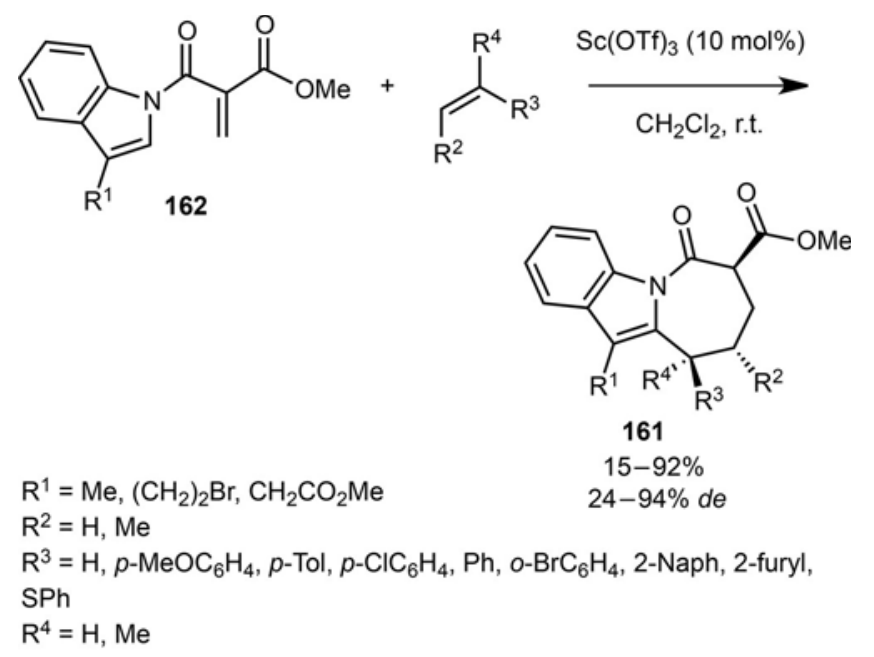

proposed mechanism:

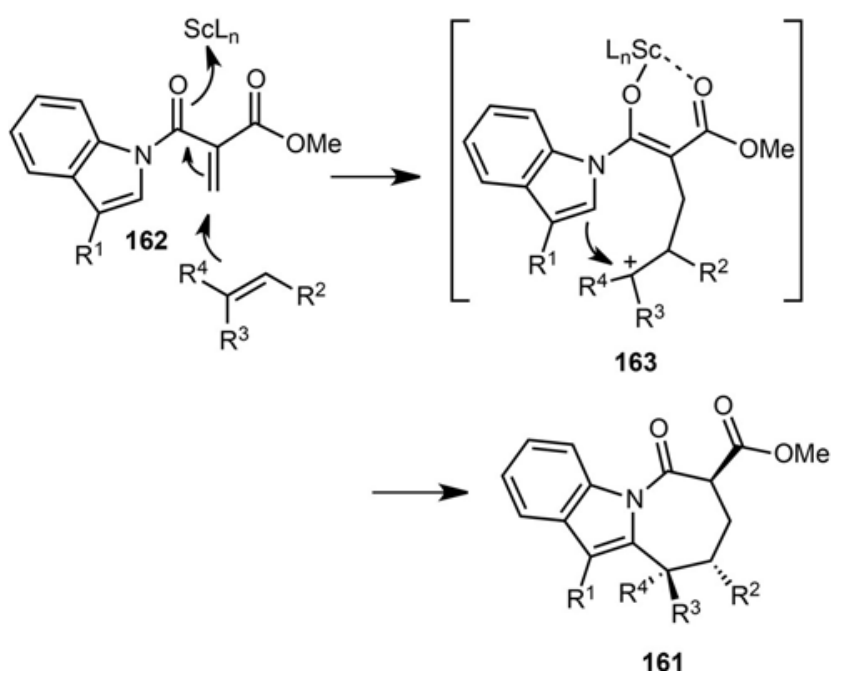

Scheme 45. Scandium-catalyzed [5+2] cycloaddition of $N$-indolyl alkylidene $\beta$-amide esters and alkenes.

the corresponding 2,3-dihydro- $1 H$-azepines $\mathbf{1 6 5}$ in moderate to good yields (47-73\%), as shown in Scheme 46. The reaction featured a broad scope with respect to a wide range of both variously substituted 2-(2-aminoethyl)oxiranes and terminal as well as alkyl-substituted internal alkynes. Comparable results were obtained in the reactions of aromatic, heteroaromatic and alkyl terminal alkynes. Alkyl/phenyl internal alkynes were also compatible substrates leading to the corresponding products in good yields (52-66\%) while 1,2-diarylalkynes showed lower reactivity ( $\leq$ $12 \%$ yield). A possible mechanism for this novel process is depicted in Scheme 46. Both $\mathrm{FeCl}_{3}$ and $\mathrm{BF}_{3}\left(\mathrm{Et}_{2} \mathrm{O}\right)$ acted as Lewis acids to form the carbocation intermediate 166 by coordinating with the oxygen atom in 2-(2-aminoethyl)oxirane 164 followed by ring-opening. Then, intermediate 166 coordinated with alkyne to give oxocarbenium ion intermediate 


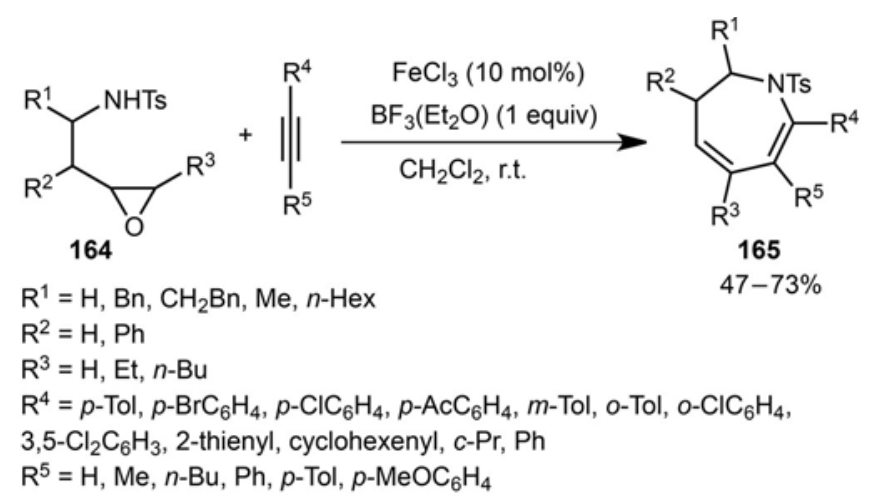

possible mechanism with $R^{1}=R^{2}=R^{3}=R^{5}=H, R^{4}=P h$ :

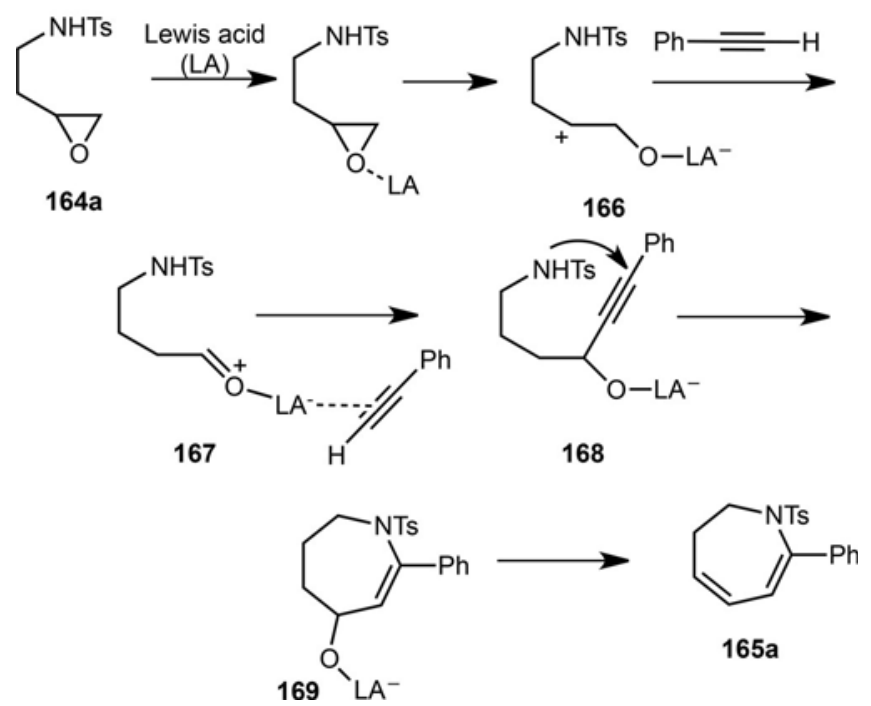

Scheme 46. The [5+2] cycloaddition of 2-(2-aminoethyl)oxiranes and alkynes promoted by a combination of $\mathrm{FeCl}_{3}$ and $\mathrm{BF}_{3}\left(\mathrm{Et}_{2} \mathrm{O}\right)$.

167. The electrophilic anti-addition of intermediate 167 across the $\mathrm{C} \equiv \mathrm{C}$ triple bond in the alkyne selectively led to vinyl cation intermediate $\mathbf{1 6 8}$. The latter subsequently underwent cyclization to yield the seven-membered intermediate $\mathbf{1 6 9}$, which was further submitted to elimination to afford the final product and $\mathrm{H}_{2} \mathrm{O}$. The authors demonstrated that use of a combination of $\mathrm{FeCl}_{3}$ and $\mathrm{BF}_{3}\left(\mathrm{Et}_{2} \mathrm{O}\right)$ as Lewis acids was necessary to achieve the products in high yields with $\mathrm{FeCl}_{3}$ promoting the ring-opening step, and $\mathrm{BF}_{3}\left(\mathrm{Et}_{2} \mathrm{O}\right)$ employed in stoichiometric amounts was accelerating the process and promoting the final elimination step. It must be noted that this study represented the first example of using oxiranes in [5+2] intermolecular cycloadditions with alkynes.

In 2015, Abood et al. reported the synthesis of novel 1,3-oxazepine derivatives $\mathbf{1 7 0}$ and $\mathbf{1 7 1}$ exhibiting an azo group and a 1,3,4-thiadiazole moiety on the basis of [5+2] cycloadditions of the corresponding azoimines 172 with maleic and phthalic anhydrides
173 and 174. ${ }^{[97]}$ As shown in Scheme 47, the reactions occurred through simple thermolysis at $70^{\circ} \mathrm{C}$ in benzene. The reactions involving maleic anhydride $\mathbf{1 7 3}$ led to products $\mathbf{1 7 0}$ in uniformly high yields $(68-80 \%)$

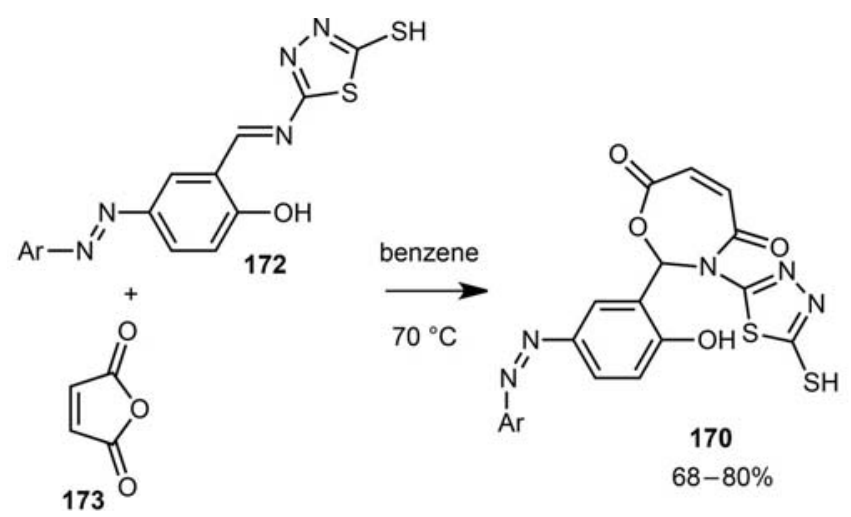

$\mathrm{Ar}=p-\mathrm{ClC}_{6} \mathrm{H}_{4}, p-\mathrm{O}_{2} \mathrm{NC}_{6} \mathrm{H}_{4}, p-\mathrm{MeOC}_{6} \mathrm{H}_{4}, 2,4-\mathrm{Cl}_{2} \mathrm{C}_{6} \mathrm{H}_{3}, 2,4-\mathrm{Me}_{2} \mathrm{C}_{6} \mathrm{H}_{3}$, 3-pyridyl

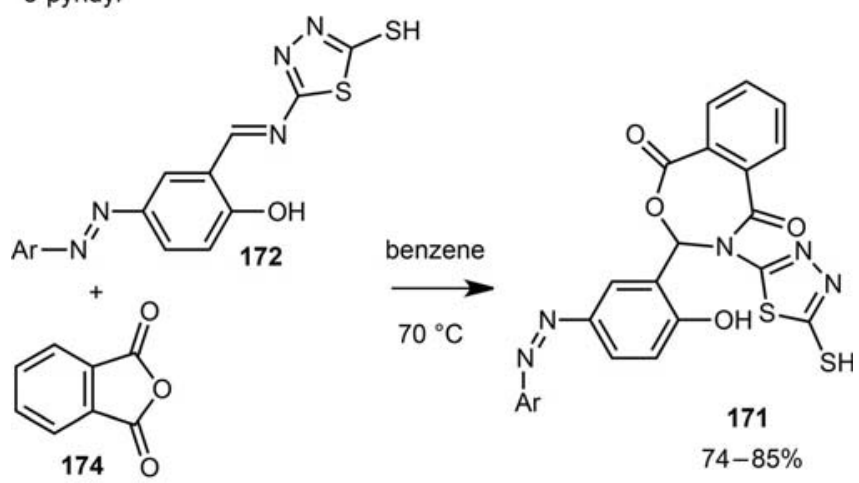

$\mathrm{Ar}=p-\mathrm{ClC}_{6} \mathrm{H}_{4}, p-\mathrm{O}_{2} \mathrm{NC}_{6} \mathrm{H}_{4}, p-\mathrm{MeOC}_{6} \mathrm{H}_{4}$

Scheme 47. The [5+2] cycloadditions of azoimines with maleic and phthalic anhydrides.

while those with phthalic anhydride $\mathbf{1 7 4}$ provided products 171 in slightly higher yields (74-85\%). Moreover, the electronic nature of the aromatic substituent (Ar) of the azoimine was found important since the rate of the cycloaddition was relatively increased in the presence of electron-donating groups on the benzene ring and relatively decreased in the presence of electron-withdrawing groups on the same ring.

An unprecedented formal [5+2] cycloaddition between nitrones and ortho-carboryne to afford carborane-fused seven-membered heterocycles was described by Xie et al., in 2015. ${ }^{[98]}$ ortho-Carboryne $\mathbf{1 7 5}$ was in situ generated in the presence of $\mathrm{CsF}$ from phenyl[ $o$-(trimethylsilyl)carboranyl]iodonium acetate 176. In THF at $25^{\circ} \mathrm{C}$, it reacted with a range of diarylnitrones $\mathbf{1 7 7}$ to give the corresponding formal [5+2] cycloadducts $\mathbf{1 7 8}$ in moderate to high yields (31$84 \%$ ), as illustrated in Scheme 48. Both electron-withdrawing groups and electron-donating groups on the $\mathrm{C}$ - and $\mathrm{N}$-aryl rings of the diarylnitrones were well 

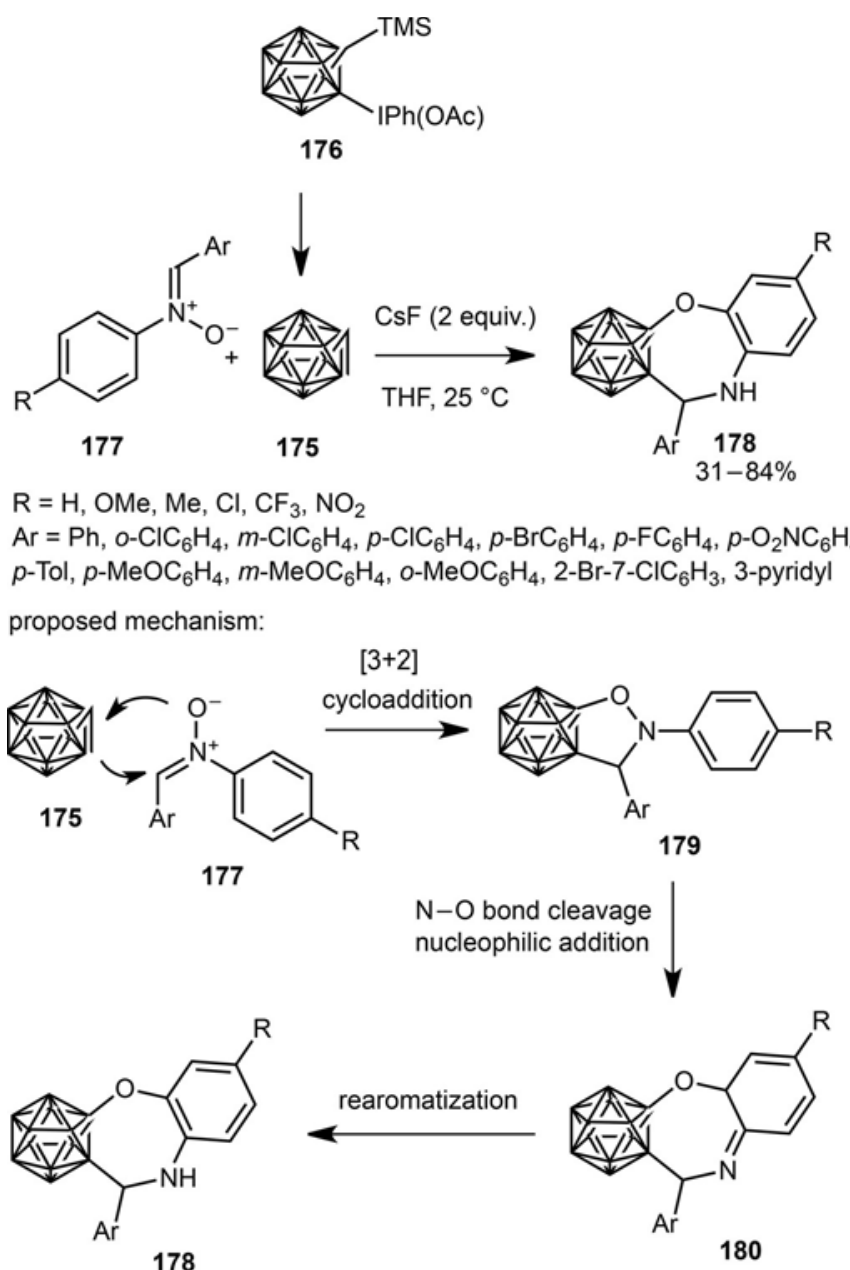

Scheme 48. The [5+2] cycloaddition of nitrones and orthocarboryne.

tolerated. Generally, nitrones with electron-donating groups resulted in higher yields than those with electron-withdrawing groups. The authors have proposed the mechanism depicted in Scheme 48 based on sequential [3+2] cycloaddition, oxygen migration and rearomatization steps. Indeed, the process began with a [3+2] cycloaddition occurring between diarylnitrone 177 and ortho-carboryne 175, affording the corresponding cycloadduct $\mathbf{1 7 9}$. The latter was subsequently submitted to a heterocyclic cleavage of the $\mathrm{N}-\mathrm{O}$ bond to give intermediate $\mathbf{1 8 0}$ which further rearomatized to afford the final product. It must be noted that this study represented a rare example in which nitrones were employed as five-atom building units.

A [5+2] cycloaddition of quinones was developed by Trauner et al. as key step in a total synthesis of the natural product epicolactone exhibiting antimicrobial and antifungal activities. ${ }^{[99]}$ As shown in Scheme 49, this [5+2] cycloaddition occurred between methoxy$o$-quinone 181 and epicoccine in the presence of $\mathrm{K}_{3}\left[\mathrm{Fe}(\mathrm{CN})_{6}\right]$ as an oxidant in acetonitrile to give the corresponding carbonyl-bridged product $\mathbf{1 8 2}$ in $42 \%$
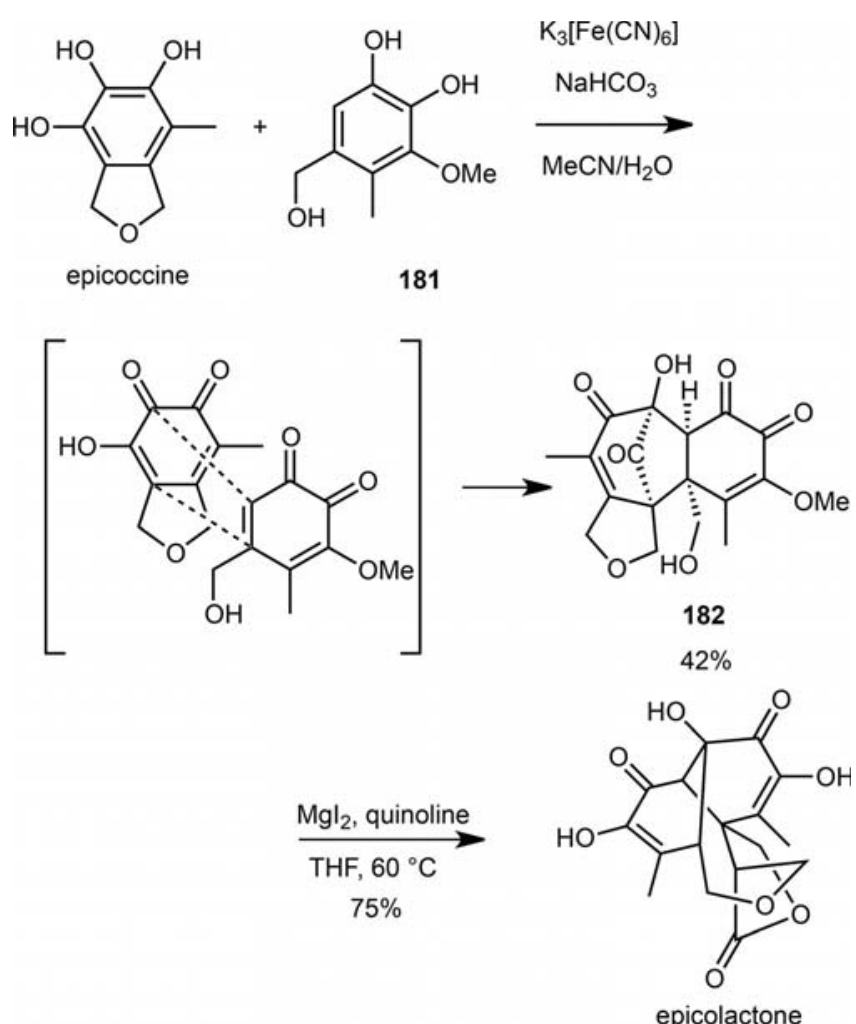

Scheme 49. The $[5+2]$ cycloaddition of quinones and a total synthesis of epicolactone.

yield. The latter was further submitted to the removal of its methyl ether by treatment with $\mathrm{MgI}_{2}$ and quinolone in THF to yield the expected natural product epicolactone in $75 \%$ yield.

Various domino reactions include [5+2] cycloadditions. As a recent example, Ding et al. developed an unprecedented domino [5+2] cycloaddition/pinacoltype 1,2-acyl migration reaction of phenol $\mathbf{1 8 3}$ as key step in the total synthesis of ent-kaurenoids. ${ }^{[100]}$ In the presence of $\mathrm{PhI}\left(\mathrm{CF}_{3} \mathrm{CO}_{2}\right)_{2}$ as oxidant and $\mathrm{K}_{2} \mathrm{CO}_{3}$ in HFIP, a diastereomeric mixture of phenol 183 underwent an oxidative dearomatization-induced [5+2] cycloaddition to give intermediate 184. The latter evolved through pinacol-type 1,2-acyl migration to afford the corresponding tetracyclic diketone $\mathbf{1 8 5}$ in $70 \%$ yield as a single diastereomer (Scheme 50 ). This highly oxygenated bicyclo[3.2.1]octane was converted into several ent-kaurenoids, such as pharicin A, pharicin $\mathrm{B}$, 7-O-acetylpseurata $\mathrm{C}$ and pseurata $\mathrm{C}$ (Scheme 50).

Finally, $\mathrm{Li}$ et al. reported rhodium-catalyzed domino reactions including a [5+2] cycloaddition as second step of the sequence. ${ }^{[101]}$ These domino $[3+2]$ cycloaddition/[5+2] cycloaddition reactions occurred between 4-aryl-1,2,3-triazoles $\mathbf{1 8 6}$ and 2 equivalents of internal alkynes in the presence of $\left[\left\{\mathrm{Cp} * \mathrm{RhCl}_{2}\right\}_{2}\right]$ as catalyst, $\mathrm{AgSbF}_{6}$ and $\mathrm{Cu}(\mathrm{OAc})_{2}$ as co-catalysts, and 3 equivalents of water in $\mathrm{DCE}$ at $85^{\circ} \mathrm{C}$. When using 


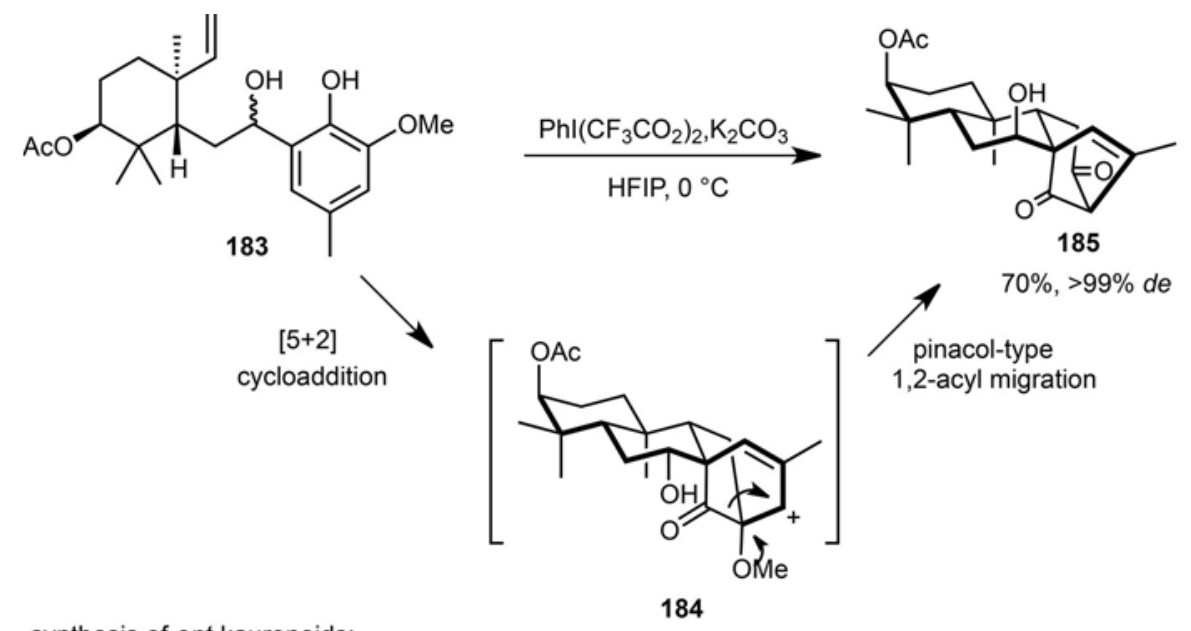

synthesis of ent-kaurenoids:

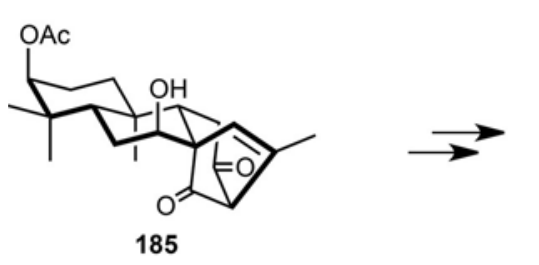

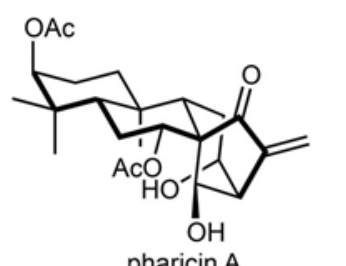

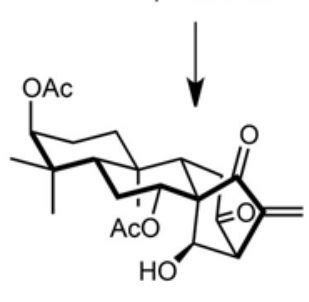

7-O-acetylpseurata C
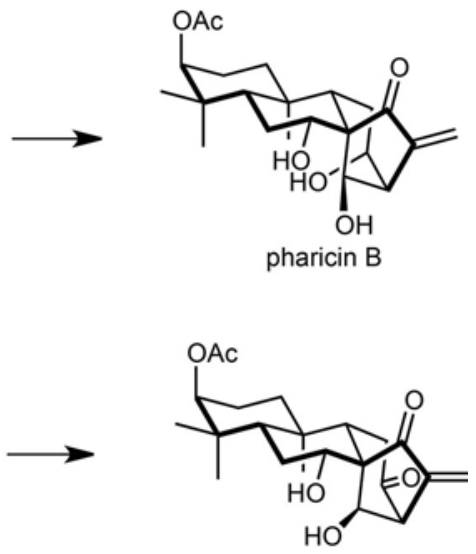

pseurata C

Scheme 50. Domino [5+2] cycloaddition/pinacol-type 1,2-acyl migration reaction of a phenol derivative and total synthesis of ent-kaurenoids.

1,2-diarylalkynes $\mathbf{1 8 7}$ as substrates, the reactions with 4-aryl-1,2,3-triazoles $\mathbf{1 8 6}$ led to the corresponding indeno[1,7-cd]azepin-1-ols $\mathbf{1 8 8}$ in moderate to good yields $(48-71 \%)$ and uniformly excellent diastereoselectivity $(>90 \% d e)$, as shown in Scheme 51. A range of substituents on the aromatic ring of the 4-aryl moiety of substrates was compatible, including $\mathrm{Me}$, $\mathrm{OMe}, \mathrm{CO}_{2} \mathrm{Me}, \mathrm{F}, \mathrm{Cl}$ and $\mathrm{Br}$. Moreover, the presence of substituents at the para- or meta-positions of the aromatic ring of symmetrical internal 1,2-diarylalkynes was tolerated, providing the corresponding products in $48-61 \%$ yields. The scope of the process was extended to internal alkyl/aryl alkynes 189 but in this case, the reaction led chemoselectively to the corresponding 1-methyleneindeno[1,7-cd]azepines 190 rather than indeno[1,7-cd]azepin-1-ols. These products were achieved under the same reaction conditions in good yields (52-67\%), as shown in Scheme 51 (second equation). In addition to a series of methyl/ aryl alkynes $\left(\mathrm{R}^{2}=\mathrm{H}\right)$, 1-(4-methoxyphenyl)hept-1-yne $\left(\mathrm{R}^{2}=n-\mathrm{Bu}, \mathrm{Ar}=p-\mathrm{MeOC}_{6} \mathrm{H}_{4}\right)$ also underwent the reaction to give the corresponding domino product in
$58 \%$ yield as a $Z / E$ mixture of diastereomers $(Z / E=$ 71:29). To explain these results, the authors have proposed the mechanism depicted in Scheme 51 which began with the reaction of 4-aryl-1,2,3-triazole $\mathbf{1 8 6}$ with the active species $\mathrm{Cp}^{*} \mathrm{RhX}_{2}$, in situ generated from $\left[\left\{\mathrm{Cp}^{*} \mathrm{RhCl}_{2}\right\}_{2}\right]$ and $\mathrm{AgSbF}_{6}$, to give the rhodium(III) carbenoid intermediate 191. The addition of the latter to the alkyne generated intermediate $\mathbf{1 9 2}$, which underwent electrophilic cyclization involving one of the phenyl groups to provide intermediate $\mathbf{1 9 3}$. Then, a second annulation of intermediate 193 with a second equivalent of alkyne led to the formation of the $\mathrm{Cp} *(\mathrm{H}) \mathrm{Rh}$-coordinated intermediate 194. The latter underwent a trans addition to give intermediate 195 as a result of the coordination of $\mathrm{Rh}$ with the nitrogen atom. In the case of using 1,2-diarylalkynes 187 as substrates, the cleavage of the $\mathrm{C}-\mathrm{Rh}$ bond in intermediate 195 took place through hydration with $\mathrm{H}_{2} \mathrm{O}$ in the presence of $\mathrm{Cu}(\mathrm{OAc})_{2}$ to yield product 188 and regenerated the active species $\mathrm{Cp}^{*} \mathrm{RhX}_{2}$. On the other hand, when an alkyl/aryl alkyne 189 was employed as substrate, the $\mathrm{C}-\mathrm{Rh}$ bond in $\mathbf{1 9 5}$ was 
with 1,2-diarylalkynes:<smiles>[R]c1ccc(-c2cn([AsH2-])nn2)cc1</smiles>
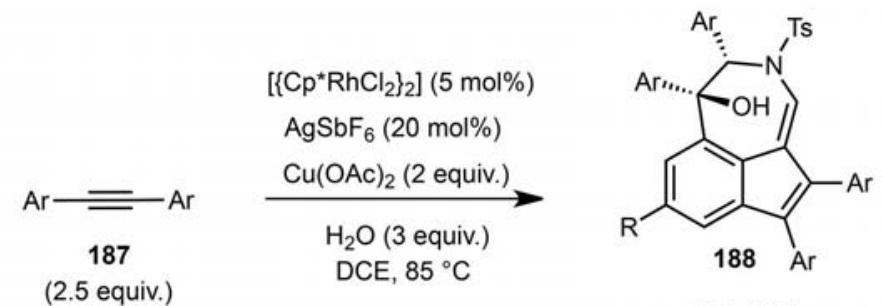

$\mathrm{R}=\mathrm{H}, \mathrm{Me}, \mathrm{OMe}, \mathrm{CO}_{2} \mathrm{Me}, \mathrm{F}, \mathrm{Cl}, \mathrm{Br}$ (2.5 equiv.)

$\mathrm{Ar}=\mathrm{Ph}, p$ - Tol, $p$ - $\mathrm{MeOC}_{6} \mathrm{H}_{4}, p-\mathrm{ClC}_{6} \mathrm{H}_{4}, m-\mathrm{Tol}$

with alkyl/arylalkynes:<smiles>[R]c1ccc(-c2cn([3H])nn2)cc1</smiles><smiles></smiles>

same conditions

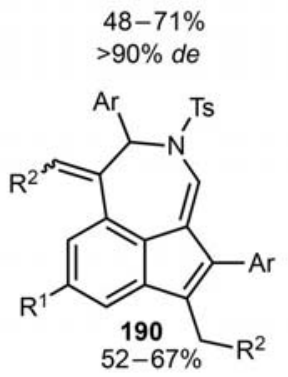

$\mathrm{R}^{1}=\mathrm{H}, \mathrm{Me}, \mathrm{OMe}, \mathrm{CO}_{2} \mathrm{Me}, \mathrm{F}, \mathrm{Cl}, \mathrm{Br}$

$\mathrm{R}^{2}=\mathrm{H}, n-\mathrm{Bu}$

$\mathrm{Ar}=\mathrm{Ph}, p$ - Tol, $p-\mathrm{MeOC}_{6} \mathrm{H}_{4}, p-\mathrm{ClC}_{6} \mathrm{H}_{4}, p-\mathrm{BrC}_{6} \mathrm{H}_{4}, p-\mathrm{MeO}_{2} \mathrm{CC}_{6} \mathrm{H}_{4}$

possible mechanism:

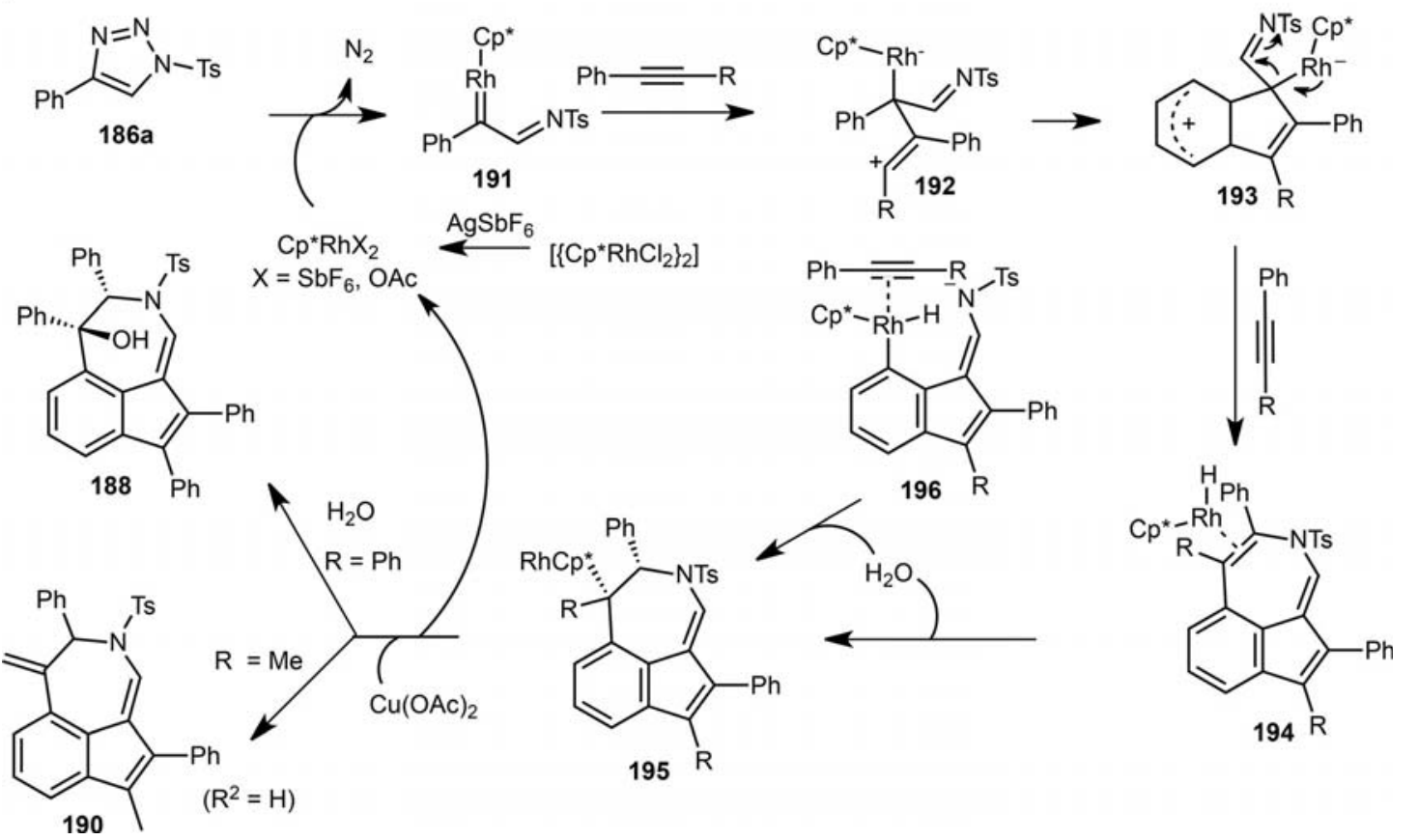

Scheme 51. Rhodium-catalyzed domino [3+2] cycloaddition/[5+2] cycloaddition reactions of 4-aryl-1,2,3-triazoles and internal alkynes.

cleaved by $\mathrm{Cu}(\mathrm{OAc})_{2}$, and a selective $\beta$-H elimination then provided product 190. It can also be envisaged that a second annulation proceeded through a $\mathrm{C}-\mathrm{H}$ activation process from intermediate $\mathbf{1 9 3}$ to intermediate 196.

\section{Conclusions}

The [5+2] cycloaddition approach has become a highly useful tool in the synthesis of a wide number of complex natural products and important biologically active products containing seven-membered rings. This review updates the recent developments in the $[5+2]$ cycloaddition reported in the literature since the beginning of 2014, dealing successively with 
metal-catalyzed [5+2] cycloadditions of vinyl-substituted three-membered (hetero)rings, [5+2] cycloadditions of (oxido)pyrylium and (oxido)pyridinium ions, rhodium-catalyzed [5+2] cycloadditions of 3-acyloxy1,4-enynes, metal-catalyzed [5+2] cycloadditions of ortho-vinylphenols and ortho-vinyl/arylanilines, [5+2] cycloadditions of metal-containing 5-C components, and miscellaneous [5+2] cycloadditions. Indeed, the last four years have witnessed significant developments in the efficiency and scope of these different methodologies to prepare a diversity of complex highly functionalized products. Among them, the rhodium-catalyzed vinylcyclopropane [5+2] cycloaddition reactions with various $\pi$-systems have become powerful routes to seven-membered ring systems as a result of the important pioneering works reported by the Wender group. Recently, these methodologies have been applied to develop highly efficient domino and tandem reactions. For example, Wender reported tandem rhodium-catalyzed [5+2] cycloaddition/protodesilylation reactions between vinylcyclopropanes and propargyltrimethylsilanes performed with up to $96 \%$ yield. In addition, three-component domino/tandem rhodium-catalyzed [5+2] cycloaddition/vinylogous Peterson/[4+2] cycloaddition reactions of vinylcyclopropanes, 4-(trimethylsilyl)but-2-yn-1-ol, and alkenes or alkynes were achieved with up to $88 \%$ and $96 \%$ yields, respectively. While metals other than rhodium, such as ruthenium, nickel or iron, have been successfully employed by several groups as catalysts in intramolecular versions of these reactions, iridium was recently introduced by Strand in both intra- and intermolecular versions, providing up to quantitative yields. Furthermore, rhodium-catalyzed hetero [5+2] cycloadditions of vinyl-substituted three-membered heterocycles were only recently reported for the first time by Zhang and Feng, demonstrating that both vinylaziridines and vinyloxiranes could react with alkenes and alkynes with up to $96 \%$ and $75 \%$ yields, respectively. To illustrate the utility of these novel methodologies, several highly efficient domino and tandem reactions starting from an intramolecular hetero [5+2] cycloaddition of vinyloxiranes and alkynes or diynes followed by a Claisen rearrangement have been successfully developed with high yields.

However, the potentially prohibitive cost associated with metals such as rhodium renders these procedures less attractive, especially on a large scale. The synthesis of seven-membered rings can also be achieved through thermal [5+2] cycloadditions of in situ generated oxidopyrylium species with $\pi$-systems, leading to functionalized oxa-bridged cycloadducts. Despite the potential of these methodologies, asymmetric variants still remain limited with most of them being based to the use of chiral auxiliaries. Recently, several highly enantioselective organocatalytic versions have been reported by Vicario and Reyes, and Jacobsen and
Witten. They dealt with [5+2] cycloadditions of $\alpha, \beta$ unsaturated aldehydes and oxidopyrylium ylides based on dienamine activation with up to $99 \% e e$, and [5+2] cycloadditions of pyrylium ions with vinyl ethers achieved with up to $96 \% e e$. In the area of racemic reactions, $\mathrm{Li}$ recently reported the first dearomative indole [5+2] cycloaddition of oxidopyrylium ions with up to $90 \%$ yield and complete diastereoselectivity. The presence of an oxa-bridge and other functionalities in these cycloadducts have allowed their further manipulation into various types of functionalized carbocyclic systems related to different classes of natural products, such as (-)-colchicine and eurifoloid A recently synthesized by $\mathrm{Li}$.

The cycloaddition of oxidopyridinium species with $\pi$-systems has also been developed and applied to the synthesis of many 8-azabicyclo[3.2.1]octane skeletons which are the common structural units of biologically active tropane alkaloids. In this context, Yoo recently reported the first catalytic three-component [5+2] cycloaddition of pyridines, 1-sulfonyl-1,2,3-triazoles and activated alkynes performed with up to $88 \%$ yield.

A significant advance in the field of the [5+2] cycloaddition was recently reported by Tang who demonstrated that 3-acyloxy-1,4-enynes could be employed as novel five-carbon building blocks in rhodium-catalyzed [5+2] cycloadditions with various $\pi$-systems. Intermolecular versions between 3-acyloxy-1,4enynes and propargylic alcohols leading to tropones have been achieved with remarkable yields (up to quantitative). The first intramolecular versions of this type of reaction have also been developed with alkynes, tethered alkenes as well as allenes in good yields. Furthermore in these systems, chirality transfer could be achieved for the asymmetric synthesis of 5-7 fused bicyclic compounds.

In another area, Gulias and Mascarenas recently demonstrated that ortho-vinylphenols underwent a rhodium-catalyzed [5+2] cycloaddition with alkynes or allenes, leading to highly valuable benzoxepines in quantitative yields. By using palladium instead of rhodium catalysts, related methodologies were applied to ortho-vinylanilides which reacted with allenes to give a wide variety of important 2,3-dihydro- $1 H$-benzo[b]azepines with up to $92 \%$ yield. Comparable yields were also described by Luan in a novel diastereoselective synthesis of dibenzo[b,d]azepines based on palladium-catalyzed [5+2] cycloaddition of orthoarylanilines with 1,3-dienes. The utility of these novel methodologies was illustrated by Wang in a rhodiumcatalyzed domino reaction of 3-(1H-indol-3-yl)-3-oxopropanenitriles with two equivalents of symmetrical internal alkynes, leading to a range of $4 \mathrm{H}$-oxepino[2,3,4,5-def]carbazoles in up to $78 \%$ yield.

Other novel highly efficient miscellaneous methodologies to achieve [5+2] cycloaddition have been developed in the last four years, such as the diastereose- 
lective synthesis of azepino[1,2-a]indoles with up to $92 \%$ yield based on the reaction of $N$-indolyl alkylidene $\beta$-amide esters with aromatic alkenes reported by France. In addition, $\mathrm{Li}$ and Luo have developed the first hetero [5+2] cycloadditions of 2-(2-aminoethyl)oxiranes with alkynes promoted by a combination of $\mathrm{FeCl}_{3}$ and $\mathrm{BF}_{3}\left(\mathrm{Et}_{2} \mathrm{O}\right)$ to provide 2,3-dihydro$1 \mathrm{H}$-azepines in good yields. Furthermore, [5+2] cycloadditions of azoimines with maleic and phthalic anhydrides were developed by Abood, leading to novel 1,3-oxazepine derivatives exhibiting an azo group and a 1,3,4-thiadiazole moiety in up to $85 \%$ yield. An unprecedented formal [5+2] cycloaddition between nitrones and ortho-carboryne to afford carborane-fused seven-membered heterocycles in up to $84 \%$ yield was also described by Xie. Moreover, novel domino reactions including $[5+2]$ cycloadditions were described by Ding, such as domino [5+2] cycloaddition/pinacoltype 1,2-acyl migration reaction of a phenol applied to a total synthesis of ent-kaurenoids, and domino $[3+2]$ cycloaddition/[5+2] cycloaddition reactions reported by Li, occurring between 4-aryl-1,2,3-triazoles and alkynes to afford indeno[1,7-cd]azepin-1-ols in good yields.

\section{References}

[1] a) W. Carruthers, in: Cycloaddition Reactions in Organic Synthesis, Pergamon, Oxford, 1990; b) L. Ghosez, in: Stereocontrolled Organic Synthesis, (Ed.: B. M. Trost), Blackwell Science, Oxford, 1994, pp 193 233 ; c) C. P. Dell, Contemp. Org. Synth. 1997, 4, 87117; d) C. P. Dell, J. Chem. Soc. Perkin Trans. 1 1998, 3873-3905; e) Advances in Cycloaddition; JAI Press, Greenwich, 1988-1999, Vols. 1-6; f) N. Nishiwaki, Methods and Applications of Cycloaddition Reactions in Organic Syntheses, Wiley-VCH, Hoboken, 2014.

[2] a) J. K. Cha, J. Oh, Curr. Org. Chem. 1998, 2, 217-232; b) J. Huang, R. P. Hsung, Chemtracts 2005, 18, 207214 ; c) A. Padwa, J. Boonsombat, P. Rashatasakhon, J. Willis, Org. Lett. 2005, 7, 3725-3727; d) M. A. Battiste, P. M. Pelphrey, D. L. Wright, Chem. Eur. J. 2006, 12, 3438-3447; e) S. Nakamura, Y. Sugano, F. Kikuchi, S. Hashimoto, Angew. Chem. 2006, 118, 6682-6685; Angew. Chem. Int. Ed. 2006, 45, 6532-6535; f) P. A. Wender, M. P. Croatt, N. M. Deschamps, in: Comprehensive Organometallic Chemistry III, (Eds.: R. H. Crabtree, D. M. P. Mingos), Elsevier, Oxford, 2007, pp 603-647; g) A. Padwa, M. J. Chughtai, J. Boonsombat, P. Rashatasakhon, Tetrahedron 2008, 64, 47584767; h) D. B. England, J. M. Eagan, G. Merey, O. Anac, A. Padwa, Tetrahedron 2008, 64, 988-1001; i) H. Butenschön, Angew. Chem. 2008, 120, 5367-5370; Angew. Chem. Int. Ed. 2008, 47, 5287-5290; j) D. M. Hodgson, R. Glen, A. J. Redgrave, Tetrahedron: Asymmetry 2009, 20, 754-757; k) N. Shimada, H. Naoyuki, K. Taiki, Y. Kurosaki, K. Takeda, M. Anada, H. Nambu, M. Shiro, S. Hashimoto, J. Org. Chem. 2010, 75, 6039-6042; 1) Y. Kurosaki, N. Shimada, M.
Anada, H. Nambu, S. Hashimoto, Bull. Korean Chem. Soc. 2010, 31, 694-696.

[3] H. Clavier, H. Pellissier, in: Methods and Applications of Cycloaddition Reactions in Organic Syntheses, (Ed. N. Nishiwaki), Wiley-VCH, Hoboken, 2014.

[4] H. Pellissier, Adv. Synth. Catal. 2011, 353, 189-218.

[5] a) P. G. Sammes, Gazz. Chim. Ital. 1986, 116, 109-114; b) A. R. Katritzky, N. Dennis, Chem. Rev. 1989, 89, $827-861$; c) P. A. Wender, J. A. Love, in: Advances in Cycloaddition, JAI Press, Greenwich, 1999, Vol. 5, pp 1-45; d) J. L. Mascarenas, in: Advances in Cycloaddition, JAI Press, Greenwich, 1999, Vol. 6, pp 1-54; e) P. A. Wender, G. G. Gamber, T. J. Williams, in: Modern Rhodium-Catalyzed Organic Reactions, (Ed.: P. A. Evans), Wiley-VCH, Weinheim, 2005, pp 263299.

[6] a) K. V. Radhakrishnan, Top. Curr. Chem. 2008, 13, 71-98; b) V. Singh, U. M. Krishna, V. Vikrant, G. K. Trivedi, Tetrahedron 2008, 64, 3405-3428.

[7] K. E. O. Ylijoki, J. M. Stryker, Chem. Rev. 2013, 113, 2244-2266.

[8] a) I. Ojima, M. Tzamarioudaki, Z. Li, R. J. Donovan, Chem. Rev. 1996, 96, 635-662; b) M. Lautens, W. Klute, W. Tam, Chem. Rev. 1996, 96, 49-92; c) E.-I. Negeshi, C. Coperet, S. Ma, S.-Y. Liou, F. Liu, Chem. Rev. 1996, 96, 365-394; d) L. Yet, Chem. Rev. 2000, 100, 2963-3007; e) C. Aubert, O. Buisine, M. Malacria, Chem. Rev. 2002, 102, 813-834; f) I. Nakamura, Y. Yamamoto, Chem. Rev. 2004, 104, 2127-2198; g) J. Montgomery, Angew. Chem. 2004, 118, 3980-3998; Angew. Chem. Int. Ed. 2004, 43, 3891-3908; h) B. M. Trost, M. U. Frederiksen, M. T. Rudd, Angew. Chem. 2005, 117, 6788-6825; Angew. Chem. Int. Ed. 2005, 44, 6630-6666.

[9] a) P. N. Peet, Prog. Heterocycl. Chem. 1989, 1, 297316; b) L. Sun, C. Simmerling, I. Ojima, ChemMedChem 2009, 4, 719-731; c) S. V. Maifeld, D. Lee, Synlett 2006, 1623-1644; d) L. A. Paquette, Chemtracts 2002, 15, 345-366; e) J. A. Smith, P. P. Molesworth, J. H. Ryan, Prog. Heterocycl. Chem. 2009, 21, 491530 ; f) D. Niu, W. Yan, E. Sharif, M. Rajaratnam, G. A. O'Doherty, Chemtracts 2009, 22, 89-95; g) J. K. Cha, O. L. Epstein, Tetrahedron 2006, 62, 1329-1343; h) T. J. Nelson, D. L. Alkon, Trends Biochem. Sci. 2009, 34, 136-145.

[10] R. I. Khusnutdinov, U. M. Dzhemilev, J. Organomet. Chem. 1994, 471, 1-18.

[11] P. A. Wender, H. Rieck, M. Fuji, J. Am. Chem. Soc. 1998, 120, 10976-10977.

[12] P. Liu, P. H.-Y. Cheong, Z.-X. Yu, P. A. Wender, K. N. Houk, Angew. Chem. 2008, 120, 4003-4005; Angew. Chem. Int. Ed. 2008, 47, 3939-3941.

[13] P. A. Wender, L. E. Sirois, R. T. Stemmler, T. J. Williams, Org. Lett. 2010, 12, 1604-1607.

[14] P. A. Wender, F. Inagaki, M. Pfaffenbach, M. C. Stevens, Org. Lett. 2014, 16, 2923-2925.

[15] H. A. Wegner, A. de Meijere, P. A. Wender, J. Am. Chem. Soc. 2005, 127, 6530-6531.

[16] a) L. F. Tietze, U. Beifuss, Angew. Chem. 1993, 105, 137-170; Angew. Chem. Int. Ed. Engl. 1993, 32, 131163; b) L. F. Tietze, Chem. Rev. 1996, 96, 115-136; c) L. F. Tietze, A. Modi, Med. Res. Rev. 2000, 20, 304- 
322; d) L. F. Tietze, G. Brasche, K. Gericke, Domino Reactions in Organic Synthesis, Wiley-VCH, Weinheim, 2006; e) L. F. Tietze, Domino Reactions - Concepts for Efficient Organic Synthesis, Wiley-VCH, Weinheim, 2014.

[17] a) G. H. Posner, Chem. Rev. 1986, 86, 831-844; b) T.L. Ho, in: Tandem Organic Reactions, Wiley, New York, 1992; c) H. Waldmann, Nachr. Chem. Tech. Lab. 1992, 40, 1133-1140; d) K. Fukumoto, Synth. Org. Chem. Jpn. 1994, 52, 2-18; e) R. A. Bunce, Tetrahedron 1995, 51, 13103-13159; f) P. J. Parsons, C. S. Penkett, A. J. Shell, Chem. Rev. 1996, 96, 195-206; g) P. C. F. Balaure, P. I. A. Filip, Rev. Roum. Chim. 2002, 46, 809-833; h) E. Capdevila, J. Rayo, F. Carrion, I. Jové, J. I. Borrell, J. Teixido, Afinidad 2003, 506, 317-337; i) C. Hulme, V. Gore, Curr. Med. Chem. 2003, 10, 51-80; j) L. F. Tietze, N. Rackelmann, Pure Appl. Chem. 2004, 76, 1967-1983; k) P. I. Dalko, L. Moisan, Angew. Chem. 2004, 116, 5248-5286; Angew. Chem. Int. Ed. 2004, 43, 5138-5175; 1) D. J. Ramon, M. Yus, Angew. Chem. 2005, 117, 1628-1661; Angew. Chem. Int. Ed. 2005, 44, 1602-1634; m) J. Zhu, H. Bienaymé, Multicomponent Reactions, Wiley-VCH, Weinheim, 2005; n) H. Pellissier, Tetrahedron 2006, 62, 2143-2173; o) H. Pellissier, Tetrahedron 2006, 62, 1619-1665; p) D. Enders, C. Grondal, M. R. M. Hüttl, Angew. Chem. 2007, 119, 1590-1601; Angew. Chem. Int. Ed. 2007, 46, 1570-1581; q) G. Guillena, D. J. Ramon, M. Yus, Tetrahedron: Asymmetry 2007, 18, 693-700; r) D. M. D'Souza, T. J. J. Müller, Chem. Soc. Rev. 2007, 36, 1095-1108; s) C. J. Chapman, C. G. Frost, Synthesis 2007, 1-21; t) A. Padwa, S. K. Bur, Tetrahedron 2007, 63, 5341-5378; u) A.-N. Alba, X. Companyo, M. Viciano, R. Rios, Curr. Org. Chem. 2009, 13, 1432-1474; v) K. C. Nicolaou, J. S. Chen, Chem. Soc. Rev. 2009, 38, 2993-3009; w) B. B. Touré, D. G. Hall, Chem. Rev. 2009, 109, 4439-4486; x) C. Grondal, M. Jeanty, D. Enders, Nat. Chem. 2010, 2, 167-178; y) J. E. Biggs-Houck, A. Younai, J. T. Shaw, Curr. Opin. Chem. Biol. 2010, 14, 371-382; z) Synthesis of Heterocycles via Multicomponent Reactions, in: Topics in Heterocyclic Chemistry, Vols. I and II, (Eds.: R. V. A. Orru, E. Ruijter), Springer, Berlin, 2010; aa) M. Ruiz, P. Lopez-Alvarado, G. Giorgi, J. C. Menéndez, Chem. Soc. Rev. 2011, 40, 3445-3454; ab) L. Albrecht, H. Jiang, K. A. Jørgensen, Angew. Chem. 2011, 123, 8642-8660; Angew. Chem. Int. Ed. 2011, 50, 8492-8509; ac) H. Pellissier, Adv. Synth. Catal. 2012, 354, 237-294; ad) C. De Graaff, E. Ruijter, R. V. A. Orru, Chem. Soc. Rev. 2012, 41, 3969-4009; ae) H. Pellissier, Chem. Rev. 2013, 113, 442-524; af) H. Pellissier, Asymmetric Domino Reactions, Royal Society of Chemistry, Cambridge, 2013; ag) H. Pellissier, Curr. Org. Chem. 2016, 20, 234-265; ah) S. A. Snyder, Applications of Domino Transformations in Organic Synthesis, in: Science of Synthesis, Thieme Verlag, Stuttgart, 2016, Vols. 1 and 2.

[18] P. A. Wender, D. N. Fournogerakis, M. S. Jeffreys, R. V. Quiroz, F. Inagaki, M. Pfaffenbach, Nat. Chem. 2014, 6, 448-452.

[19] X. Hong, M. C. Stevens, P. Liu, P. A. Wender, K. N. Houk, J. Am. Chem. Soc. 2014, 136, 17273-17283.
[20] a) B. M. Trost, F. D. Toste, H. Shen, J. Am. Chem. Soc. 2000, 122, 2379-2380; b) B. M. Trost, H. C. Shen, Org. Lett. 2000, 2, 2523-2525; c) B. M. Trost, H. C. Shen, Angew. Chem. 2001, 113, 2375-2378; Angew. Chem. Int. Ed. 2001, 40, 2313-2316; d) B. M. Trost, F. D. Toste, Angew. Chem. Int. Ed. 2001, 113, 1148-1150; Angew. Chem. Int. Ed. 2001, 40, 1114-1116; e) B. M. Trost, H. C. Shen, T. Schulz, C. Koradin, H. Schirok, Org. Lett. 2003, 5, 4149-4151; f) B. M. Trost, H. C. Shen, D. B. Horne, F. D. Toste, B. G. Steinmetz, C. Koradin, Chem. Eur. J. 2005, 11, 2577-2590; g) B. M. Trost, Y. Hu, D. B. Horne, J. Am. Chem. Soc. 2007, 129, 11781-11790.

[21] G. Zuo, J. Louie, J. Am. Chem. Soc. 2005, 127, 57985799.

[22] A. Fürstner, K. Majima, R. Martin, H. Krause, E. Kattnig, R. Goddard, C. W. Lehmann, J. Am. Chem. Soc. 2008, 130, 1992-2004.

[23] M.-C. Melcher, H. von Wachenfeldt, A. Sundin, D. Strand, Chem. Eur. J. 2015, 21, 531-535.

[24] P. A. Wender, H. Takahashi, B. Witulski, J. Am. Chem. Soc. 1995, 117, 4720-4721.

[25] T. J. L. Mustard, P. A. Wender, P. H.-Y. Cheong, ACS Catal. 2015, 5, 1758-1763.

[26] a) P. A. Wender, D. Sperandio, J. Org. Chem. 1998, 63, 4164-4165; b) Z.-X. Yu, P. H.-Y. Cheong, P. Liu, C. Y. Legault, P. A. Wender, K. N. Houk, J. Am. Chem. Soc. 2008, 130, 2378-2379.

[27] B. Wang, P. Cao, X. Zhang, Tetrahedron Lett. 2000, 41, 8041-8044.

[28] S. R. Gilbertson, G. S. Hoge, Tetrahedron Lett. 1998, 39, 2075-2078.

[29] P. A. Wender, T. J. Williams, Angew. Chem. 2002, 114, 4732-4735; Angew. Chem. Int. Ed. 2002, 41, 45504553.

[30] a) C.-H. Liu, Z.-X. Yu, Angew. Chem. 2017, 129, 8793-8797; Angew. Chem. Int. Ed. 2017, 56, 86678671; b) L. Jiao, S. Ye, Z.-X. Yu, J. Am. Chem. Soc. 2008, 130, 7178-7179; c) F. J. Gomez, N. E. Kamber, N. M. Deschamps, A. P. Cole, P. A. Wender, R. M. Waymouth, Organometallics 2007, 26, 4541-4545; d) P. A. Wender, L. O. Haustedt, J. Lim, J. A. Love, T. J. Williams, J.-Y. Yoon, J. Am. Chem. Soc. 2006, 128, 6302-6303; e) P. A. Wender, C. O. Husfeld, E. Langkopf, J. A. Love, N. Pleuss, Tetrahedron 1998, 54, 7203-7220.

[31] D. E. Thurston, D. S. Bose, Chem. Rev. 1994, 94, 433465.

[32] a) G. Pandey, P. Banerjee, S. R. Gadre, Chem. Rev. 2006, 106, 4484-4517. b) For an early example of thermal [5+2] cycloadditions of vinylaziridines with activated alkenes, see: A. Hassner, R. D'Costa, Tetrahedron Lett. 1981, 22, 3691-3694.

[33] P. A. Wender, T. M. Pedersen, M. J. C. Scanio, J. Am. Chem. Soc. 2002, 124, 15154-15155.

[34] J.-J. Feng, T.-Y. Lin, H.-H. Wu, J. Zhang, J. Am. Chem. Soc. 2015, 137, 3787-3790.

[35] L. Zhu, X. Qi, Y. Lan, Organometallics 2016, 35, 771777.

[36] J.-J. Feng, T.-Y. Lin, H.-H. Wu, J. Zhang, Angew. Chem. 2015, 127, 16080-16084; Angew. Chem. Int. Ed. 2015, 54, 15854-15858. 
[37] J.-J. Feng, T.-Y. Lin, C.-Z. Zhu, H. Wang, H.-H. Wu, J. Zhang, J. Am. Chem. Soc. 2016, 138, 2178-2181.

[38] X. Zhang, H. Zou, G. Huang, ChemCatChem 2016, 8, 2549-2556.

[39] J.-J. Feng, J. Zhang, ACS Catal. 2017, 7, 1533-1542.

[40] P. Chiu, M. Lautens, Top. Curr. Chem. 1997, 190, 1-85.

[41] a) J. B. Hendrickson, J. S. Farina, J. Org. Chem. 1980, 45, 3359-3361; b) J. B. Hendrickson, J. S. Farina, J. Org. Chem. 1980, 45, 3361-3363.

[42] a) P. G. Sammes, L. J. Street, J. Chem. Soc. Chem. Commun. 1982, 1056-1057; b) P. G. Sammes, L. J. Street, J. Chem. Soc. Perkin Trans. 1 1983, 2729-2734; c) P. G. Sammes, L. J. Street, J. Chem. Soc. Perkin Trans. 1 1983, 1261-1265; d) P. G. Sammes, L. J. Street, J. Chem. Res. Synop. 1984, 196-197; e) P. G. Sammes, R. J. Whitby, J. Chem. Soc. Chem. Commun. 1984, 702-703; f) P. G. Sammes, R. J. Whitby, J. Chem. Soc. Perkin Trans. 1 1987, 195-202; g) A. Delgado, L. Castedo, J. L. Mascarenas, Org. Lett. 2002, 4, 30913094; h) V. K. Aggarwal, R. S. Grainger, G. K. Newton, P. L. Spargo, A. D. Hobson, H. Adams, Org. Biomol. Chem. 2003, 1, 1884-1893; i) C. W. G. Fishwick, G. Mitchell, P. F. W. Pang, Synlett 2005, 285-286.

[43] a) K. A. Marshall, A. K. Mapp, C. H. Heathcock, J. Org. Chem. 1996, 61, 9135-9145; b) R. M. Adlington, J. E. Baldwin, A. V. W. Mayweg, G. J. Pritchard, Org. Lett. 2002, 4, 3009-3011; c) J. E. Baldwin, A. V. W. Mayweg, G. J. Pritchard, R. M. Adlington, Tetrahedron Lett. 2003, 44, 4543-4545; d) U. M. Krishna, G. K. Trivedi, Tetrahedron Lett. 2004, 45, 257-259; e) B. B. Snider, J. F. Grabowski, Tetrahedron Lett. 2005, 46, 823-825; f) B. B. Snider, J. F. Grabowski, Tetrahedron Lett. 2006, 62, 5171-5172; g) B. B. Snider, X. Wu, S. Nakamura, S. Hashimoto, Org. Lett. 2007, 9 , 873-874; h) K. C. Nicolaou, Q. Kang, S. Y. Ng, Y.-K. Chen, J. Am. Chem. Soc. 2010, 132, 8219-8222.

[44] K. Tchabanenko, C. Sloan, Y.-M. Bunetel, P. Mullen, Org. Biomol. Chem. 2014, 10, 4215-4219.

[45] N. Z. Burns, M. R. Witten, E. N. Jacobsen, J. Am. Chem. Soc. 2011, 133, 14578-14581.

[46] A. Orue, U. Uria, E. Reyes, L. Carrillo, J. L. Vicario, Angew. Chem. 2015, 127, 3086-3089; Angew. Chem. Int. Ed. 2015, 54, 3043-3046.

[47] D. Roca-Lopez, U. Uria, E. Reyes, L. Carrillo, K. A. Jørgensen, J. L. Vicario, P. Merino, Chem. Eur. J. 2016, 22, 884-889.

[48] M. P. D'Erasmo, C. Meck, C. A. Lewis, R. P. Murelli, J. Org. Chem. 2016, 81, 3744-3751.

[49] M. R. Witten, E. N. Jacobsen, Angew. Chem. 2014, 126, 6022-6026; Angew. Chem. Int. Ed. 2014, 53, $5912-5916$.

[50] B.-C. Hong, J.-L. Wu, A. K. Gupta, M. S. Hallur, J.-H. Liao, Org. Lett. 2004, 6, 3453-3456.

[51] P. A. Wender, K. D. Rice, M. E. Schnute, J. Am. Chem. Soc. 1997, 119, 7897-7898.

[52] P. Magnus, M. J. Waring, C. Ollivier, V. Lynch, Tetrahedron Lett. 2001, 42, 4947-4950.

[53] N. Ohmori, Chem. Commun. 2001, 1552-1553.

[54] P. Magnus, L. Shen, Tetrahedron 1999, 55, 3553-3560.

[55] Y. Li, C. C. Nawrat, G. Pattenden, J. M. Winne, Org. Biomol. Chem. 2009, 7, 639-640.
[56] a) B. Tang, C. D. Bray, G. Pattenden, Tetrahedron Lett. 2006, 47, 6401-6404; b) P. A. Roethle, P. T. Hernandez, D. Trauner, Org. Lett. 2006, 8, 5901-5904; c) B. Tang, C. D. Bray, G. Pattenden, Org. Biomol. Chem. 2009, 7, 4448-4457.

[57] P. A. Wender, F. C. Bi, N. Buschmann, F. Gosselin, C. Kan, J.-M. Kee, H. Ohmura, Org. Lett. 2006, 8, 53735376.

[58] M. Zhang, N. Liu, W. Tang, J. Am. Chem. Soc. 2013, 135, 12434-12438.

[59] J.-H. Sohn, Bull. Korean Chem. Soc. 2009, 30, 2517 2518.

[60] J.-H. Sohn, Bull. Korean Chem. Soc. 2014, 35, 23-24.

[61] J. A. Simanis, C. M. Law, E. L. Woodall, C. G. Hamaker, J. R. Goodell, T. A. Mitchell, Chem. Commun. 2014, 50, 9130-9133.

[62] G. Mei, H. Yuan, Y. Gu, W. Chen, L. W. Chung, C.-C. Li, Angew. Chem. 2014, 126, 11231-11235; Angew. Chem. Int. Ed. 2014, 53, 11051-11055.

[63] G. Mei, X. Liu, C. Qiao, W. Chen, C.-C. Li, Angew. Chem. 2015, 127, 1774-1778; Angew. Chem. Int. Ed. 2015, 54, 1754-1758.

[64] X. Liu, J. Liu, J. Zhao, S. Li, C.-C. Li, Org. Lett. 2017, 19, 2742-2745.

[65] S. Celanire, F. Marlin, J. E. Baldwin, R. M. Adlington, Tetrahedron 2005, 61, 3025-3032.

[66] B. Chen, X. Liu, Y.-J. Hu, D.-M. Zhang, L. Deng, J. Lu, L. Min, W.-C. Ye, C.-C. Li, Chem. Sci. 2017, 8, 4961-4966.

[67] M. P. Smith, C. George, A. P. Kozikowski, Tetrahedron Lett. 1998, 39, 197-200.

[68] M. J. Sung, H. I. Lee, Y. Chong, J. K. Cha, Org. Lett. 1999, 1, 2017-2019.

[69] K. M. Peese, D. Y. Gin, J. Am. Chem. Soc. 2006, 128, 8734-8735.

[70] a) K. M. Peese, D. Y. Gin, Org. Lett. 2005, 7, 33233325 ; b) N. R. Curtis, R. G. Ball, J. J. Kulagowski, Tetrahedron Lett. 2006, 47, 2635-2638.

[71] V. K. Aggarwal, J. Drabowicz, R. S. Grainger, Z. Gultekin, M. Lightowler, P. L. Spargo, J. Org. Chem. 1995, 60, 4962-4963.

[72] a) S. Kruger, T. Gaich, Angew. Chem. 2015, 127, 320322; Angew. Chem. Int. Ed. 2015, 54, 315-317; b) S. Krüger, T. Gaich, Eur. J. Org. Chem. 2016, 4893-4899.

[73] a) D. J. Lee, H. S. Han, J. Shin, E. J. Yoo, J. Am. Chem. Soc. 2014, 136, 11606-11609; b) E. J. Yoo, Synlett 2015, 26, 2189-2193.

[74] J. Shin, J. Lee, D. Ko, N. De, E. J. Yoo, Org. Lett. 2017, 19, 2901-2904.

[75] X.-Z. Shu, S. Huang, D. Shu, I. A. Guzei, W. Tang, Angew. Chem. 2011, 123, 8303-8306; Angew. Chem. Int. Ed. 2011, 50, 8153-8156.

[76] a) X.-Z. Shu, X. Li, D. Shu, S. Huang, C. M. Schienebeck, X. Zhou, P. J. Robichaux, W. Tang, J. Am. Chem. Soc. 2012, 134, 5211-5221; b) X.-Z. Shu, C. M. Schienebeck, W. Song, I. A. Guzei, W. Tang, Angew. Chem. 2013, 125, 13846-13850; Angew. Chem. Int. Ed. 2013, 52, 13601-13605; c) C. M. Schienebeck, X. Li, X.-Z. Shu, W. Tang, Pure Appl. Chem. 2014, 80, 409417.

[77] C. M. Schienebeck, W. Song, A. M. Smits, W. Tang, Synthesis 2015, 47, 1076-1084. 
[78] W. Song, B.-M. Xi, K. Yang, W. Tang, Tetrahedron 2015, 71, 5979-5984.

[79] a) X.-Z. Shu, C. M. Schienebeck, X. Li, X. Zhou, W. Song, L. Chen, I. A. Guzei, W. Tang, Org. Lett. 2015, 17, 5128-5131; b) W. Song, J. C. Lynch, X.-Z. Shu, W. Tang, Adv. Synth. Catal. 2016, 358, 2007-2011.

[80] X. Li, W. Song, X. Ke, X. Xu, P. Liu, K. N. Houk, X. Zhao, W. Tang, Chem. Eur. J. 2016, 22, 7079-7083.

[81] A. Seoane, N. Casanova, N. Quinones, J. L. Mascarenas, M. Gulias, J. Am. Chem. Soc. 2014, 136, 834-837.

[82] N. Casanova, K. P. Del Rio, R. Garcia-Fandino, J. L. Mascarenas, M. Gulias, ACS Catal. 2016, 6, 33493353.

[83] B. Cendon, N. Casanova, C. Comanescu, R. GarciaFandino, A. Seoane, M. Gulias, J. L. Mascarenas, Org. Lett. 2017, 19, 1674-1677.

[84] L. Bai, Y. Wang, Y. Ge, J. Liu, X. Luan, Org. Lett. 2017, 19, 1734-1737.

[85] T. Zhou, B. Li, B. Wang, Chem. Commun. 2017, 53, 6343-6346.

[86] A. M. Wilson, T. E. Waldman, A. L. Rheingold, R. D. Ernst, J. Am. Chem. Soc. 1992, 114, 6252-6254.

[87] R. Tomaszewski, I. Hyla-Kryspin, C. L. Mayne, A. M. Arif, R. Gleiter, R. D. Ernst, J. Am. Chem. Soc. 1998 120, 2959-2960.

[88] R. Basta, B. G. Harvey, A. M. Arif, R. D. Ernst, Inorg. Chim. Acta 2004, 357, 3883-3888.

[89] a) C. G. Kreiter, E.-C. Koch, W. Frank, G. J. Reiss, Inorg. Chim. Acta 1994, 220, 77-83; b) C. Wang, J. B. Sheridan, H.-J. Chung, M. L. Coté, R. A. Lalancette, A. L. Rheingold, J. Am. Chem. Soc. 1994, 116, 89668972.
[90] W. Chen, H.-J. Chung, C. Wang, J. B. Sheridan, M. L. Coté, R. A. Lalancette, Organometallics 1996, 15, 3337-3344.

[91] R. D. Witherell, K. E. O. Ylijoki, J. M. Stryker, J. Am. Chem. Soc. 2008, 130, 2176-2177.

[92] K. E. O. Ylijoki, A. D. Kirk, S. Böcklein, R. D. Witherell, J. M. Stryker, Organometallics 2015, 34, 33353357.

[93] C. D. Ramful, Z. E. Konway, S. Boudreau, J. Areephong, K. N. Robertson, K. E. O. Ylijoki, J. Organomet. Chem. 2016, 824, 166-171.

[94] M. Kudo, F. Kondo, H. Maekawa, T. Shimizu, M. Miyashita, K. Tanino, Tetrahedron Lett. 2014, 55, 1192-1195.

[95] R. Shenje, M. C. Martin, S. France, Angew. Chem. 2014, 126, 14127-14131; Angew. Chem. Int. Ed. 2014, 53, 13907-13911.

[96] C. Hu, R.-J. Song, M. Hu, Y. Yang, J.-H. Li, S. Luo, Angew. Chem. 2016, 128, 10579-10582; Angew. Chem. Int. Ed. 2016, 55, 10423-10426.

[97] Z. H. Abood, M. M. Hussein, I. M. Shaheed, Asian J. Chem. 2015, 27, 3074-3078.

[98] D. Zhao, J. Zhang, Z. Xie, J. Am. Chem. Soc. 2015, 137, 13938-13942.

[99] P. Ellerbrock, N. Armanino, M. K. Ilg, R. Webster, D. Trauner, Nat. Chem. 2015, 7, 879-882.

[100] C. He, J. Hu, Y. Wu, H. Ding, J. Am. Chem. Soc. 2017, 139, 6098-6101.

[101] Y. Yang, M.-B. Zhou, X.-H. Ouyang, R. Pi, R.-J. Song, J.-H. Li, Angew. Chem. 2015, 127, 6695-6699; Angew. Chem. Int. Ed. 2015, 54, 6595-6599. 